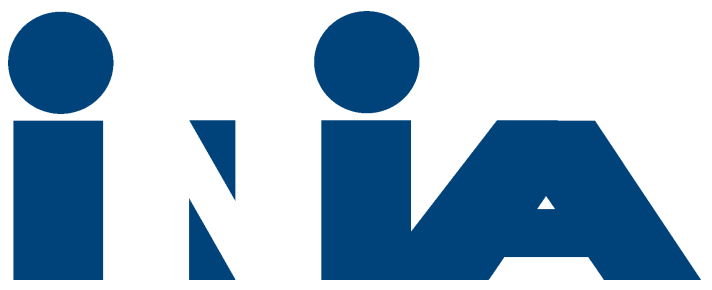

INSTITUTO NACIONAL DE INVESTIGACIÓN AGROPECUARIA

URUGUAY

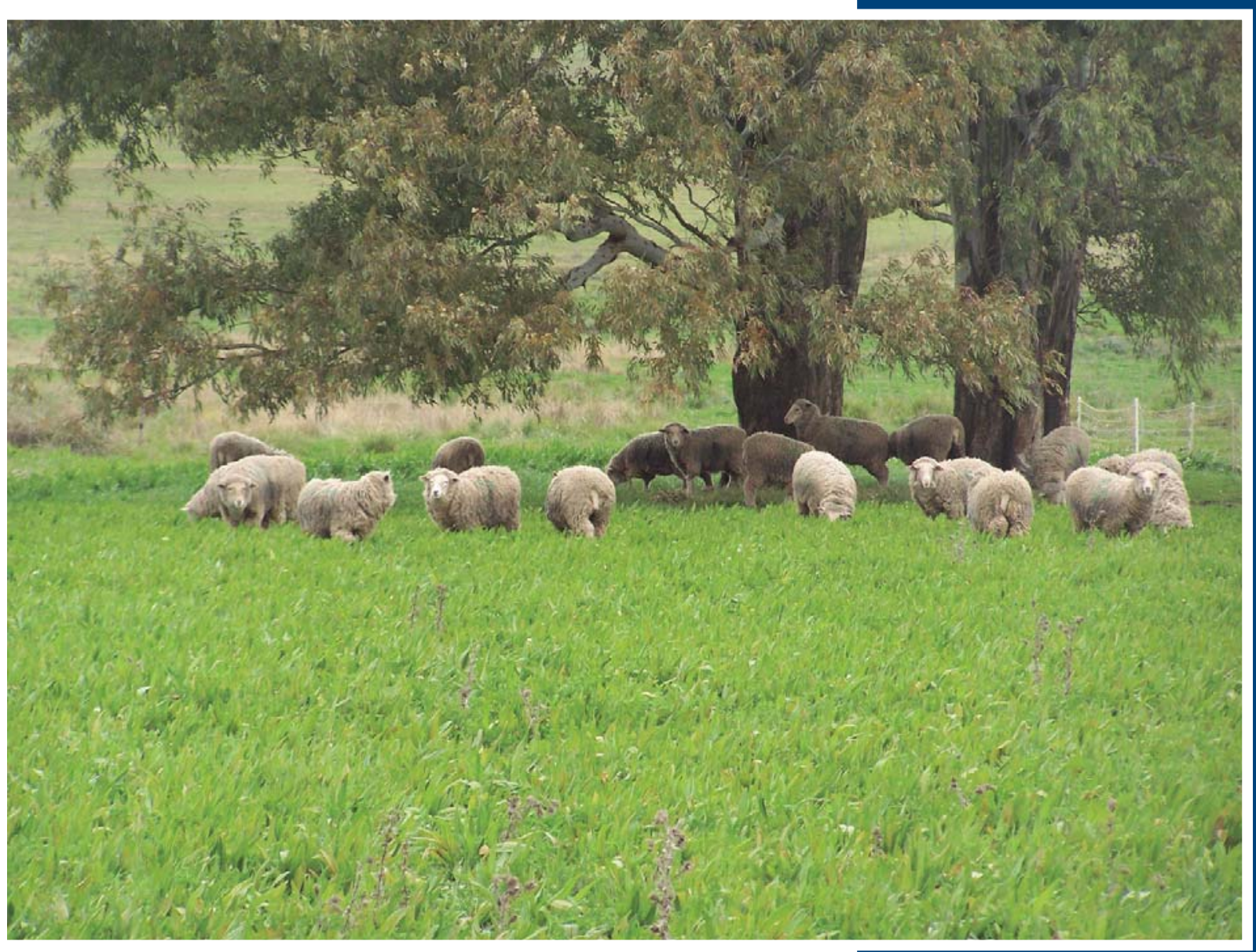

ESTRATEGIAS DE ALIMENTACIÓNY MANEJO DE LA RECRÍA Y ENGORDE ESTIVAL DE CORDEROS EN LA REGIÓN BASÁLTICA

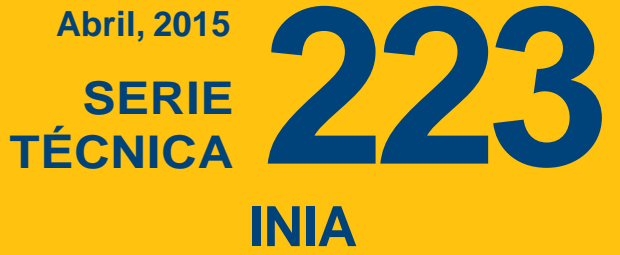




\title{
ESTRATEGIAS DE ALIMENTACIÓN Y MANEJO DE LA RECRÍA Y ENGORDE ESTIVAL DE CORDEROS EN LAREGIÓN BASÁLTICA
}

\author{
Autores: Fabio Montossi* \\ Fiorella Cazzuli** \\ Carolina Silveira ${ }^{* * *}$ \\ Ignacio De Barbieri ${ }^{* * * *}$ \\ ${ }^{\dagger}$ Diego Fernando Risso ${ }^{* * * * *}$
}


Título: ESTRATEGIAS DE ALIMENTACIÓN Y MANEJO DE LA RECRÍA Y ENGORDE ESTIVAL DE CORDEROS EN LA REGIÓN BASÁLTICA

Autores: Fabio Montossi

Fiorella Cazzuli

Carolina Silveira

Ignacio De Barbieri

${ }^{\dagger}$ Diego Fernando Risso

Serie Técnica $N^{\circ} 223$

(C) 2015, INIA

Editado por la Unidad de Comunicación y Transferencia de Tecnología del INIA Andes 1365, Piso 12. Montevideo - Uruguay

http://www.inia.uy

Quedan reservados todos los derechos de la presente edición. Esta publicación no se podrá reproducir total o parcialmente sin expreso consentimiento del INIA. 


\section{I nstituto Nacional de I nvestigación Agropecuaria}

\section{Integración de la Junta Directiva}

Ing. Agr., MSc., PhD. Álvaro Roel - Presidente

D.M.T.V., PhD. J osé Luis Repetto - Vicepresidente

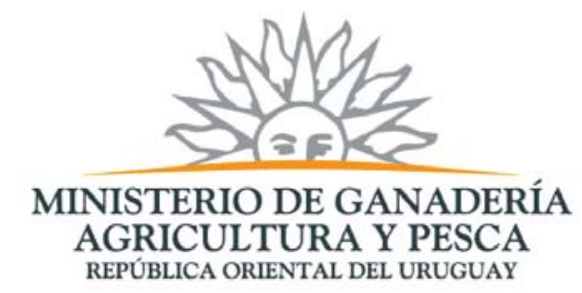

D.M.V. Álvaro Bentancur

D.M.V., MSc. Pablo Zerbino
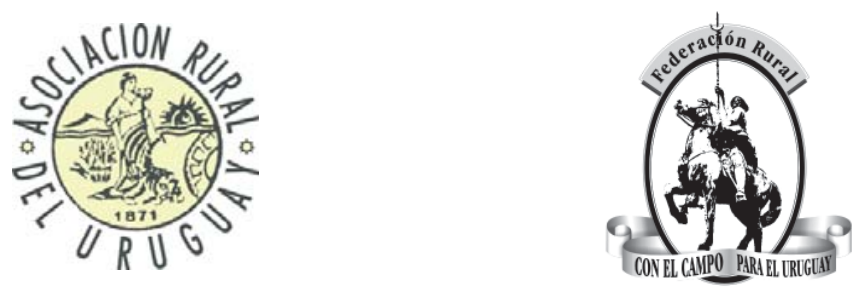

Ing. Agr. J oaquín Mangado

Ing. Agr. Pablo Gorriti
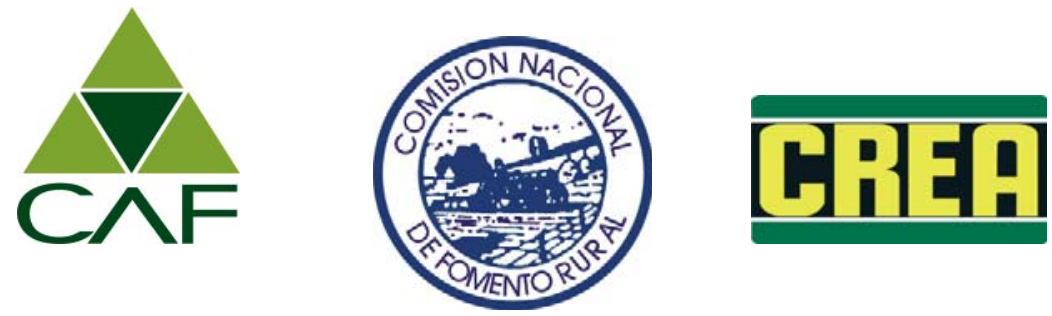



\section{CONTENIDO}

Página

\section{CAPÍTULO I: INTRODUCCIÓN}

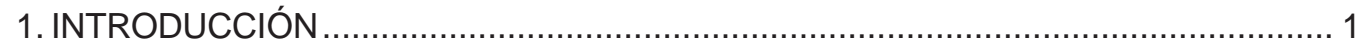

1.1. Producción, faena y mercados de la carne ovina a nivel local y mundial ....... 1

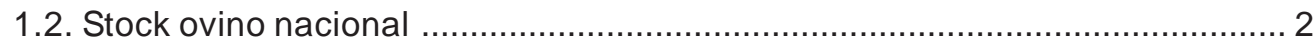

2. ANTECEDENTES Y DESAFÍOS DE LA MEJORA DE LA PRODUCCIÓN

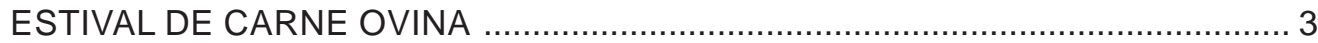

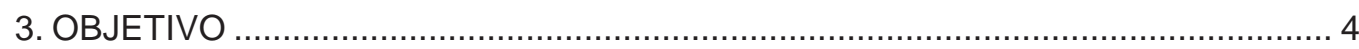

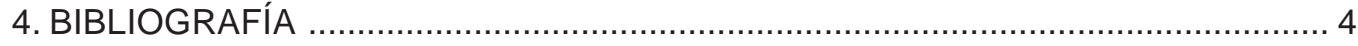

\section{CAPÍTULO II: REVISIÓN BIBLIOGRÁFICA}

1. REQUERIMENTOS NUTRICIONALES DE CORDEROS: Energía y proteína ........... 7

2. REVISIÓN BIBLIOGRÁFICA INTERNACIONAL ................................................. 8

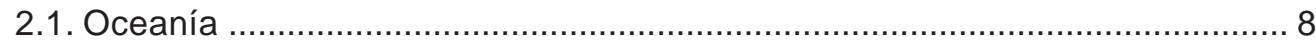

2.1.1. Generalidades de los sistemas de engorde de corderos de Australia y Nueva Zelanda ............................................................................ 8

2.1.2. Resultados de la investigación ....................................................... 8

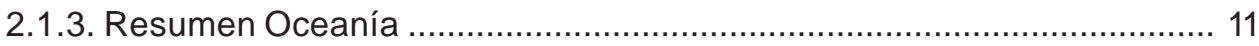

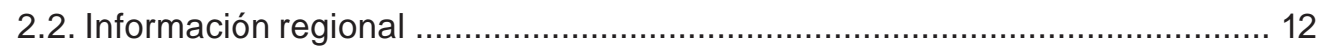

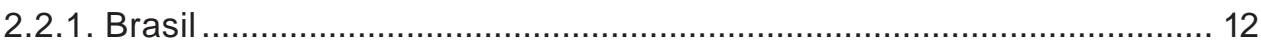

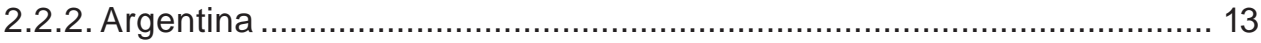

2.2.3. Resumen Argentina y Brasil .............................................................. 14

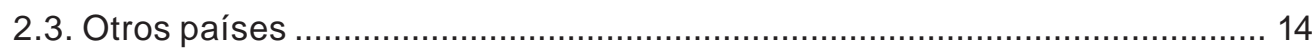

2.3.1. Resultados de investigación ......................................................... 14

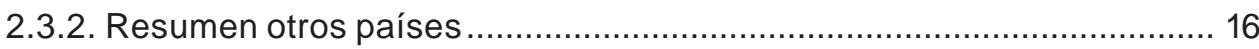

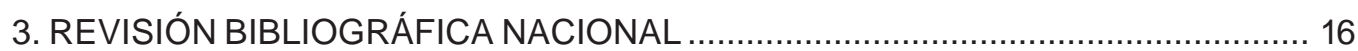

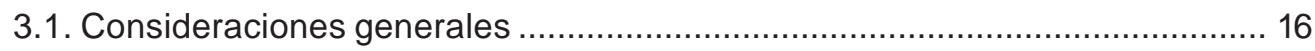

3.2. Resultados experimentales y de campo sobre bases forrajeras mejoradas .......... 17

3.3. Resultados experimentales y de campo sobre bases forrajeras irrigadas ......... 21

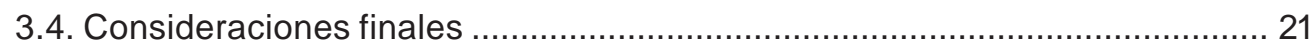

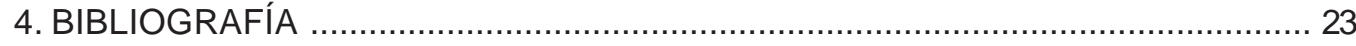




\section{CAPÍTULO III: RESULTADOS Y DISCUSIÓN}

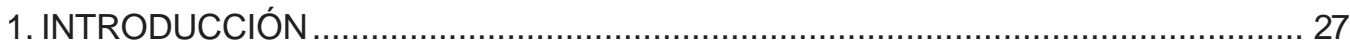

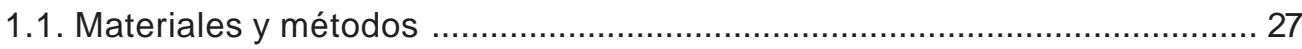

1.1.1. Determinaciones en pasturas y animales ........................................ 27

1.1.2. Manejo de los animales .................................................................. 29

2. RECRÍA Y ENGORDE DE CORDEROS SOBRE MEJORAMIENTOS

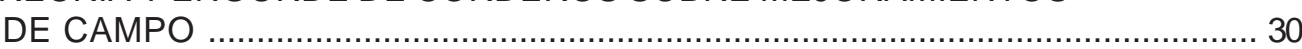

2.1. Evaluación de la carga, suplementación y género sobre mejoramiento de campo con Lotus corniculatus cv. INIA Draco ..................................... 30

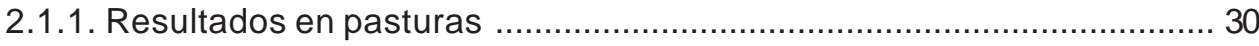

2.1.2. Resultados en comportamiento y producción animal .......................... 37

2.1.3. Comentarios y conclusiones …..................................................... 41

3. RECRÍA Y ENGORDE DE CORDEROS SOBRE PRADERAS ARTIFICIALES

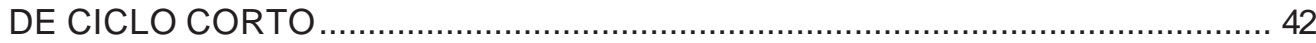

3.1. Evaluación de la carga, sistema de pastoreo y género sobre pastura de trébol rojo y achicoria ............................................................................. 42

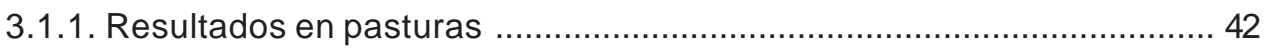

3.1.2. Resultados en comportamiento y producción animal ........................... 44

3.1.3. Comentarios y conclusiones ........................................................ 47

3.2. Evaluación de la carga, suplementación y género sobre pastura de trébol

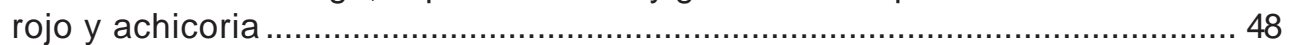

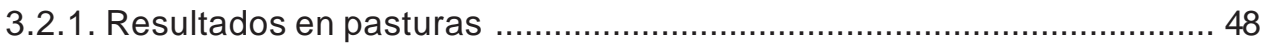

3.2.2. Resultados en producción animal ................................................... 49

3.2.3. Comentarios y conclusiones ......................................................... 52

3.3. Evaluación de suplementación sobre pastura irrigada de trébol rojo ............ 52

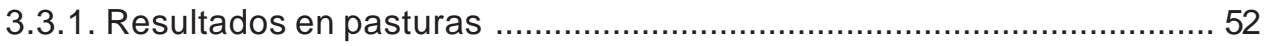

3.3.2. Resultados en producción animal ...................................................... 53

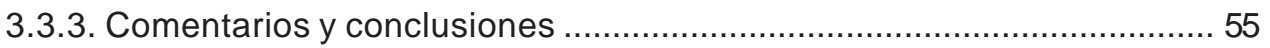

3.4. Comentarios y conclusiones de praderas de ciclo corto ............................. 55 
4. RECRÍA Y ENGORDE DE CORDEROS SOBRE PRADERAS ARTIFICIALES PERMANENTES.

4.1. Evaluación del nivel de suplementación sobre pastura de trébol blanco, Lotus corniculatus y raigrás 54

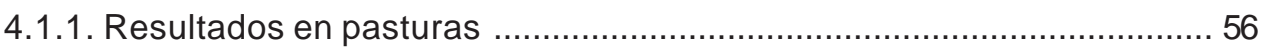

4.1.2. Resultados en comportamiento y producción animal ...........................5 57

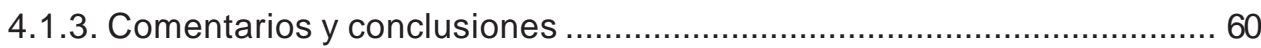

5. RECRÍA Y ENGORDE DE CORDEROS SOBRE VERDEOS ESTIVALES ........... 60

5.1. Evaluación de la suplementación y carga sobre cultivo de moha ..................61 61

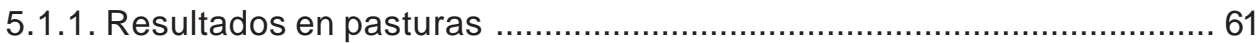

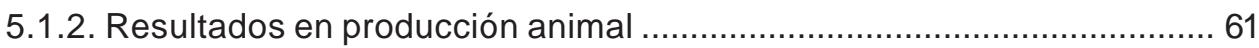

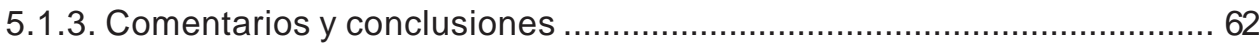

5.2. Evaluación de la suplementación y carga sobre cultivo de sudangrás ..........63 63

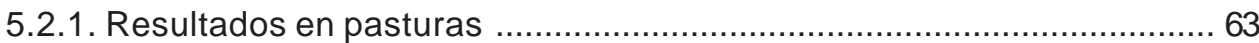

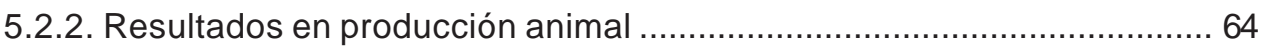

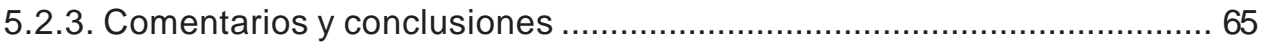

5.3. Comentarios y conclusiones de verdeos anuales estivales ........................... 66

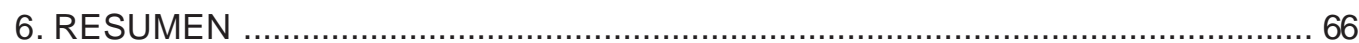

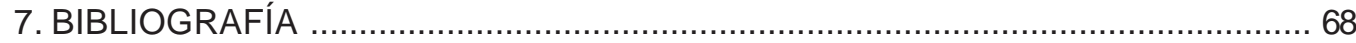

\section{CAPÍTULO IV: CONSIDERACIONES Y REFLEXIONES FINALES}

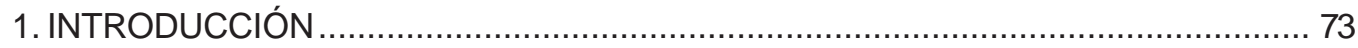

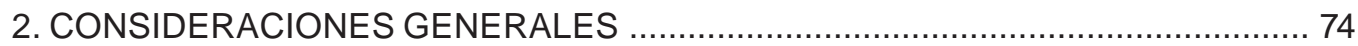

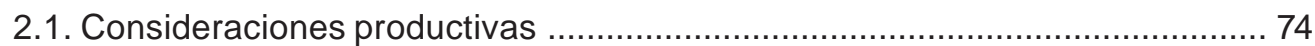

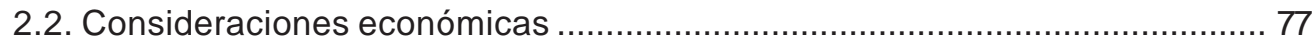

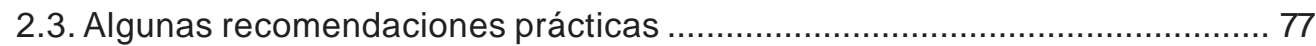

3. CONCLUSIONES E IMPLICANCIAS FUTURAS ................................................ 79

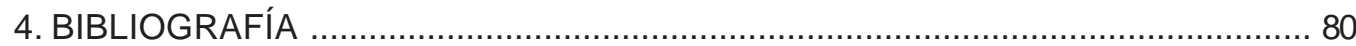




\section{ÍNDICE DE CUADROS}

Página

\section{CAPÍTULO II: REVISIÓN BIBLIOGRÁFICA}

Cuadro 1. Requerimientos de energía metabolizable (MCalEM/día) de corderos de 6 a 12 meses de edad, según peso vivo y ganancia de peso (GMD)

Cuadro 2. Requerimientos de proteína cruda (\%) de corderos que se alimentan con raciones balanceadas, según la concentración de energía de la dieta (MCal/kgMS) y el peso vivo del animal $(\mathrm{kg})$

Cuadro 3. Resumen de performances animales y cargas animales evaluadas, en ensayos de Australia y Nueva Zelanda de engorde de corderos durante el verano..... 11

Cuadro 4. Resumen de performances animales y cargas animales evaluadas, en ensayos de Brasil y Argentina de engorde de corderos durante el verano 15

Cuadro 5. Resumen de performances animales y cargas animales evaluadas, en ensayos de varios países de engorde de corderos durante el verano.

Cuadro 6. Respuesta en performance animal al pastoreo estival con bases forrajeras mejoradas (adaptado de Piaggio, 2013)

Cuadro 7. Producción animal (kgPV/ha) por hectárea sobre diferentes bases forrajeras irrigadas

Cuadro 8. Resumen de performances animales individuales y por unidad de superficie y cargas animales evaluadas, en ensayos nacionales de recría y engorde estival de corderos sobre diferentes bases forrajeras mejoradas durante el verano.

\section{CAPÍTULO III: RESULTADOS Y DISCUSIÓN}

Cuadro 1. Resumen de la base forrajera utilizadas, factores evaluados y añoperíodo de realización de los ensayos INIA sobre la recría y el engorde estival de corderos en la Unidad Experimental «Glencoe».

Cuadro 2. Disponibilidad y calidad del forraje ofrecido y remanente promedio 30

Cuadro 3. Disponibilidad de forraje y de hoja de lotus verde del ofrecido ( $\mathrm{kg} \mathrm{MS/ha),}$ según carga (C) y nivel de suplementación (S).

Cuadro 4. Performance animal en producción de carne, según factor evaluado 38

Cuadro 5. Características de la canal y la carne, según carga y nivel de suplementación.

Cuadro 6. Características de producción y calidad de lana, según carga y nivel de suplementación

Cuadro 7. Disponibilidad y calidad del forraje ofrecido y remanente promedio 42

Cuadro 8. Performance animal en producción de carne, según factor evaluado 45 
Página

Cuadro 9. Performance animal en producción y calidad de lana, según factor evaluado 46

Cuadro 10. Disponibilidad y calidad del forraje ofrecido y remanente promedio. ........ 48

Cuadro 11. Performance animal en producción de carne, según factor evaluado. ...... 49

Cuadro 12. Características de la canal y la carne, según carga y nivel de suplementación. 51

Cuadro 13. Disponibilidad y calidad del forraje ofrecido y remanente promedio 52

Cuadro 14. Performance animal en producción y calidad de carne y canal, según nivel de suplementación. 54

Cuadro 15. Disponibilidad y calidad del forraje ofrecido y remanente promedio 56

Cuadro 16. Performance animal en producción de carne, según nivel de suplementación 58

Cuadro 17. Características de la canal y la carne, según nivel de suplementación 59

Cuadro 18. Performance animal en producción y calidad de lana, según nivel de suplementación 59

Cuadro 19. Disponibilidad y calidad del forraje ofrecido y remanente promedio. 61

Cuadro 20. Performance animal en producción de carne, según factor evaluado. 62

Cuadro 21. Disponibilidad y calidad del forraje ofrecido y remanente promedio......... 64

Cuadro 22. Performance animal en producción de carne, según factor evaluado. 64

Cuadro 23. Niveles de productividad animal logrados en sistemas de recría/engorde de corderos pesados durante el período estival sobre distintas opciones forrajeras en la región de Basalto.

\section{CAPÍTULO IV: CONSIDERACIONES Y REFLEXIONES FINALES}

Cuadro 1. Precios mensuales promedio 2008-2013 


\section{ÍNDICE DE FIGURAS}

Página

\section{CAPITULO II: REVISIÓN BIBLIOGRÁFICA}

Figura 1. Biomas de Brasil. .... 12

Figura 2. Biomas Argentina. 14

\section{CAPÍTULO III: RESULTADOS Y DISCUSIÓN}

Figura 1. Evolución de la altura del forraje disponible según ciclo de pastoreo 31

Figura 2. Composición botánica de los diferentes componentes botánicos de la pastura ofrecida y rechazada a lo largo del experimento.....

Figura 3. Corderos pastoreando mejoramiento de campo con Lotus corniculatus cv. INIA Draco.

Figura 4. Composición relativa de los diferentes estratos del tapiz por tratamiento al final del ensayo (4to ciclo de pastoreo), según estado fenológico y componentes de las especies

Figura 5. Valor nutritivo del forraje ofrecido y de rechazo promedio para todo el período

Figura 6. Conducta animal, según carga y nivel de suplementación 37

Figura 7. Evolución del PV en función del tiempo, según factor evaluado 39

Figura 8. Composición botánica según factor evaluado 43

Figura 9. Conducta animal, según factor evaluado 44

Figura 10. Evolución del PV en función del tiempo, según factor evaluado 46

Figura 11. Diferencia de disponibilidades de forraje debido al efecto de la carga animal.

Figura 12. Evolución del PV en función del tiempo, según factor evaluado. ... 50

Figura 13. Corderos pastoreando trébol rojo bajo riego. 53

Figura 14. Evolución del PV en función del tiempo, según suplementación. 54

Figura 15. Composición botánica según nivel de suplementación ..... 57

Figura 16. Conducta animal, según factor evaluado ..... 57

Figura 17. Evolución del PV en función del tiempo, según nivel de suplementación 58

Figura 18. Evolución del PV en función del tiempo, según factor evaluado 62

Figura 19. Evolución del PV en función del tiempo, según factor evaluado. 65 


\section{AGRADECIMIENTOS}

El cuerpo técnico del INIA responsable de llevar adelante esta publicación, quiere agradecer muy especialmente a los siguientes individuos:

- A los estudiantes de agronomía que contribuyeron con sus trabajos tesis a la realización de esta publicación: Rodolfo Franco, Daniel Gutierrez, Carolina Silveira y Agustín Urrestarazú.

- A los investigadores del INIA Tacuarembó, y en particular a los Ings. Agrs. Santiago Luzardo, Roberto San Julián, Robin Cuadro, Gustavo Brito, Elbio Berretta, Enrique Pérez Gomar, Virginia Porcile y la D.M.V. América Mederos.

- Al personal de apoyo de INIA Tacuarembó: Wilfredo Zamit, Juan Levratto, Julio Frugoni, Ana Viana, Homero Martínez, Máximo Suárez, Julio Costales, Gerónimo Lima, Orosildo Presa, Fernando Rovira, Angel Zarza, Mauro Bentancur, Raúl Armand Ugón y Daniel Bottero. 



\section{CAPÍTULO I. INTRODUCCIÓN}

\section{INTRODUCCIÓN}

\subsection{Producción, faena y mercados de la carne ovina a nivel local y mundial}

Las señales que se han venido observando el rubro ovino desde hace mucho tiempo a nivel mundial (ej.: Australia y Nueva Zelanda) muestran la necesidad de consolidar y fortalecer un camino innovador a transitar a nivel local. En el mismo, se hace necesario:

a) tener acceso a todos los mercados de alto valor,

b) un incremento de la productividad y calidad del producto mediante una mejora de la eficiencia en el uso de los factores de producción,

c) promover la especialización de la producción de acuerdo a los sistemas de producción predominantes y a lo que los mercados demandan,

d) la incorporación de tecnologías de última generación,

e) fortalecer la remuneración de la producción por parte de la industria de acuerdo a la calidad del producto generado, promoviendo así una diferenciación y agregado de valor de los productos a lo largo de las Cadenas de Valor Agroindustriales textil-lanera y de carne ovina, certificación de productos y procesos, en un contexto de producción amigable con el medio ambiente y cuidado del bienestar animal (Montossi, com pers).

A nivel mundial, Uruguay se encuentra entre los primeros 10 países exportadores de carne ovina, con tan solo el 1,3\% del volumen exportado total. Esto es explicado por el hecho de que la exportación está concentrada en pocos países: Nueva Zelanda (35\%), Australia (26\%), Reino Unido (11\%) e Irlanda (5\%) en su conjunto representan aproximadamente el $77 \%$ del valor total exporta- do. Por otra parte, los principales mercados compradores a escala mundial son: Francia (13\%), seguido por EEUU y Reino Unido (11\% cada uno). En cuanto a la proporción de la producción local que es exportada al mercado internacional, se mantiene el mismo orden de los 4 primeros países exportadores, con Nueva Zelandia como mayor exportador de carne ovina mundial y Uruguay se posiciona en el puesto número 8 . A nivel de América, Uruguay es el primer país exportador con aproximadamente el $36 \%$ del volumen y el $42 \%$ del valor exportado (FAO, 2011).

Uruguay exportó en el ejercicio 20122013, 20,8 miles de toneladas de peso de canal ( $89 \%$ congelada y $11 \%$ enfriada), cifra que asciende de forma sostenida en los últimos años, ya que representa $21 \%$ más que en el período $2011-2012$ y 31\% más que en el período 2010-2011. Los volúmenes exportados mencionados significaron aproximadamente 80 millones de dólares, lo que debido al descenso de los precios de la carne ovina no representaron prácticamente variación con respecto al ejercicio anterior (2011-2012) y apenas un 5\% superior con respecto al ejercicio 2010-2011. El valor de la tonelada de carne ovina exportada en el ejercicio 20122013 fue $21 \%$ inferior al valor del ejercicio anterior (2011-2012) y 23\% inferior al del ejercicio 2011-2012 (INAC, 2013).

Las exportaciones de carne ovina representan un $3,4 \%$ del total de productos cárnicos exportados por el país, significando un $4,4 \%$ del monto total de exportaciones de productos cárnicos de Uruguay (INAC, 2013).

Los principales destinos de exportación de carne ovina desde nuestro país son: América del Sur (50\%) -especialmente Brasil (47\% del total)- la Unión Europea (27\%) y Asia (21\%) (INAC, 2013). Durante el año 2013, se verificó un relevante aumento de exportaciones hacia China y Medio Oriente, siendo éste un cambio favorable, ya que cada vez se colocan en esos mercados cortes de mayor valor (Recalde, 2013) y se diversificaron los destinos de nuestra expor- 
tación, particularmente hacia las regiones del mundo donde existen mayores oportunidades de crecimiento.

El mercado europeo ha sido históricamente uno de nuestros principales destinos de exportación para los cortes de alto valor. Por la crisis económica y por cambios en las tendencias de consumo, este mercado ha quedado levemente relegado. Aún así hay señales de que se viene revirtiendo desde la crisis económica, por lo cual, se puede suponer que este mercado puede volver a tener un mayor peso en nuestras exportaciones (Recalde, 2013).

Las perspectivas de comercialización de carne ovina de calidad en el mundo son más que alentadoras, aunque el país tiene deberes para hacer en la búsqueda de la consolidación de una corriente exportadora de carne ovina a EEUU, Canadá y México y de ampliar la cuota asignada en la Unión Europea. Sin embargo, a nivel local la información de INAC estima que el consumo/habitante/año de carne ovina de nuestro país

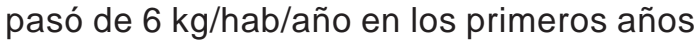
del 2000 a 4 kg/hab/año en la última zafra (Recalde, 2013).

Entre 1996 y 2002, el porcentaje de corderos faenados con respecto al total de la faena en plantas habilitadas (frigoríficos y mataderos) se duplicó (Azzarini, 2003). La producción de carne ovina emergió con gran fuerza en el período considerado con la aparición del producto «Cordero Pesado», el cual constituyó una nueva alternativa productiva y de comercialización para toda la Cadena Cárnica, complementaria a la producción de lana, destacándose por ser un elemento de diversificación y estímulo de la producción y la rentabilidad de los productores ovinos de nuestro país (Montossi et al., 2003a).

Este «producto» es un animal proveniente de los genotipos de mayor difusión en el país, generalmente menor a un año de edad (sin erupción de incisivos permanentes), que alcanza un peso de faena en al rango de 34 a $45 \mathrm{~kg}$ de peso vivo, con un grado de terminación establecido de común acuerdo con la industria frigorífica, de una condición corporal $\geq 3,5$ en la escala del 1 al 5 y originando canales entre 16 y $20 \mathrm{~kg}$ (Azzarini, 2003).
La faena ovina total correspondiente al ejercicio agrícola 2012-2013 se estimó en 1.507 miles de cabezas (OPYPA en base a datos del SUL, INAC, DICOSE y DNA, citados por Recalde, 2013). Respecto a estacionalidad de la faena, en este último ejercicio la distribución fue la siguiente: el $33 \%$ ocurre en primavera, $30 \%$ en verano, $21 \%$ en otoño y $16 \%$ invierno. En cuanto a la distribución estacional por categoría, las categorías adultas (ovejas, capones y carneros) son faenadas especialmente en otoño (33\%) y verano (28\%), sumando así más del $60 \%$ de la faena del año en esas dos estaciones. En contraposición, las categorías más jóvenes (borregos y corderos) tienen su faena concentrada en primavera (38\%) y verano (32\%), sumando $70 \%$ del total de la faena del año (INAC, 2013). Cabe destacar, que la mayoría de estos corderos tiene una edad a la faena de 10 a 12 meses, lo cual es una oportunidad de mejora en la eficiencia productiva con respecto a los corderos generados en otros países de referencia como lo son Australia y Nueva Zelanda, donde estos se faenan en su gran mayoría con 5 a 7 meses de edad y pesos de canales superiores o similares a los del Uruguay, respectivamente.

\subsection{Stock ovino nacional}

A pesar del contexto favorable de precios y la apertura de nuevos mercados existentes para la carne ovina a nivel mundial, el stock ovino de Uruguay disminuye desde 1991, donde se registro un máximo histórico de 26 millones de cabezas, para ubicarse en el 2002 en 10,9 millones. Desde el 2002 hasta el 2010 osciló entre 8 y 11 millones para situarse definitivamente en el cierre del año agrícola 2012-2013 en 8,2 millones de cabezas ovinas (INAC, 2013). Según Recalde (2013), el rubro ovino fue desplazado en los últimos años por el crecimiento de la forestación, la agricultura y también por la ganadería vacuna; esa tendencia que fue muy clara en la última década de los 2000. A pesar de los buenos precios de la carne, existen una serie de factores adicionales que están influyendo negativamente en el mantenimiento o crecimiento del stock, entre 
otros a destacar: precios de la lana, problemas sanitarios, costo y disponibilidad de mano de obra y abigeato.

Según datos publicados por DIEA (2013), el $53 \%$ de los ovinos se encuentran en los departamentos de Salto (18\%), Artigas (15\%), Tacuarembó (10\%) y Paysandú (10\%), departamentos del norte del país, ubicados sobre la región de Basalto. En el litoral oeste y sur, algunas zonas de las regiones del Cristalino del Centro, del Basalto Profundo y de los sistemas arroz-pasturas del Este, la competitividad del ovino frente a otros rubros dependerá que se generen alternativas tecnológicas capaces de capitalizar la excelente oferta forrajera que se puede producir en dichas regiones: la orientación será hacia la producción de carne de calidad y la producción de lanas de alto vaIor (Montossi, com pers).

\section{ANTECEDENTES Y DESAFÌOS DE LA MEJORA DE LA PRODUCCIÓN ESTIVAL DE CARNE OVINA}

Habida cuenta de la relevancia de la producción y exportación de la carne ovina para el Uruguay en términos productivos y económicos, se agrega la alta demanda de mano de obra que presenta la ovinocultura en el país, y por lo tanto el elevado impacto social que ésta tiene sobre los territorios en donde se asienta dicha producción. Según Irigoyen (2004) el rubro ovino es importante para el país -entre otras razones- por el nivel de ocupación en el sector primario que éste tiene, así como la demanda de servicios de pre y pos producción.

En ocasión de la Primera Auditoría de Calidad de la Cadena Cárnica Ovina del Uruguay en el período 2002-2003, la zafralidad de la producción fundamentalmente referida a la oferta fue identificada como una restricción para que el funcionamiento de la cadena tenga continuidad en el tiempo, de forma tal que exista un abastecimiento regular durante todo el año de nuestros mercados. En dicha oportunidad, lo planteado para le- vantar la limitante identificada fue ampliar el período de faena, para lo cual, entre otras medidas, se encontraba la de mejorar la base forrajera (Montossi et al., 2003b). En ocasión de la Segunda Auditoría de Calidad llevada a cabo en los años 2006-2007, nuevamente se identificó la estacionalidad de la producción como uno de los problemas a resolver de manera de contribuir a la mejora del funcionamiento de toda la Cadena Cárnica; entre las causas de la estacionalidad se encontraba la curva de producción del forraje (Montossi y Robaina, 2011).

Montossi et al. (2013) remarcan que aún restan una serie de temáticas tecnológicas y comerciales por resolver para consolidar la producción de corderos pesados en el país, entre los que se destaca la estacionalidad en la producción, concentrando la oferta a fines de invierno-primavera, seguido por el otoño, con un marcado déficit estival.

En una visión integral del sistema productivo, el hecho de poder terminar los corderos a fines del verano o principios del otoño posee varias ventajas. Se extrae del establecimiento una categoría que requiere especiales cuidados productivos, bajando así automáticamente la carga invernal del sistema, con las ventajas que ello conlleva productiva y económicamente en sistemas más intensivos (Ganzábal, 2013). Esto permite, a su vez, dejar un tiempo de descanso y optimizar el manejo de las pasturas mejoradas durante fines de verano y otoño. Luego, éstas serán utilizadas en el invierno con otras opciones productivas dentro del establecimiento. Estas pueden utilizarse, entre otras, para terminar otro lote de corderos «de cola» para su venta en primavera, para mejorar el plano alimenticio de ovejas o vacas en el final de la gestación, incurrir en categorías más eficientes como las de recría y engorde bovino o utilizar la misma área para la siembra de un verdeo o cultivo de invierno.

Es conocido que en la región de Basalto se presentan limitantes en el verano en cuanto a disponibilidad y calidad del forraje en años «promedio» y se presentan situaciones realmente críticas en veranos secos. Son muchos los esfuerzos realizados por la investigación nacional y en particular del INIA con el fin de paliar estas limitantes, algunos 
de los cuales se presentan y desarrollan en la presente publicación.

Tradicionalmente los trabajos de investigación se centraron en la búsqueda de opciones forrajeras para el engorde invierno-primaveral.

La mitad de los productores con experiencia en el Operativo Cordero Pesado y engordando como mínimo 350 corderos por año, que fueron entrevistados en el marco del Proyecto de Validación de Tecnología (INIA y CLU) denominado «Producción de Corderos Pesados en base a diferentes opciones de alimentación y manejo para el engorde» (Dighiero et al., 2003), puntualizaron que uno de los problemas tecnológicos que los afectaban era la falta de opciones forrajeras para el verano que permitieran lograr una buena alimentación y adecuadas ganancias de peso vivo de los mismos en este período.

Con el objetivo de buscar soluciones tecnológicas a esta problemática, se plantearon diferentes experimentos por parte de INIA que contribuyan con alternativas a esta restricción productiva, con particular énfasis para los sistemas ganaderos de la región de $\mathrm{Ba}$ salto. A continuación se presentan los resultados de evaluaciones realizadas durante el verano, con diversas opciones forrajeras y sistemas de producción, donde se han obtenido resultados promisorios.

\section{OBJETIVO}

El objetivo de esta publicación es presentar y resumir la información generada por INIA durante los últimos 10 años sobre diferentes alternativas tecnologías de alimentación y manejo para la producción de carne ovina de calidad en la región de Basalto durante el período estival. Esta información es clave para brindar herramientas tecnológicas a productores y técnicos que contribuyan al incremento, complementación y diversificación de la producción ovina en los sistemas ganaderos de la región de Basalto así como a la desestacionalización de la oferta de corderos hacia la industria frigorífica y el abastecimiento más regular de los mercados de exportación del Uruguay.

\section{BIBLIOGRAFÍA}

AZZARINI, M. 2003. El cordero pesado tipo SUL: un ejemplo de desarrollo integrado en la producción de carne ovina del Uruguay. En: CONGRESO MUNDIAL CORRIEDALE (12., 2003, Montevideo, Uruguay). p. 11-17.

DIGUIERO, A.; FERREIRA, G.; IRIGOYEN, R.; MONTOSSI, F. 2003. [CD-ROM]. Integración vertical en la producción de corderos pesados: Central Lanera Uruguaya y Frigorífico San Jacinto, encuesta de casos a productores. En: CONGRESO MUNDIAL CORRIEDALE (12 ${ }^{\circ}$., 2003, Montevideo, Uruguay).

FAO. 2013. FAOSTAT. Consultado 10 abr.2013 de: http://faostat3.fao.org/faostatgateway/go/to/download/T/TP/E

GANZÁBAL, A. 2013. Impacto productivo y económico del uso de biotipos maternales en la producción de corderos. En: Seminario de actualización técnica: Producción de carne ovina de calidad, INIA Treinta y Tres. Montevideo: INIA. p. 135142. (Serie Actividades de Difusión; 719).

INAC. 2013. Informe estadístico año agrícola julio 2012-Junio 2013. Montevideo: INAC. $85 \mathrm{p}$.

IRIGOYEN, R. 2004. La oveja ante una nueva «Guerra de Corea». El País Agropecuario, 113: 18-19.

MONTOSSI, F; DIGHIERO, A.; DE BARBIERI, I. 2013. Introducción al proyecto de validación de tecnologías para el engorde de corderos pesados. En: Montossi, F.; De Barbieri, I. (eds.). Tecnologías de engorde de corderos pesados sobre pasturas cultivadas en Uruguay. Montevideo: INIA. p 1-14. (Serie Técnica; 206).

MONTOSSI, F; GÓMEZ MILLER, R.; PIGURINA, G.; LUZARDO, S. 2003. Fase III Evaluación y cuantificación de las pérdidas en la cadena. En: Montossi, F. (ed.). 1era. Auditoría de calidad de la cadena cárnica, INIA Tacuarembó. Montevideo: INIA. p. 103-112. (Serie Técnica; 138).

MONTOSSI, F; ROBAINA, R. 2011. Principales problemas de la cadena cárnica ovina del Uruguay. En: San Julián, R.; Brito, G.; Lagomarsino, X. (eds.). Segunda 
Auditoría de calidad de la cadena cárnica, INIA Tacuarembó. Montevideo: INIA. p 73-78. (Serie Técnica; 186)

MONTOSSI, F.; SAN JULIÁN, R.; BRITO, G.; DE LOS CAMPOS, G.; GANZÁBAL, A.; DIGHIERO, A.; DE BARBIERI, I.; CASTRO, L.; ROBAINA, R.; PIGURINA, G.; DE MATTOS, D.; NOLLA, M. 2003. Producción de carne ovina de calidad con la raza Corriedale: recientes avances y desafíos de la innovación tecnológica en el contexto de la cadena cárnica ovina del
Uruguay. En: CONGRESO MUNDIAL CORRIEDALE $\left(12^{\circ}\right.$ 2003, Montevideo, Uruguay) p. 74-90.

RECALDE, E. 2013. Producción ovina: situación y perspectivas. En: Anuario OPYPA 2013. Montevideo: MGAP. p. 57-72.

URUGUAY. MGAP, DIEA. 2013. Anuario Estadístico Agropecuario 2013. Montevideo: DIEA. 270 p. 

1. REQUERIMENTOS NUTRICIONALES DE CORDEROS: Energía y proteína

Bajo pastoreo, las necesidades totales de energía de los animales van a depender de los siguientes factores: peso vivo, condición corporal, ganancia media diaria, composición de dicha ganancia, nivel de actividad dedicado a ingerir y cosechar el forraje y posibles efectos climáticos (Geenty y Rattray, 1987).

Los requerimientos totales de energía de los animales en pastoreo son en promedio $10-20 \%$ mayores que los requerimientos de los mismos estabulados, debido al esfuerzo adicional que implica la búsqueda y cosecha del forraje asó como a la influencia de las condiciones climáticas sobre la producción animal (Hodgson, 1990).
Se estima que las necesidades nutricionales de los corderos en crecimiento, de $30 \mathrm{~kg}$ de peso vivo, ganando $100-$ 150 g/an/día son de 1,3 kgMS/día con una dieta que contiene $16 \%$ de proteína cruda y $80 \%$ de digestibilidad de la materia orgánica (NRC, 1985).

En los Cuadros 1 y 2 se presentan los requerimientos de energía metabolizable y proteína cruda de corderos de acuerdo a su peso vivo y tasa de ganancia.

El incremento de los requerimientos de energía depende de los cambios en la composición corporal del animal que ocurre normalmente con el incremento de peso vivo. Los requerimientos de energía para crecimiento están determinados por las proporciones de grasa, proteína y agua de los tejidos depositados (Jones et al., 1989). Los requerimientos proteicos declinan como porcentaje en la dieta, a medida que el animal

Cuadro 1. Requerimientos de energía metabolizable (MCalEM/día) de corderos de 6 a 12 meses de edad, según peso vivo y ganancia de peso (GMD) (Adaptado de Geenty y Rattray, 1987).

\begin{tabular}{|c|c|c|c|}
\hline \multirow{2}{*}{ GMD (g/día) } & \multicolumn{3}{|c|}{ Peso Vivo (kg) } \\
\cline { 2 - 4 } & $\mathbf{3 0}$ & $\mathbf{3 5}$ & $\mathbf{4 0}$ \\
\hline 0 & 2,39 & 2,63 & 2,87 \\
50 & 3,11 & 3,35 & 3,83 \\
100 & 3,83 & 4,31 & 4,55 \\
150 & 4,55 & 5,02 & 5,50 \\
200 & 5,26 & 5,98 & 6,46 \\
\hline
\end{tabular}

Cuadro 2. Requerimientos de proteína cruda (\%) de corderos que se alimentan con raciones balanceadas, según la concentración de energía de la dieta (MCal/kgMS) y el peso vivo del animal $(\mathrm{kg})$ (Adaptado de Bell et al., 1991).

\begin{tabular}{|c|c|c|c|c|}
\hline \multirow{2}{*}{ Energía (MCal/kgMS) } & \multicolumn{4}{|c|}{ Peso Vivo (kg) } \\
\cline { 2 - 5 } & $\mathbf{2 0}$ & $\mathbf{3 0}$ & $\mathbf{4 0}$ & $\mathbf{5 0}$ \\
\hline 3,11 & 18,2 & 17,5 & 16,8 & 15,5 \\
2,87 & 16,5 & 15,8 & 13,9 & 12,6 \\
2,63 & 14,5 & 13,5 & 11.0 & 10.0 \\
2,39 & 12,8 & 11,8 & 9,2 & 8,6 \\
\hline
\end{tabular}


envejece y que engorda. La edad y condición corporal del cordero, la historia nutricional previa, el tipo de alimentación, el tiempo de alimentación y cómo es procesado el alimento pueden afectar los requerimientos proteicos del animal. Se espera que los corderos de más edad que han alcanzado la mayor parte de su crecimiento potencial, requieran menos proteína que los más jóvenes (Orksov y Grubb, 1979, citados por Church, 1984).

\section{REVISIÓN BIBLIOGRÁFICA INTERNACIONAL}

\subsection{Oceanía}

\subsubsection{Generalidades de los sistemas de engorde de corderos de Australia y Nueva Zelanda}

Los autores australianos Thompson et al. (2010), afirman que una producción de corderos que sea rentable en sistemas pastoriles depende en forma determinante de una alta producción de las pasturas y su eficiente utilización, así como de una genética superior de los ovinos utilizados.

En el sur de Australia frecuentemente se hace difícil engordar corderos tipo «premium lamb» para la exportación desde medidos a fines del verano bajo condiciones de secano, dada la baja tasa de crecimiento de las pasturas asociada a los déficits hídricos que normalmente se presentan en esta región australiana (Sanderson et al., 1980). Asimismo, Freer et al. (1994), citados por Hopkins, et al. (1991), afirman que los sistemas de producción australianos para engordar corderos durante el verano tienen por lo general bajas tasas de ganancia de peso. Holst et. al. (2006), Ponnampalam et al. (2005) y Burnett et al. (2012) afirman que en esta región la principal limitante para la producción de corderos durante el verano radica en el bajo valor nutritivo del forraje disponible.

En Nueva Zelanda, la producción estacional de corderos para faena está determinada por el patrón de crecimiento estacional de las pasturas, concentrando aproximadamente la mitad de la faena de los mismos durante el período comprendido entre enero y abril (de Nicolo et al., 2008).

En estos países con algunas de sus características y condiciones ambientales similares a las nuestras, en muchas ocasiones se presentan problemas productivos semejantes a los del Uruguay.

Un ejemplo de esto es el caso de Australia, en donde en la zona de altas precipitaciones de las planicies de New South Wales, donde los productores deben enfrentar el inconveniente de la falta de persistencia de las especies perennes sembradas en sus pasturas, donde la causa más importante a este problema es el manejo inadecuado de las mismas (Dowling et al., 2006). Estudios llevados adelante por Dowling et al. (1996), Kemp et al. (1996) y Garden et al. (2000), citados por Dowling et al. (2006) demostraron que descansos tácticos en estas pasturas pueden revertir su deterioro, a través del aumento de la abundancia de especies perennes en detrimento de las anuales. El problema es que el manejo del pastoreo debería ser lo suficientemente flexible como para mantener un balance adecuado entre especies perennes y anuales y ello es muy difícil de lograr en la práctica. Esto es así ya que un manejo adecuado de una pastura con especies perennes implicaría un descanso táctico durante el verano: el desafío que se plantea en esta zona de Australia es el balance entre un correcto manejo de estas pasturas en general -y en particular durante el verano- con los períodos de su utilización.

\subsubsection{Resultados de la investigación}

En Australia, Salmon et al. (2004) realizaron un estudio sobre la variabilidad de los márgenes económicos de la producción de corderos pesados en diferentes ambientes pastoriles mediante modelación utilizando un software específico para tales efectos. Se evaluaron tres ambientes: a) ambiente con predominancia de precipitaciones estivales (860 mm anuales; AmbEst) utilizando pasturas a base de Phalaris sp., festuca y trébol blanco; b) ambiente con precipitaciones regulares a lo largo de todo el año (609 
mm anuales; AmbReg), utilizando pasturas a base de festuca, gramíneas anuales y trébol subterráneo y c) ambiente con precipitaciones predominantemente invernales (679 $\mathrm{mm}$ anuales; Amblnv), utilizando pasturas en base a raigrás perenne y trébol subterráneo. La raza ovina de las madres de los corderos era cruza Border Leicester x Merino y éstas eran encarneradas con razas carniceras y de alto tamaño, produciendo corderos de tipo «cruza terminal» nacidos en tres momentos diferentes; a) a finales de julio (ambiente con marcada precipitación estival), b) a mediados de setiembre (ambiente sin estacionalidad en las precipitaciones) y c) a finales de junio (ambiente con marcada precipitación invernal). Si bien se evaluaron varios parámetros como para realizar estudios económicos, para esta revisión se centra la presentación de los resultados de nuestro interés, es decir, los que involucran engorde durante el verano.

Los corderos (machos criptorquídeos y hembras) llegaban al PV final (52 y $62 \mathrm{~kg})$ a los 9 meses (AmbEst), 7 meses (AmbReg) o 10 meses de edad (Amblnv). Las producciones por hectárea de canal de cordero promediaron entre los tres ambientes en $233 \mathrm{~kg} / \mathrm{ha}$, lo que aproximadamente equivaldría a $512 \mathrm{kgPV} / \mathrm{ha}$, variando la producción/ha por ambiente: $529 \mathrm{kgPV} /$ ha en AmbEst, $482 \mathrm{kgPV} / \mathrm{ha}$ en AmbReg y $528 \mathrm{~kg} / \mathrm{ha}$ en Amblnv.

Entre las principales conclusiones a las que arribaron los autores se encuentra que la producción de cordero/ha (comparables a resultados experimentales y resultados a nivel de los mejores productores) se lograron -entre otros factores- a través de pasturas con una proporción importante de leguminosas y correctamente fertilizadas que permiten sostener altas cargas animales por hectárea, así como a través de la ausencia de enfermedades en las plantas forrajeras y en los animales. Para el caso de los AmbEst y AmbReg, la presencia de pequeñas cantidades de pasturas de componente verde durante el verano fue suficiente como para que los corderos alcanzaran buenos PV finales con una menor necesidad de suplementación que para el caso del Amblnv. Para los tres ambientes, los machos criptorquídeos alcanzaron los PV objetivos en una mayor propor- ción de años que las hembras. Uno de los factores asociados al riesgo económico de mayor relevancia encontrado en este estudio fue la dependencia de la suplementación para poder sobrellevar las crisis forrajeras. En este estudio quedó establecido que los márgenes brutos y el riesgo económico están fuertemente relacionados con el tipo de ambiente en el que se trabaja (distintos regímenes hídricos), especialmente con los PV finales más altos.

En otro estudio llevado a cabo en Australia (SW Victoria; $700 \mathrm{~mm}$ anuales de precipitación) por Thompson et al. (2010), por dos años consecutivos demostraron la conveniencia del engorde de corderos durante los meses estivales, utilizando un cultivo puro de Trifolium vesiculosum cv. Arrotas (trébol Alejandrino), siendo éste un material seleccionado por su madurez tardía y se compararon con trébol subterráneo o raigrás perenne. Las cargas animales variaron entre 12, 18, 24, 30 y 36 corderos/ha (según el año del experimento), con PV iniciales de 28-30 kg con 12 semanas de edad (raza materna Coopworth $\mathrm{x}$ Corriedale cruzadas con raza paterna carnicera terminal). Los corderos fueron faenados con un PV final de $45 \mathrm{~kg}$ a finales del mes de enero - principios de febrero. Ninguno de los tratamientos fue suplementado en ningún momento.

Los corderos pastoreando trébol Alejandrino durante los meses estivales de diciembre y enero, con una carga animal de 24 corderos/ha lograron ganancias de 100 g/an/día o mayores. Por otro lado, los corderos que durante el mismo período pastoreaban trébol subterráneo o raigrás perenne no pudieron mantener sus ganancias diarias de PV desde mediados-fines de diciembre y debieron ser retirados de las pasturas. Con las cargas más altas, la producción total por hectárea con trébol vesiculoso se ubicó en $400 \mathrm{kgPV} / \mathrm{ha}$, más del doble que lo logrado en los otros tratamientos.

Las razones atribuidas por los autores a las performances animales superiores de la pastura con trébol Alejandrino, se asociaron al alargamiento de la estación de crecimiento de esta especie, así como su valor nutritivo superior (su digestibilidad nunca fue menor al 50\% hasta mediados de febrero). 
Sanderson et al. (1980) realizaron un experimento en New South Wales (Australia) con corderos Dorset Horn x Merino donde evaluaron las ganancias medias estivales y de principios de otoño luego del destete sobre la base comparativa de tres bases forrajeras: alfalfa en condiciones de secano, alfalfa bajo riego y trébol rojo bajo riego. Las ganancias obtenidas fueron de 124, 155 y $178 \mathrm{~g} / \mathrm{an} / \mathrm{día}$, respectivamente, siendo los valores de secano significativamente distintos a los valores obtenidos bajo riego. Las disponibilidades de forraje iniciales fueron siempre superiores a $1600 \mathrm{kgMS} / \mathrm{ha}$ para los tratamientos irrigados, no así para el tratamiento en secano cuya disponibilidad fue limitante en varias ocasiones. Las cargas totales manejadas fueron 5,5 corderos/ha para alfalfa de secano, 14 corderos/ha para alfalfa bajo riego y 27,5 corderos/ha para el trébol rojo bajo riego.

Las ganancias obtenidas sobre alfalfa de secano son consideradas insuficientes para los niveles productivos esperados. Las diferencias de performances entre cada base forrajera son atribuidas a las distintas digestibilidades de cada pastura, en donde la pastura de secano obtuvo valores por debajo de $55 \%$ de digestibilidad de la materia orgánica durante el primer y segundo ciclo de pastoreo.

En un estudio realizado en Australia por Hopkins et al. (1991) se utilizaron corderos de razas Border Leicester x Merino x Poll Dorset recién destetados y fueron asignados a diferentes tratamientos: pastura de alfalfa sin suplementación, alfalfa más grano de avena ad libitum o alfalfa más silo deshidratado de alfalfa ad libitum. La carga manejada fue de 12 corderos/ha y la disponibilidad de forraje nunca fue menor a los 1000 $\mathrm{kgMS} / \mathrm{ha}$. Los corderos fueron faenados cuando la mitad de éstos llegó a los 48 kg PV.

Los pesos de las canales se ubicaron en el rango de 23,4 a 27,6 kg entre tratamientos, sin diferencias significativas entre ellos. Tampoco se registraron diferencias significativas entre tratamientos para otras características de las canales y la carne, como en el punto GR (indicador del grado de engrasamiento de la canal: 13,1-13,8 mm), pH (to- dos por debajo de 5,8) o color. Sí se encontró diferencia significativa para terneza, siendo la misma mayor para el tratamiento con suplemento de silo de alfalfa y menor para los otros dos tratamientos.

Por otra parte, Holst et al. (2006) registraron en Australia ganancias medias diarias durante 3 años de corderos en engorde sobre un mejoramiento mezcla de achicoria, trébol blanco y trébol subterráneo durante el verano, en el rango de 230 y 296 g/an/día. Los animales entraron a la pastura con un promedio de 36,2 kgPV hasta alcanzar el peso objetivo de $48 \mathrm{~kg}$. Estos autores recomendaron que la carga que se maneje para obtener más de 125 g/an/día sea de 10 corderos/ha, ya que la carga previamente recomendada a productores fue de 12 corderos/ha y no sería capaz de soportar el pastoreo si se presentara un déficit hídrico. También concluyen que es necesario utilizar razas de buena genética, para generar corderos con buenos pesos al inicio del período de engorde.

Reed et al. (1972), citados por Burnett et al. (2012) hacen referencia a que en el sureste australiano, pasturas de alfalfa o achicoria fueron las bases forrajeras que habilitaron buenas ganancias para corderos o capones (de menos de un año de edad) durante los meses estivales y principio de otoño. Asimismo, Burnett et al. (2012) argumentan que, si la industria frigorífica aspira a ser abastecida con corderos para faena consistentemente a lo largo del año en las zonas templadas, debería hacerse foco en la utilización de pasturas perennes con crecimiento estival (como es el caso de la alfalfa), así como se debería considerar el uso de suplementos en combinación con forrajes de baja calidad. Estos autores llevaron adelante un ensayo de engorde estival de corderos utilizando como base forrajera una pastura mezcla de alfalfa y falaris, en las que obtuvieron ganancias de 141 g/an/día, sin suplementación y con una disponibilidad promedio de forraje de $2200 \mathrm{kgMS} / \mathrm{ha}$. Los corderos cruza (Poll Dorset, Border Leicester y Merino) llegaron a peso de faena con $45,4 \mathrm{~kg}$ y obtuvieron valores de espesor del punto GR de 12,67 mm. 
También en Australia, Ponnampalam et al. (2005) realizaron un ensayo con corderos cruza (Merino, Border Leicester y Poll Dorset) con PV iniciales de $32,2 \mathrm{~kg}$ cuya dieta base era heno de alfalfa (30\%) y heno de avena $(70 \%)$ combinado con varios tipos de suplementos lípido-proteicos. Con esta dieta se buscó que el contenido de energía y proteína fuera similar a la de las pasturas comúnmente utilizadas durante la estación estival. Las ganancias obtenidas solamente utilizando la dieta base fueron de $74 \mathrm{~g} / \mathrm{an} /$ día, mientras las ganancias obtenidas con la adición de los suplementos proteicos variaron de 123 a $163 \mathrm{~g} / \mathrm{an} /$ día.

Kelman y Dove (2007) realizaron en Australia un ensayo en donde corderos cruza de las razas Border Leicester x Merino pastoreaban un cultivo puro de nabo forrajero (Brassica campestris) a una carga promedio de 67 corderos/ha. La asignación diaria de forraje promedio fue de $71 \mathrm{kgMS} / \mathrm{animal} \mathrm{y}$ comenzaron el ensayo con un PV de $36 \mathrm{~kg}$ hasta llegar a un PV final de 45,3 kg. La producción estimada de carne por hectárea fue de $637 \mathrm{~kg} / \mathrm{ha}$ y las ganancias promedio fueron de 358 g/an/día.
Burtt y Hill (1990) en Nueva Zelanda reportaron ganancias de corderos de $97 \mathrm{~g} / \mathrm{an} /$ día destetados sobre lupino (Lupinus angustifolius) sembrado en primavera y pastoreado en los meses de febrero y marzo, con utilizaciones del forraje de $57 \%$ y $72 \%$.

Por otro lado, Bluett et al. (2001) en Nueva Zelanda realizaron un ensayo de engorde de corderos durante el verano, pastoreando raigrás perenne bajo pastoreo rotativo del tipo líderes-seguidores. Los corderos eran cruza Suffolk x Romney, con PV incial de 25,9 kg, pastoreando a una carga promedio de 31 cordero/ha. El ciclo de pastoreo duraba 42 días y la altura del forraje pre pastoreo varió entre 7,2 y 13,6, mientras que la disponibilidad inicial de cada franja varió entre 3690 y $3880 \mathrm{kgMS} / \mathrm{ha}$. Las ganancias variaron desde 92 g/an/día de los coderos «líderes» hasta $53 \mathrm{~g} / \mathrm{an} /$ día de los corderos «seguidores», resultando en PV finales de 35,2 y $30,5 \mathrm{~kg}$ $\mathrm{PV}$ respectivamente.

\subsubsection{Resumen Oceanía}

El Cuadro 3 presenta un resumen de los datos obtenidos en Oceanía en ensayos involucrando engorde estival de corderos.

Cuadro 3. Resumen de performances animales y cargas animales evaluadas, en ensayos de Australia y Nueva Zelanda de engorde de corderos durante el verano.

\begin{tabular}{|c|c|c|c|c|}
\hline Fuente & BF & GMD & cord/ha & PV/ha \\
\hline \multicolumn{5}{|c|}{ AUSTRALIA } \\
\hline Thompson et al. (2010) & T. Alej. & mín 100 & $12-36$ & $\max 400$ \\
\hline Sanderson et al. (1980) & $A A+T R(r)$ & $124-178$ & $5.5-27.5$ & $s / d$ \\
\hline Hopkins et al. (1991) & $A A^{*}$ & $\mathrm{~s} / \mathrm{d}$ & 12 & $s / d$ \\
\hline Holst et al. (2006) & Ach + TB + T. Subt. & $296-230$ & $4.6-8.2$ & $s / d$ \\
\hline Burnett et al. (2012) & $A A+P h$ & 141 & $\mathrm{~s} / \mathrm{d}$ & $s / d$ \\
\hline Ponnanpalam et al. (2005) & Heno + Supl & $74-163$ & $\mathrm{n} / \mathrm{a}$ & $\mathrm{n} / \mathrm{a}$ \\
\hline Kelman y Dove (2007) & Nabo & 358 & 67 & 637 \\
\hline \multicolumn{5}{|c|}{ NUEVA ZELANDA } \\
\hline Burtt y Hill (1990) & Lupino & 97 & $s / d$ & $s / d$ \\
\hline Bluett et al. (2001) & $\operatorname{Rg} p$ & $53-92$ & 31 & $s / d$ \\
\hline
\end{tabular}

Nota: $\mathrm{BF}=$ Base forrajera; GMD = ganancia media diaria (g/an/día); PV/ha = producción de PV por hectárea; cord $/$ ha $=$ corderos $/$ ha; $\mathrm{T}$. Alej = trébol alejandrino; $\mathrm{AA}=$ Alfalfa; $\mathrm{TR}(\mathrm{r})=$ trébol rojo irrigado; $\mathrm{Ph}=$ falaris; $\mathrm{T}$ Subt; Supl = suplemento; $\mathrm{n} / \mathrm{a}=$ no aplica; $\mathrm{s} / \mathrm{d}=\sin$ dato; $\mathrm{Rg} \mathrm{p}=$ raigrás perenne; * Incluye evaluación suplementación. 


\subsection{Información regional}

\subsubsection{Brasil}

Durante los últimos años la ovinocultura en Brasil es una actividad que viene en significativo aumento, impulsada principalmente por el elevado potencial de consumo de los grandes centros urbanos (Macedo et al., 1999). Según Gonzaga (2007) el mercado de los productos ovinos es relativamente inestable, observándose en determinados períodos una remuneración insatisfactoria. Dentro de la información recabada en el tema para Brasil, se encontraron varios trabajos ubicados en los distintos agroecosistemas 0 «biomas» de este país (Figura 1). En cada caso se explicita a qué bioma corresponde la investigación.

Guedes et al. (2012) realizaron un ensayo con corderos sobre una pastura de Panicum maximum cv. Tanzânia bajo riego. Las ganancias de los corderos de biotipos locales promediaron $191 \mathrm{~g} / \mathrm{an} /$ día. También en el Nordeste brasilero, Wander et al. (2002) realizaron un ensayo con corderos manejando dos cargas (40 y 60 corderos/ha), sobre Cynodon dactylon y Panicum maximum cv. Tanzânia, obteniéndose ganancias entre 61 y $91 \mathrm{~g} / \mathrm{an} / \mathrm{dí}$. Por último, en este mismo ambiente semiárido, Voltolini et al. (2009) realizaron un ensayo de corderos cruza con el biotipo Santa Inés en proceso de engorde sobre Cynodon dactylon cv. Tifton 85 y suplementados y obtuvieron ganancias entre 60 y 100 g/an/día.

Un poco más al sur en el estado de Paraná (bioma Mata Atlántica), Macedo et al. (1999) realizaron un ensayo utilizando corderos con sangre Corriedale, Bergamácia y Hampshire Down. Éstos pastoreaban una pastura de Cynodon dactylon (con un contenido de proteína bruta de $18 \%$ en promedio), en donde se registraron ganancias entre el destete y la faena de 106 g/an/día.

En Río Grande del Sur, Brasil, Castro (2002) utilizó un verdeo anual estival de Pennisetum americanum (mijo perla) para engordar corderos enteros cruza (Suffolk, Texel e Île de France) durante el verano. Los tratamientos fueron las distintas alturas de forraje remanente pos pastoreo de 10, 20, 30 y $40 \mathrm{~cm}$. La producción del cultivo osciló en un rango de 10300 a $20600 \mathrm{kgMS} / \mathrm{ha}$. Las

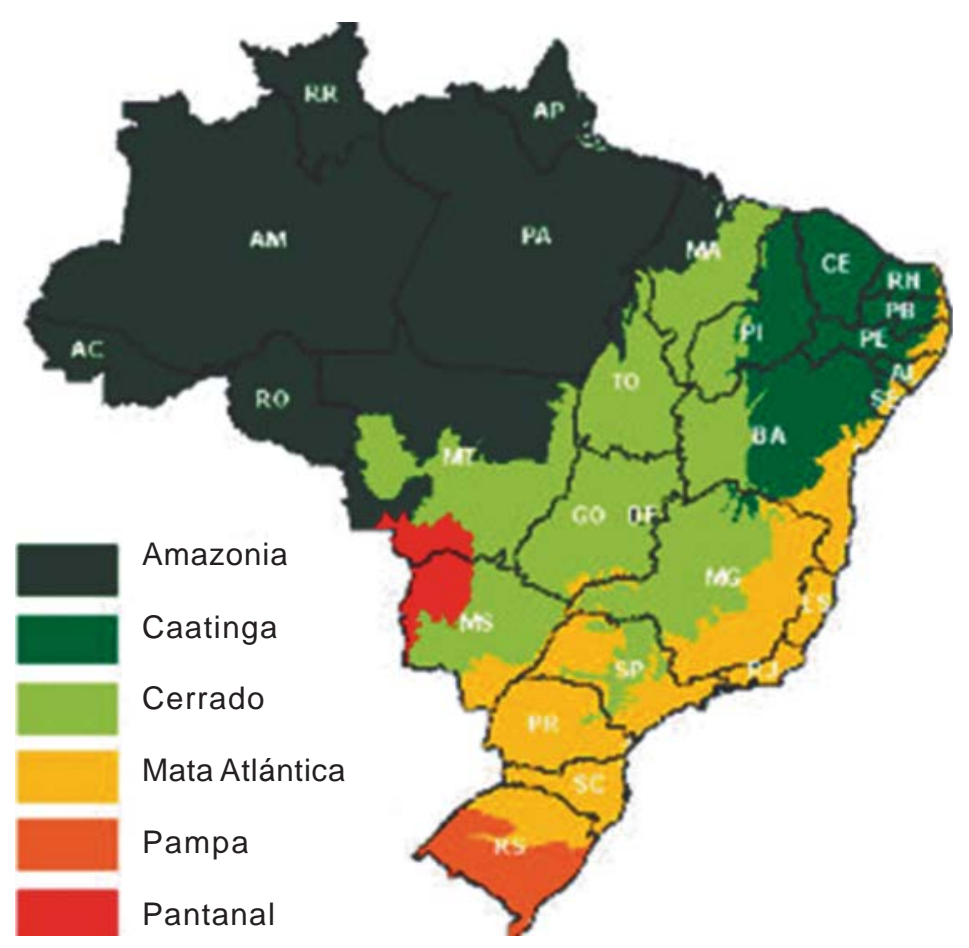

Figura 1. Biomas de Brasil. 
ganancias medias diarias registradas fueron de $67 \mathrm{~g} / \mathrm{an} /$ día para el tratamiento de $10 \mathrm{~cm}$ de altura y de 115 g/an/día para el resto de los tratamientos, los cuales no presentaron diferencias significativas entre ellos. La producción de PV por hectárea fue de $\quad 214$ $\mathrm{kgPV} / \mathrm{ha}$ para la altura de $10 \mathrm{~cm}$ de forraje, mientras que para las alturas de 20, 30 y 40 $\mathrm{cm}$ de forraje no hubieron diferencias entre éstas, promediándose una producción de 555 $\mathrm{kgPV} / \mathrm{ha}$. Los rendimientos carniceros fueron todos estadísticamente iguales entre sí -promediando 36,6\%- al igual que las medidas de espesor de grasa, que promediaron $2,43 \mathrm{~mm}$. La carga animal promedio fue inferior para la altura de $10 \mathrm{~cm}(1228 \mathrm{kgPV} / \mathrm{ha} /$ día) con respecto el resto de los tratamientos, no se registraron diferencias estadísticamente significativas entre estos (1892 kg/PV/ha promedio).

Gonzaga (2007) realizó un ensayo en Bagé (RS) utilizando un verdeo estival de Penisetum glaucum (mijo perla) a dos alturas contrastantes de forraje pos pastoreo (20 y $40 \mathrm{~cm}$ ). Los corderos Corriedale utilizados en los experimentos fueron asignados a las diferentes alturas de forraje durante el período estival y principio de otoño (90 días desde fin de enero a marzo). Las disponibilidades promedio de los tratamiento de 20 y $40 \mathrm{~cm}$ fueron de $907 \mathrm{kgMS} / \mathrm{ha}$ y de $1442 \mathrm{kgMS} / \mathrm{ha}$, respectivamente. No se observaron diferencias significativas para el $P V$ final de los corderos, ni para peso de canal, promediando $31 \mathrm{kgPV}$ y $11,8 \mathrm{kgPV}$, respectivamente. Las ganancias medias fueron de $29 \mathrm{~g} / \mathrm{an} / \mathrm{día}$.

Brum et al. (2008) reportaron ganancias de corderas Corriedale en la etapa de recría de 151 g/an/día sobre Pennisetum americanum (mijo), en contraste con los 53 y $58 \mathrm{~g} / \mathrm{an} / \mathrm{día}$ obtenidos sobre campo natural y campo natural mejorado respectivamente, durante los meses estivales, donde se destaca que se presentó una importante sequía instalada en San Gabriel (Río Grande del Sur). La carga animal promedio fue de $914 \mathrm{kgPV} / \mathrm{ha}$ para el tratamiento sobre el verdeo de mijo, significativamente diferente a las cargas de $261 \mathrm{kgPV} / \mathrm{ha}$ y $467 \mathrm{kgPV} / \mathrm{ha}$ correspondientes a los tratamiento de campo natural y campo natural mejorado, respectivamente. El ob- jetivo de asignación forrajera para los tres tratamientos fue de $10 \mathrm{kgMS} / 100 \mathrm{kgPV}$. Asimismo, los $\mathrm{PV}$ finales del tratamiento sobre verdeo de mijo fue de 36,1 kgPV, siendo significativamente distinto al resultado de los otros dos tratamientos que promediaron 29,7 kgPV.

También en Río Grande del Sur, Lemes et al. (2014) obtuvieron PV finales en corderos Corriedale de $31 \mathrm{kgPV}$, al utilizar dos alturas de forraje (20 y $40 \mathrm{~cm}$ ) sobre la misma base forrajera que utilizo Castro (2002) (mijo perla).

Carvalho et al. (2006) Ilevaron adelante un ensayo en Río Grande del Sur con corderos cruza Texel durante los meses primaverales (setiembre a diciembre), utilizando un cultivo de verano como es el Cynodon dactylon cv. Tifton 85 y suplementación a tasas que oscilaban entre el 0 al 2,5 \%PV. Los PV finales y ganancias aumentaban a medida que se incrementaba el nivel de suplementación, con valores que oscilaban entre 28,8 - 35,5 kgPV y 104 - 194 g/an/día, respectivamente. También durante la primavera (setiembre a diciembre), De Almeida (2004) evaluó la performance de corderos Ideal e Ideal x Border Leicester en diferentes tratamientos: pastura cultivada más suplemento al 1,5\%PV, pastura cultivada sin suplemento y pastura natural con suplemento al $1,5 \% \mathrm{PV}$, bajo una asignación de forraje objetivo de $10 \%$ PV. Las ganancias de los corderos que se registraron oscilaron entre 211 y 273 g/an/día.

Por otro lado, Poli et al. (2008) realizaron un ensayo entre los meses de octubre y enero con corderos de la raza Suffolk sobre pasturas de Cynodon dactylon cv. Tifton 85 intersembrada con raigrás. El pastoreo era continuo y la carga animal promedio en el período fue de 18,3 corderos/ha. Las ganancias registradas fueron de 107 g/an/día y los corderos fueron faenados con $32 \mathrm{kgPV}$ a los 131 días de edad.

\subsubsection{Argentina}

En algunas regiones de Argentina la producción ovina tiene algunos aspectos similares a la producción ovina nacional. Los distintos biomas de Argentina son representados en la Figura 2. 


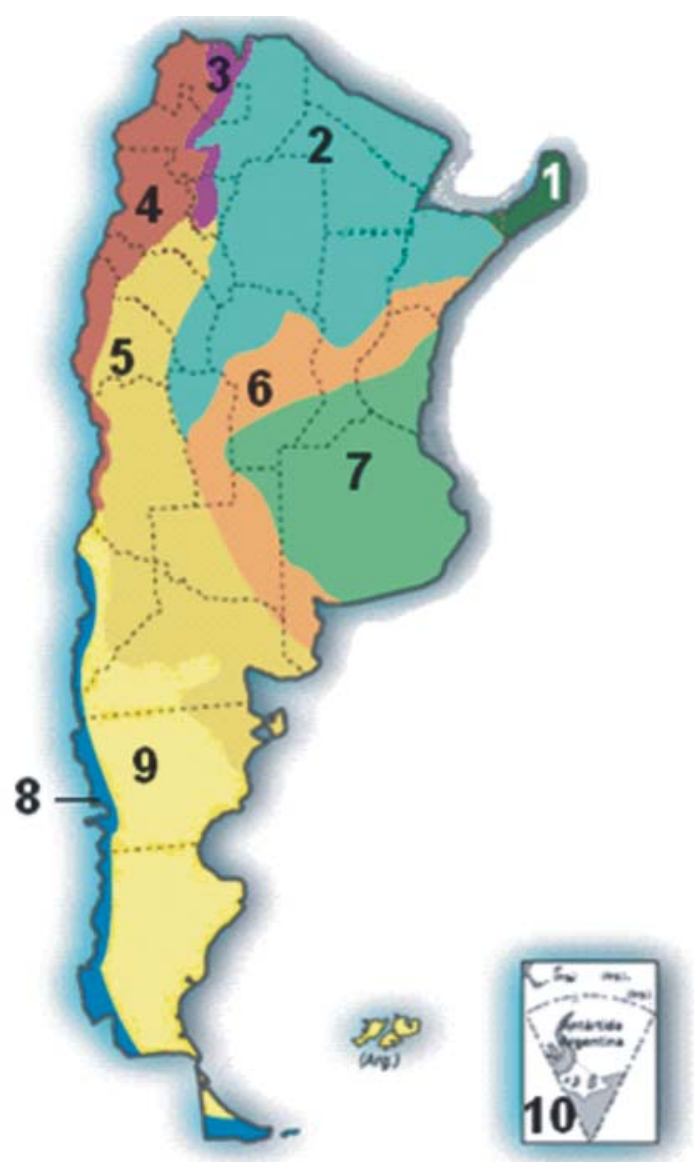

1. Selva misionera

2. Bosque chaqueño

3. Selva tucumana-salteña

4. Desierto andino

5. Monte

6. Espinal

7. Pastizal pampeano

8. Bosque andino patagónico

9. Estepa patagónica

10. Desierto antártico

Figura 2. Biomas de Argentina.

En el sur de la provincia de Corrientes y el norte de Entre Ríos (Bioma Espinal), la producción de carne de calidad de corderos es poco importante, caracterizándose por su estacionalidad anual acentuada con la venta de corderos livianos de «fin de año» (Revidatti et al., 2004). En la provincia de Río Negro (Bioma Patagónico/Monte) la producción más clásica de carne ovina es de cordero liviano, pero que se faenan más tarde que en Bioma Espinal; entre los meses de noviembre y marzo (Villar, 2009).
Si bien existen estudios argentinos de engorde de corderos de tipo «pesado» (35$40 \mathrm{kgPV}$ ), la información de invernada de corderos durante los meses estivales es muy escasa.

Se realizó un ensayo de engorde de corderos sobre campo natural entre los meses de enero y junio en la provincia de Corrientes. Se utilizó una carga de 0,78 UG/ha con pastoreo mixto vacuno y ovino, con dos tratamientos: con suplementación al 1\%PV con expeller de trigo y sin suplementación para el engorde de corderos con distintas proporciones de sangre de razas carniceras. Se obtuvieron ganancias de 59 y 62 g/an/día, sin diferencias significativas entre tratamientos. (Capellari et al., 2005).

\subsubsection{Resumen Argentina y Brasil}

En el Cuadro 4 se presenta un resumen de la información generada en experimentos realizados para el engorde estival de corderos en Argentina y Brasil.

\subsection{Otros países}

\subsubsection{Resultados de investigación}

En el sureste de los Estados Unidos, Miller et al. (2011) llevaron adelante un ensayo con corderos pastoreando gramilla (Cynodon dactylon) y achicoria (Cichorium intibus) durante los meses de verano. Corderos de la raza Southdown con PV iniciales de $25,7 \mathrm{~kg}$ fueron engordados sobre gramilla hasta los 33,1 kg con ganancias medias de 80 g/an/día sobre gramilla y por otro lado, sobre achicoria, llegaron a los 49,2 kg con ganancias medias de $290 \mathrm{~g} / \mathrm{an} / \mathrm{día}$.

En Grecia, Zervas et al. (1999) compararon dos grupos de corderos machos cruza de razas Karagounico x Boutsiko pastoreando una base forrajera mejorada de $5^{\text {to }}$ año sin suplementación en comparación con corderos engordados a corral, durante los meses de la primavera, siendo esta estación el único período que habilita el pastoreo en este país. Los animales comenzaron con un peso vivo (PV) de $29 \mathrm{kgPV}$ de 124 - 126 días de edad. Las características del forraje eran: contenido de MS de 20,3\%, contenido de 
Cuadro 4. Resumen de performances animales y cargas animales evaluadas, en ensayos de Brasil y Argentina de engorde de corderos durante el verano.

\begin{tabular}{|c|c|c|c|c|}
\hline Fuente & Ambiente & BF & GMD & cord/ha \\
\hline \multicolumn{5}{|c|}{ BRASIL } \\
\hline Guedes et al. (2012) & Bioma Caatinga & Panicum (r) & 191 & $\mathrm{~s} / \mathrm{d}$ \\
\hline Wander et al. (2002) & Bioma Caatinga & Panicum +Cynodon & $61-91$ & $40-60$ \\
\hline Voltolini et al. (2009) & Bioma Caatinga & Cynodon* & $60-100$ & $s / d$ \\
\hline Macedo et al. (1999) & Bioma Mata Atlántica & Cynodon & 106 & $\mathrm{~s} / \mathrm{d}$ \\
\hline Castro (2002) & Bioma Pampa & Pennisetum & $67-115$ & $50-78$ \\
\hline Gonzaga (2007) & Bioma Pampa & Pennisetum & 29 & $\mathrm{~s} / \mathrm{d}$ \\
\hline Brum et al. (2008) & Bioma Pampa & Pennisetum + MCN & 151 & 32 \\
\hline Carvalho et al. (2006) & Bioma Pampa & Cynodon* & $104-194$ & 50 \\
\hline De Almeida (2004) & Bioma Pampa & $\mathrm{PP}+\mathrm{CN}^{*}$ & $211-273$ & 27 \\
\hline Poli et al. (2008) & Bioma Pampa & Cynodon + Rg & $211-273$ & 18 \\
\hline \multicolumn{5}{|c|}{ ARGENTINA } \\
\hline Capellari et al. (2005) & Bioma Pampa/Espinal & $\mathrm{CN}$ * & $59-62$ & $\mathrm{~s} / \mathrm{d}$ \\
\hline
\end{tabular}

Nota: $\mathrm{BF}=$ Base forrajera; GMD = ganancia media diaria (g/an/día); PV/ha = producción de PV por hectárea; cord $/$ ha $=$ corderos/ha; $\mathrm{MCN}=$ mejoramiento de campo $(\mathrm{Rg}+\mathrm{TR}+\mathrm{L}) ; \mathrm{PP}=$ pradera artificial permanente con varias especies; $\mathrm{n} / \mathrm{a}=$ no aplica; $\mathrm{s} / \mathrm{d}=$ sin dato; $\mathrm{CN}=$ campo natural, *incluye suplementación.

proteína cruda (PC) de 16,8\% y las especies predominantes eran Agrostis sp., Festuca sp., Plantago sp., Trifolium sp. y Alopercus sp. La altura de la pastura se mantuvo siempre por encima de $6 \mathrm{~cm}$. La disponibilidad de la pastura promedió en el total del período fue $2000 \mathrm{kgMS} / \mathrm{ha}$. La ingesta estimada de los corderos en pastoreo fue de 2,15 kgMS/animal/día. Los corderos del tratamiento a corral ingirieron fardo de pradera $\left(\mathrm{PC}=9,4 \% ; \mathrm{FDA}^{1}=40 \%\right)$ a razón de 180 g/an/día más 1,42 kgMS/animal/ día de concentrado de $18,9 \%$ de PC. Las eficiencias de conversión fueron de 10,75 y $6,52 \mathrm{kgMS} / \mathrm{kgPV}$ para los animales pastoreando y a corral, respectivamente. Los pesos finales (PVf) fueron significativamente diferentes entre tratamientos, siendo 41 y $44 \mathrm{kgPV}$ para los tratamientos a pastoreo y a corral, respectivamente. De la misma manera, los pesos de canal de cada tratamiento fueron significativamente distintos entre tratamientos, siendo $19,7 \mathrm{~kg}$ y $21,9 \mathrm{~kg}$ para tratamiento a pastoreo y a corral, respectivamente. Las ganancias registradas fueron significativamente distintas entre grupos,

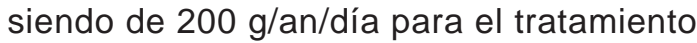
sobre pasturas y de 246 g/an/día para el tratamiento a corral.
En Zaragoza, España, Álvarez-Rodríguez et al. (2010) realizaron un ensayo utilizando corderos de raza Aragonesa a los que sometieron a cuatro tratamientos de engorde combinando: tipo de alimentación (pastoreo directo a base de alfalfa o encierro con dieta exclusiva a base de concentrado) y tipo de amamantamiento (lactancia durante todo el período de amamantamiento o destete a los $13 \mathrm{kgPV}$ ). EI PV a faena fue 22 - $24 \mathrm{kgPV}$. El experimento se desarrolló durante los meses del verano y otoño 2008. La pastura era un cultivo puro de alfalfa de $5^{\text {to }}$ año bajo riego (mensuales), utilizada durante su período vegetativo hasta la iniciación de la floración, con pastoreo rotativo y períodos de descanso de 28 días. La disponibilidad semanal de forraje tuvo un promedio de forraje disponible de $1318 \mathrm{kgMS} / \mathrm{ha}$ o $52 \mathrm{~cm}$, mientras que el rechazo semanal promedio fue de $444 \mathrm{kgMS} / \mathrm{ha}$ o $16 \mathrm{~cm}$. La pastura contenía $19 \%$ de MS y $25 \%$ de PC. Todos los corderos eran suplementados con un concentrado de $20 \%$ de PC ad libitum. Al destete, los corderos permanecían sobre la pastura a una carga de 21 corderos/ha. Las ganancias medias diarias (GMD) de los corderos sobre la pastura promediando tratamientos con y sin destete fueron de 240 g/an/día (sin

\footnotetext{
${ }^{1}$ FDA: Fibra Detergente Ácida.
} 
diferencias estadísticamente significativas entre éstos y los corderos confinados), mientras que el promedio los dos tipos de alimentación de los corderos destetados fue de 230 g/an/día.

Por otro lado en Dinamarca, Nielsen et al. (2009) realizaron un ensayo en los meses estivales con corderos Texel con PV inicial $36 \mathrm{~kg}$ a una carga de 10 corderos/ha sobre dos diferentes pasturas: trébol blanco más raigrás y la misma mezcla más achicoria. Las ganancias estivales promedio obtenidas por los animales pastoreando sobre la pastura sin achicoria fueron de 184 g/an/día, mientras que las ganancias sobre la pastura de raigrás, trébol blanco y achicoria fueron de 173 g/an/día. Los autores destacan la consistente selección en contra de la achicoria durante todo el período, es decir que los corderos consumían preferentemente raigrás y trébol blanco, rechazando la achicoria.

\subsubsection{Resumen otros países}

En el Cuadro 5 se presenta un resumen de la información obtenida en países que no se ubican en Oceanía ni en la Region, en ensayos involucrando engorde estival de corderos.

\section{REVISIÓN BIBLIOGRÁFICA NACIONAL}

\subsection{Consideraciones generales}

Las condiciones agroecológicas de los meses del verano son la principal limitante de la producción de corderos pesados precoces en el Uruguay (Bianchi et al., 2005, Bianchi et al., 2006; Garibotto y Bianchi, 2007). A través de la utilización de herramientas como el uso de cruzamientos terminales $y$ el aprovechamiento del potencial reproductivo de la especie ovina con encarneradas de otoño, la restricción principal para la producción de corderos pesado todo el año sigue siendo la escasez de alternativas forrajeras de calidad, de manera de poder engordar y terminar los corderos antes de su primer verano-otoño de vida (Bianchi et al., 2008).

Según Ayala et al. (2013b), la performance de corderos durante los meses estivales está afectada por factores nutricionales (distintas bases forrajeras), pero también por otros factores no relacionados al tipo de forraje consumido. Dentro de estos últimos, se pueden encontrar los siguientes: consumo de agua, estrés calórico y conductas de pastoreo de los animales. Si bien estos factores son relevantes en cualquier época del año, es en el verano que cobran especial importancia.

En cuanto al estrés calórico, este fenómeno se ve incrementado cuando coexisten condiciones de alta humedad y poca circulación del aire, generando en el animal reducciones en el consumo e incrementos en la producción de calor, lo que redunda en una disminución de la productividad animal (NRC, 1981, citado por Ayala et. al., 2013b). En cuanto al consumo de agua, el mismo se incrementa en dietas de alto contenido de materia seca, situación que podría darse durante el verano. Por último, en cuanto al comportamiento animal en pastoreo durante

Cuadro 5. Resumen de performances animales y cargas animales evaluadas, en ensayos de varios países de engorde de corderos durante el verano.

\begin{tabular}{|l|l|c|c|c|}
\hline \multicolumn{1}{|c|}{ País } & Fuente & BF & GMD & cord/ha \\
\hline USA & Miller et al. (2011) & Cynodon + Ach & $80-290$ & s/d \\
Grecia & Zervas et al. (1999) & PP & 200 & 20 \\
España & Álvarez-Rodríguez et al. (2010) & AA (r)* & 230 & 21 \\
Dinamarca & Nielsen et al. (2009) & TB + Rg +Ach & $173-184$ & 10 \\
\hline
\end{tabular}

Nota: $\mathrm{BF}=$ Base forrajera; GMD = ganancia media diaria (g/an/día); PV/ha = producción de PV por hectárea; cord $/$ ha = carga animal en corderos $/$ ha; $A c h=$ achicoria; $P P=$ pradera con variadas especies; $A A=$ alfalfa; $(r)=$ irrigado; $T B=$ trébol blanco; $\mathrm{Rg}=$ raigrás; $\mathrm{s} / \mathrm{d}=$ sin dato * Incluye suplementación. 
el verano, los animales incrementan las actividades de descanso y rumia durante las horas de mayor temperatura.

Por otra parte, dentro de los esfuerzos nacionales por generar información relacionada al engorde de corderos durante los meses del verano, existen una serie de trabajos con información de valor para productores y técnicos.

\subsection{Resultados experimentales y de campo sobre bases forrajeras mejoradas}

Ayala y Bermúdez (2005) realizaron registros de pastoreo sobre parcelas de campo natural mejorado con Lotus corniculatus cv. INIA Draco y Trifolium pratense cv. INIA Mizar, durante 62 días en el período enero-marzo. Con disponibilidades de $3700 \mathrm{kgMS} / \mathrm{ha}$ y una carga de 18 corderos/ha, se lograron ganancias de $140 \mathrm{~g} / \mathrm{an} /$ día y producciones de $157 \mathrm{~kg}$ $\mathrm{PV} / \mathrm{ha}$ sobre el mejoramiento con Lotus corniculatus cV. INIA Draco. Por otro lado, con disponibilidades de $4100 \mathrm{kgMS} / \mathrm{ha}$ y una carga de 17 corderos/ha, se lograron ganancias de 94 g/an/día y producciones de 99 kgPV/ha sobre el mejoramiento de campo con trébol rojo. Al año siguiente, los mismos autores realizaron el mismo trabajo, obteniendo ganancias de 144-167 g/an/día y produciendo 183- $213 \mathrm{kgPV} / \mathrm{ha}$ sobre mejoramiento con Lotus corniculatus cv. San Gabriel a 13 corderos/ha. También realizaron el mismo seguimiento sobre un mejoramiento de trébol rojo, obteniendo ganancias de 129$162 \mathrm{~g} / \mathrm{an} / \mathrm{dí}$ y producciones de 114 $142 \mathrm{kgPV} / \mathrm{ha}$ con una carga animal de 9 corderos/ha.

Magallanes y Paiva (2007), citados por Barrios et al. (2013), utilizaron un mejoramiento de campo de tercer año con Trifolium pratense cv. INIA Mizar con 64 corderos/ha durante los meses de verano, contrastando el mencionado tratamiento con una mezcla de Cichorium intybus cv. INIA Lacerta de segundo año intersembrado con el mismo trébol rojo, a una carga de 48 corderos/ha. Debido al déficit hídrico reinante, se debió suspender el pastoreo por falta de forraje de calidad. Bajo estas condiciones reinantes y sólo comparando el período que efectivamente se pastorearon ambas bases forrajeras, las performances individuales resultaron en pérdidas de 19 g/an/día para ambos tratamientos sin diferencias significativas entre ellos.

El pastoreo controlado sobre mejoramientos de campo con lotus Maku, el pastoreo de un cultivo de soja o el sorgo forrajero, también son opciones válidas para la recría ovina. Los mejoramientos de campo pueden ser utilizados como suplementación horaria o como suplementación por días en la semana. La soja también puede ser utilizada ya sea como suplemento en pastoreos horarios o como único alimento. El pastoreo sobre cultivo de sorgo forrajero tipo BMR fotosensitivos manejado a altas cargas y mantenido a menos de $60 \mathrm{~cm}$ de altura presenta alta respuesta a la suplementación proteica (Piaggio, 2013).

El Cuadro 6 presenta una serie de resultados de investigación de corderos en engorde durante el período estival, por Piaggio (2013).

Piaggio et al. (2014) trabajaron con corderos al destete desde fines de enero hasta fines de abril y contrastaron los siguientes tratamientos: pastoreo sobre campo natural $(T)$; pastoreo sobre campo natural + bloques proteicos (BL); pastoreo sobre campo natural + expeller de soja (EXP); pastoreo sobre campo natural + 3 horas por día sobre pastura con Lotus uliginosus cv. Maku (3HR): pastoreo sobre campo natural +3 horas 1 vez cada 3 días sobre pastura con Lotus uliginosus cv. Maku (3HRc/3D). El objetivo fue comparar suplementos proteicos ya sea como bloques o ración en contraste con un «banco verde» de una pastura con alta concentración de proteína cruda.

En términos de ganancias medias diarias, los tratamientos $3 \mathrm{HR}$ y $3 \mathrm{HRc} / 3 \mathrm{D}$ fueron superiores $(P<0,05)$ a $T$, y a su vez no se diferenciaron de los tratamientos $B L$ y EXP. Las ganancias registradas (g/an/día) fueron: $\mathrm{T}=46$ (b); $\mathrm{BL}=51$ (b); $\mathrm{EXP}=71$ $(\mathrm{ab}) ; 3 \mathrm{HR}=87(\mathrm{a}) ; 3 \mathrm{HRc} / 3 \mathrm{D}=62(\mathrm{ab})$. Estadísticamente, el pastoreo sobre campo natural o la suplementación con bloque proteico sobre campo natural, tuvieron el 
Cuadro 6. Respuesta en performance animal al pastoreo estival con bases forrajeras mejoradas (adaptado de Piaggio, 2013).

\begin{tabular}{|c|c|c|c|c|c|c|}
\hline Alternativa Alimenticia & 2004 & 2005 & 2006 & 2007 & 2012 & 2013 \\
\hline Respuesta animal (g/an/día) & & & & & & \\
\hline Campo Natural & 33 & 46 & & 2 & 57 & \\
\hline Pradera & 93 & 61 & 70 & & & \\
\hline $\begin{array}{l}\text { Cultivo de soja } 6 \text { hs/d ( } 40 \text { cord/ha) } \\
+ \text { encierro c/agua y sombra }\end{array}$ & & & 103 & & & \\
\hline $\begin{array}{l}\text { Cultivo de soja pastoreo permanente } \\
\text { ( } 25 \mathrm{cord} / \mathrm{ha} \text { ) c/agua y sombra }\end{array}$ & & & 172 & & & \\
\hline $\begin{array}{l}\text { Cultivo de soja pastoreo permanente } \\
\text { ( } 30 \mathrm{cord} / \mathrm{ha} \text { ) c/agua y sombra }\end{array}$ & & & & 125 & & \\
\hline $\begin{array}{l}\text { Cultivo de soja } 3 \text { h/d (70 cord/ha) } \\
\text { + Campo Natural c/agua y sombra }\end{array}$ & & & & 87 & & \\
\hline $\begin{array}{l}\text { Cultivo de sorgo BMR fotosensitivo } \\
\text { (50 cord/ha) c/agua en parcela }\end{array}$ & & & & & 73 & 56 \\
\hline $\begin{array}{l}\text { Cultivo de sorgo BMR fotosensitivo } \\
\text { ( } 50 \mathrm{cord} / \mathrm{ha} \text { ) c/agua en parcela } \\
+200 \mathrm{~g} / \mathrm{an} / \mathrm{de} \text { soja }\end{array}$ & & & & & 149 & \\
\hline $\begin{array}{l}\text { Cultivo de sorgo BMR fotosensitivo } \\
\text { ( } 50 \mathrm{cord} / \mathrm{ha} \text { ) c/agua en parcela } \\
+115 \mathrm{~g} / \mathrm{an} / \mathrm{d} \text { harina de soja }\end{array}$ & & & & & & 104 \\
\hline $\begin{array}{l}\text { Cultivo de sorgo BMR fotosensitivo } \\
\text { ( } 50 \text { cord/ha) c/agua en parcela } \\
+ \text { bloques proteicos ( } 330 \mathrm{~g} / \mathrm{an} / \mathrm{d})\end{array}$ & & & & & 133 & \\
\hline
\end{tabular}

Nota: Carga animal sobre $\mathrm{CN}=10$ corderos/ha.

mismo efecto en la performance animal, mientras que el acceso a 3 horas de pastoreo sobre un «banco de proteína» como el lotus Maku fue significativamente superior a una suplementación con bloque proteico.

Piaggio et al. (2014) concluyen que el pastoreo controlado fue efectivo en mejorar las performances productivas de los corderos que pastorean sobre campo natural en el período otoño-invernal.

En INIA Treinta y Tres se realizó un ensayo sobre una pastura pura de llantén (Plantago lanceolata) utilizando corderos Corriedale durante el período entre diciembre y marzo, contrastando cuatro cargas de $10,5,13,2,15$, 8 y 18,4 corderos/ha. Los corderos iniciaron el experimento con 21,5 kgPV y el promedio final de los cuatro tratamientos fue de 40,3 kgPV. Las tasas de ganan- cias obtenidas fueron de 226, 188, 190 y 158 g/an/día para las cargas de 10,5, 13,2, 15,8 y 18,4 , respectivamente, mientras que las producciones de PV por unidad de superficie fueron de 231, 240, 291 y $282 \mathrm{kgPV} / \mathrm{ha}$, para las mismas cargas respectivamente. Con las tres dotaciones más bajas se logró terminar el $100 \%$ de los animales como cordero pesado. La carga que mejor combino productividad por hectárea y terminación fue la de 15,8 corderos/ha (Barrios y Ayala, 2013).

Lamarca y Bianchi (2011) realizaron una corta experiencia con engorde de corderos y corderas Poll Dorset x Southdown suplementados sobre soja, a una dotación de 48 corderos/ha. El suplemento se trataba de grano de sorgo entero a razón del 0,4 \%PV. La disponibilidad inicial de forraje de soja fue de $4070 \mathrm{kgMS} / \mathrm{ha}$. Se obtuvieron ganancias de $50 \mathrm{~g} / \mathrm{an} / \mathrm{día}$ y en período de tiempo en el 
que se llevó a cabo la evaluación se produjeron $33 \mathrm{kgPV} / \mathrm{ha}$.

Otros autores también evaluaron la performance animal de corderos sobre cultivo de soja. En una oportunidad, Garibotto y Bianchi (2007) trabajaron con una carga de 36 corderos/ha por un período de 30 días. Los corderos eran Corriedale y cruzas Southdown y Poll Dorset con PV iniciales de $35 \mathrm{~kg}$ y 134 días de edad. Las ganancias oscilaron entre 69 y 120 g/an/día y las producciones de carne por hectárea se ubicaron entre 82 y $115 \mathrm{kgPV} / \mathrm{ha}$. Durante otro año de evaluación Bianchi et al. (2005), utilizaron una carga promedio de 50,2 corderos/ha sobre un cultivo de soja por un período total de 25 días, alcanzándose ganancias de 9 y $60 \mathrm{~g} / \mathrm{an} /$ día y producciones de carne de $80 \mathrm{kgPV} / \mathrm{ha}$ en dicho período. Garibotto y Bianchi (2007) también evaluaron corderos en engorde sobre soja, con PV iniciales de $40,1 \mathrm{~kg}$ y 130 días de edad, a una carga de 34 corderos/ha durante 34 días con pastoreo restringido a las horas de la tarde y noche (pos 18:00 h). En esta ocasión las ganancias medias registradas variaron entre 140 y 150 g/an/día y producciones de carne de $150 \mathrm{kgPV} / \mathrm{ha}$.

Ayala et al. (2013a) mencionan una serie de antecedentes de ensayos realizados con ovinos sobre sudangrás y sorgo. Parma (1997), citado por Ayala et al. (2013a) obtuvo ganancias diarias de 34 g/an/día con una carga de 40 corderos/ha utilizando sudangrás.

Ayala y Bermúdez (2005) realizaron registros de pastoreo sobre distintas bases forrajeras durante 28 días en el mes de enero. Evaluaron un sudangrás con una carga de 88 corderos/ha, obteniendo una ganancia diaria de 63 g/an/día y una producción por unidad de superficie de $155 \mathrm{kgPV} / \mathrm{ha}$. También evaluaron un cultivo de moha con una carga de 50 corderos/ha, logrando ganancias de $70 \mathrm{~g} / \mathrm{an} /$ día y una producción de peso vivo de $99 \mathrm{kgPV} / \mathrm{ha}$. Las pasturas tenían disponibilidades de $1300 \mathrm{kgMS} / \mathrm{ha}$ (sudangras) y $1500 \mathrm{kgMS} / \mathrm{ha}$ (moha). Los autores mencionan que el rápido desarrollo de este tipo de verdeos genera dificultades en su utilización y también observaron que los animales ten- dían a preferir más al sudangrás que a la moha.

Ayala et al. (2013a) evaluaron la performance de corderos pastoreando sudangrás con una carga de 48 corderos/ha, obteniéndose ganancias de 117 g/an/día y producciones de $158 \mathrm{kgPV} / \mathrm{ha}$. Magallanes y Paiva (2007), citados por Ayala et al. (2013a) utilizaron sudangrás con corderos a una carga de 41 corderos/ha, no lograron los PV de terminación requeridos por el mercado de corderos pesados. Las ganancias diarias fueron de $67 \mathrm{~g} / \mathrm{an} /$ día y la producción de carne por unidad de superficie fue de $160 \mathrm{kgPV} / \mathrm{ha}$.

Ayala et al. (2007), citados por Barrios et al. (2013) realizaron un ensayo durante los meses de verano utilizando una pastura de Lotus corniculatus cv. INIA Draco, con 10, 20 y 30 corderos/ha cruza Texel. Se registraron diferencias significativas entre las cargas utilizadas, lográndose la máxima producción para el tratamiento de 20 corderos/ha con $263 \mathrm{kgPV} / \mathrm{ha}$. Las ganancias individuales registradas fueron estadísticamente iguales para las dos cargas más bajas, promediando $144 \mathrm{~g} / \mathrm{an} / \mathrm{día}$, mientras que la carga más elevada tuvo una ganancia de 71 g/an/día. En cuanto a la calidad de la canal, no se registraron diferencias entre las dos cargas más bajas para PV pre faena, peso canal caliente, peso de canal fría y punto GR, promediando valores de $39 \mathrm{~kg}$, $19,2 \mathrm{~kg}, 18,8 \mathrm{~kg}$ y $15,3 \mathrm{~mm}$, respectivamente; no obstante, los valores obtenidos para la carga más elevada fueron de $32,8 \mathrm{~kg}$, $16 \mathrm{~kg}, 16,2 \mathrm{~kg}$ y $9,2 \mathrm{~mm}$, respectivamente.

Ayala et al. (2007), citados por Ayala y Barrios (2013), realizaron un ensayo sobre un cultivo de nabo forrajero (Brassica sp. cv. Pasja), en distintas etapas del cultivo. Se utilizaron corderos Texel con un peso inicial de $26,2 \mathrm{kgPV}$, distribuidos en cuatro tratamientos de dotación animal: 24, 36, 48 y 60 corderos/ha, bajo pastoreo continuo. A su vez, estas cargas se evaluaron durante tres estadios del ciclo del cultivo: desde período vegetativo, hasta madurez avanzada, comprendiendo el período de tiempo desde mediados de enero hasta principios de abril. Durante la etapa de pastoreo en estado 
vegetativo de la pastura (3140 $\mathrm{kgMS} / \mathrm{ha}$ de forraje disponible; $12,8 \% \mathrm{MS}$ ) las ganancias se situaron entre 177 y $235 \mathrm{~g} / \mathrm{an} / \mathrm{día}$ detectándose una ganancia menor para el tratamiento con carga baja. Durante la etapa de madurez temprana del cultivo $(6700$ $\mathrm{kgMS} / \mathrm{ha}$ de forraje disponible; $11,2 \% \mathrm{MS}$ ), la performance animal fue siempre superior a $176 \mathrm{~g} / \mathrm{an} / \mathrm{día}$, si bien la carga más baja registró una tendencia a tener ganancias algo mayores. Durante la última etapa, de madurez avanzada del cultivo (6530 kgMS/ha de forraje disponible; 16,1\% MS), las ganancias fueron sensiblemente menores para todas las cargas animales, promediando $67 \mathrm{~g} / \mathrm{an} /$ día y la carga mayor fue excluida de la evaluación por considerarse excesiva.

Ayala et al. (2009), citados por Ayala y Barrios (2013) evaluaron diferentes dotaciones de corderos Corriedale sobre un cultivo de nabo forrajero (Brassica sp. cv. Goliath) y la utilización de campo natural como fuente de fibra adicional, como manera de compensar la alta digestibilidad y bajo contenido de materia seca de este cultivar de nabo forrajero. Las cargas animales evaluadas fueron de 36, 48, 60 y 72 corderos/ha y éstos pastoreaban el $68 \%$ del área de pastoreo sobre la pastura cultivada y $32 \%$ de la misma sobre campo natural. Las performances animales registradas se situaron entre 151 y los 168 g/an/día, sin diferencias significativas entre tratamientos. Sin embargo, en cuanto a la producción total por unidad de superficie, sí se encontraron diferencias significativas entre las distintas cargas, siendo la mayor producción de $457 \mathrm{kgPV} /$ ha correspondiente a la carga animal mayor (72 corderos/ha) y la menor producción de $242 \mathrm{kgPV} / \mathrm{h}$ a para la carga menor (36 corderos/ha).

Bianchi et al. (2008) utilizaron corderas Corriedale x Poll Dorset con un PV inicial de $42 \mathrm{~kg}$ y una carga animal de 40 corderos/ha, pastoreando nabo forrajero (Brassica sp. cv Graza), para evaluar parámetros de la pastura así como la performance animal. Las ganancias medias diarias de las corderas promediaron $146 \mathrm{~g} / \mathrm{an} / \mathrm{día}$.

Por otro lado, Bianchi et al. (2006) evaluaron la performance de corderos pastorean- do una pradera de segundo año compuesta de festuca, Lotus corniculatus y trébol blanco. En este ensayo se evaluó el efecto de la suplementación y de la restricción del tiempo de pastoreo sobre esta base forrajera de corderos Southdown con un PV inicial de $22 \mathrm{~kg}$, con una carga de 14 corderos/ha. Los cuatro tratamientos fueron: pastoreo libre todo el día con y sin suplementación (PLS y PLSS) y pastoreo restringido de 17:00 a 20:00 hrs, con y sin suplementación (PRS y PRSS). El suplemento se suministró a razón del 0,6\% PV con ración comercial $(16,9 \%$ PC). Solamente se encontró efecto significativo en los tratamientos con pastoreo restringido en las variables estudiadas, obteniéndose $\mathrm{PV}$ finales de $33 \mathrm{~kg}$ para los tratamientos con restricción de tiempo de pastoreo y $38 \mathrm{~kg}$ en promedio para el resto de los tratamientos. Las ganancias registradas se situaron entre 82 y 99 g/an/día.

Ayala y Bermúdez (2005) realizaron registros de pastoreo sobre una pradera de trébol rojo y achicoria durante el período estival por 50 días. Las disponibilidades de forraje eran de $800 \mathrm{kgMS} / \mathrm{ha}$ y los corderos ganaron $128 \mathrm{~g} / \mathrm{an} /$ día y produjeron $160 \mathrm{kgPV} / \mathrm{ha}$ a una carga de 25 corderos/ha. Al año siguiente, con disponibilidades del orden de los $4000 \mathrm{kgMS} / \mathrm{ha}$ se repitió el registro de pastoreo, obteniéndose ganancias en el rango de de 97-174 g/an/día y producciones de 123-188 kgPV/ha, con una carga de 13 corderos/ha.

Soca (2005), citado por Garibotto y Bianchi (2007) realizó un ensayo en donde se obtuvieron elevadas ganancias de peso de 190 g/an/día evaluando sistemas de pastoreo restringido o libre sobre una pradera de segundo año con festuca, Lotus corniculatus y trébol a una carga de 14 corderos/ha con suplementación (ración comercial 16,9\% PC). Garibotto (2006), citado por Garibotto y Bianchi (2007) evaluaron corderos suplementados con grano de maíz $(0,6 \%$ PV) como suplemento sobre una pradera con una muy baja proporción de leguminosas, a una dotación animal de 10 corderos/ha, se obtuvieron ganancias siempre por debajo de los 100 g/an/día. 


\subsection{Resultados experimentales y de campo sobre bases forrajeras irrigadas}

Formoso y Norbis (2013) realizaron ensayos de engorde de corderos sobre pasturas mejoradas bajo riego en el año 2012. En el Cuadro 7, se presenta el resumen de la producción de carne ovina y total para cada especie forrajera irrigada.

Una de las observaciones que mencionan los autores es que, a raíz de las muy altas cargas ovinas utilizadas, se manifestaron problemas sanitarios agudos, que determinaron bajas ganancias individuales con la consiguiente pérdida de utilización del forraje producido. Concluyen que se deben tomar precauciones en la asignación de carga u manejo del pastoreo ovino, así como protocolizar un seguimiento exhaustivo de los aspectos sanitarios.

\subsection{Consideraciones finales}

Partiendo de la afirmación que el campo natural de por sí es normalmente insuficien- te a la hora de lograr ganancias estivales acordes a una buena recría ovina (Piaggio, 2013), se realizaron ensayos con distintos tipos de suplementos para evaluar la posibilidad de levantar las limitantes de calidad que presenta esta base forrajera durante el verano.

En términos generales, se puede decir que desde un punto de vista biológico la suplementación proteica -tanto aquella provenientes de suplementos como de «bancos de verde» provenientes de forrajes con alta concentración proteica - efectivamente supera en algunos casos las limitantes identificadas, obteniéndose superiores a los 100 g/an/día.

Otra manera de levantar las limitantes conocidas que tiene el campo natural en el verano para la producción de carne ovina es la utilización de bases forrajeras mejoradas, ya sean mejoramientos de campo, praderas artificiales permanentes o verdeos estivales. En el Cuadro 8, se resume las ganancias medias (GMD), las cargas utilizadas (corderos/ha) y la producción por unidad de superficie (kgPV/ha) en los ensayos relevados a nivel nacional.

Cuadro 7. Producción animal (kgPV/ha) por hectárea sobre diferentes bases forrajeras irrigadas (adaptado de Formoso y Norbis, 2013).

\begin{tabular}{|l|c|c|c|c|c|}
\hline Producción (kgPV/ha) & Ach+TR & Rg+TR & F+TB & F+LM & LM \\
\hline Carne ovina & 924 & 909 & 776 & 492 & 1,123 \\
Carne ovina + vacuna & 924 & 909 & 1,491 & 1,026 & 1,123 \\
\hline
\end{tabular}

Nota: Ach = Achicoria; TR = Trébol Rojo; Rg = Raigrás Banquet II; F = Festuca Rizomat; LM = Lotus Maku. 
Cuadro 8. Resumen de performances animales individuales y por unidad de superficie y cargas animales evaluadas, en ensayos nacionales de recría y engorde estival de corderos sobre diferentes bases forrajeras mejoradas durante el verano.

\begin{tabular}{|c|c|c|c|c|}
\hline Fuente & BF & GMD & cord/ha & kgPV/ha \\
\hline $\begin{array}{l}\text { Ayala y Bermúdez (2005) } \\
\text { Magallanes y Paiva }(2007)^{2}\end{array}$ & MCN-TR & $\begin{array}{c}94-162 \\
-19\end{array}$ & $\begin{array}{c}9-17 \\
64\end{array}$ & $\begin{array}{c}99-142 \\
s / d\end{array}$ \\
\hline Magallanes y Paiva $(2007)^{2}$ & $\mathrm{MCN}-\mathrm{Ach}+\mathrm{TR}$ & -19 & 48 & $s / d$ \\
\hline Ayala y Bermúdez (2005) & MCN - lotus común & $140-167$ & $13-18$ & $157-213$ \\
\hline Barrios y Ayala (2013) & Llantén & $158-226$ & $10.5-18.4$ & $231-291$ \\
\hline $\begin{array}{l}\text { Piaggio (2013) } \\
\text { Lamarca y Bianchi (2011) } \\
\text { Bianchi et al. (2005) } \\
\text { Garibotto y Bianchi (2007) (A) } \\
\text { Garibotto y Bianchi (2007) (B) }\end{array}$ & Soja & $\begin{array}{c}87-172 \\
50^{*} \\
69-120 \\
9-90 \\
140-150\end{array}$ & $\begin{array}{c}25-70 \\
48 \\
36 \\
50.2 \\
34\end{array}$ & $\begin{array}{c}\mathrm{s} / \mathrm{d} \\
33^{\star \star} \\
85-115^{\star \star \star} \\
80^{\star \star \star *} \\
34^{\star \star \star}\end{array}$ \\
\hline $\begin{array}{l}\text { Piaggio (2013) } \\
\text { Montossi et al. }(2004)^{1} \\
\text { Montossi et al. }(2004)^{1}\end{array}$ & Sorgo & $\begin{array}{c}56-149^{\star} \\
57-64 \\
20-85\end{array}$ & $\begin{array}{c}50 \\
30-50 \\
37.5-70.4\end{array}$ & $\mathrm{~s} / \mathrm{d}$ \\
\hline Ayala y Bermúdez (2005) & Moha & 70 & 50 & $99 * \star \star \star *$ \\
\hline $\begin{array}{l}\text { Parma }(1997)^{1} \\
\text { Ayala y Bermúdez (2005) } \\
\text { Ayala et al. (2013a) } \\
\text { Magallanes y Paiva }(2007)^{1}\end{array}$ & Sudan & $\begin{array}{c}34 \\
63 \\
117 \\
67\end{array}$ & $\begin{array}{l}40 \\
88 \\
48 \\
41 \\
\end{array}$ & $\begin{array}{c}s / d \\
155^{* * * *} \\
158 \\
160 \\
\end{array}$ \\
\hline Ayala et al. $(2007)^{2}$ & Lotus común & $71-144$ & $10-30$ & 263 \\
\hline $\begin{array}{l}\text { Ayala et al. }(2007)^{3} \\
\text { Ayala et al. }(2009)^{3} \\
\text { Bianchi et al. (2008) }\end{array}$ & Brassica & $\begin{array}{c}67-235 \\
151-168 \\
146 \\
\end{array}$ & $\begin{array}{c}24-60 \\
36-72 \\
40 \\
\end{array}$ & $\begin{array}{c}s / d \\
242-457 \\
s / d\end{array}$ \\
\hline $\begin{array}{l}\text { Bianchi et al. (2006) } \\
\text { Soca }(2005)^{4}\end{array}$ & $\mathrm{~F}+\mathrm{TB}+\mathrm{L}$ & $\begin{array}{c}82-99^{*} \\
190^{*}\end{array}$ & $\begin{array}{l}14 \\
14\end{array}$ & $\begin{array}{l}\mathrm{s} / \mathrm{d} \\
\mathrm{s} / \mathrm{d}\end{array}$ \\
\hline Garibotto $(2006)^{4}$ & PP degradada & $<100^{*}$ & 10 & $\mathrm{~s} / \mathrm{d}$ \\
\hline Ayala y Bermúdez (2005) & $\mathrm{TR}+\mathrm{Ach}$ & $97-188$ & $13-25$ & $123-188$ \\
\hline Formoso y Norbis (2013) & PP irrigadas & - & - & $492-1491$ \\
\hline
\end{tabular}

Nota: $\mathrm{BF}=$ Base forrajera; GMD = ganancia media diaria (g/an/día); PV/ha = producción de PV por hectárea; cord $/ \mathrm{ha}=$ carga animal en corderos/ha; F+TB $+\mathrm{L}=$ Festuca, Trébol Blanco, Lotus corniculatus; $\mathrm{MCN}=$ Mejoramiento de campo natural; TR = Trébol Rojo; Ach = Achicoria; $\mathrm{s} / \mathrm{d}=$ sin dato; $\mathrm{PP}=$ pradera artificial permanente.

${ }^{1}$ Citado por Ayala et al. (2013a); ${ }^{2}$ Citados por Barrios et al. (2013); ${ }^{3}$ Citados por Ayala y Barrios (2013); ${ }^{4}$ Citado por Garibotto y Bianchi (2007); * = incluye suplementación; **período de evaluación 15 días; *** período de evaluación 30 días o más; **** período de evaluación 25-28 días. 


\section{BIBLIOGRAFÍA}

ÁLVAREZ-RODRÍGUEZ, J.; SANZ, A.; RIPOLLBOSCH, R.;JOY, M. 2010. Do alfalfa grazing and lactation length affect the digestive tract fill of light lambs? Small Ruminant Research, 94 (1-3): 109-116.

AYALA, W.; BARRIOS, E. 2013. Alternativas forrajeras estivales para el engorde de corderos: Brassicas forrajeras. En: Seminario de Actualización Técnica: producción de parne ovina de calidad, INIA Treinta y Tres.Montevideo: INIA. p 77-91. (Serie Actividades de Difusión; 719).

AYALA, W.; BARRIOS, E.; MAGALLANES, J.; PAIVA, M. 2013a. Utilización de verdeos de verano en la alimentación de corderos. En: Seminario de Actualización Técnica: producción de carne ovina de calidad, INIA Treinta y Tres. Montevideo: INIA. p 63-68. (Serie Actividades de Difusión; 719).

AYALA, W.; BARRIOS, E.; MAGALLANES, J.; PAIVA, M. 2013b. Algunos factores que iniciden en la performance $y$ comportamiento de corderos durante el verano. En: Seminario de Actualización Técnica: producción de carne ovina de calidad, INIA Treinta y Tres. Montevideo: INIA. p 93-99. (Serie Actividades de Difusión; 719).

AYALA, W.; BERMÚDEZ, R. 2005. Alternativas de alimentación en la recría de corderos durante el verano: resultados preliminares. En: Producción Animal Unidad Experimental Palo a Pique. INIA Treinta y Tres. Montevideo: INIA. p 3337. (Serie Actividades de Difusión; 429).

BARRIOS, E.; AYALA, W. 2013. Utilización de Plantago lanceolata en la alimentación de corderos en el período estival. En: Seminario de Actualización Técnica: producción de carne ovina de calidad, INIA Treinta y Tres. Montevideo: INIA. p 55-61. (Serie Actividades de Difusión; 719).

BARRIOS, E.; AYALA, W.; BERMÚDEZ, R.; MAGALLANES, J.; PAIVA, M. 2013. Alternativas forrajeras estivales para la producción de corderos: leguminosas. En: Seminario de Actualización Técnica:producción de carne ovina de calidad, INIA Treinta y Tres. Montevideo: INIA. p 69-75. (Serie Actividades de Difusión; 719).
BELL, A.; ROSE, H.; ARCHER, K. 1991. Final Report to WRDC, Project DAN 21, 6 p.

BIANCHI, G.; FERNÁNDEZ, M.; GARIBOTTO, G.; BENTANCUR, O. 2008. Engorde de corderos utilizando Brassica $s p$. Producción Ovina, 20: 85-96.

BIANCHI, G.; GARIBOTTO, G.; FORICHI, S.; HOFFMAN, E.; SOCA, P. 2005. Tecnologías para el engorde y la terminación de corderos en verano. Revista Cangué, 27:26-32.

BIANCHI, G.; GARIBOTTO, G.; SOCA, P.; BENTANCUR, O.; LAWLOR, D.; ORTIZ, D.; ROSALES, I. 2006. Efecto del control del tiempo de pastoreo y de la suplementación sobre el desempeño de corderos pesados. Revista Argentina de Producción Animal, 26 (S 1):348-349.

BLUETT, S.; HODGSON, J.; KEMP, P.; BARRY, T. 2001. Performance of lambs and the incidence of staggers and heat stress on two perennial ryegrass (Lolium perenne) cultivars using a leaderfollower rotational. Journal of Agricultural Science, 136: 99-110.

BRUM, M.; de QUADROS, F.; MARTINS, J.; ROSSI, G.;DANIEL, E.; MAIXNER, A.; BANDINELLI, D. 2008. Sistemas de alimentação para a recria de ovinos a pasto/ : avaliação do desempenho animal e características da forragem. Ciencia Rural, 38 (1):191-198.

BURNETT, V.; SEYMOUR, G.; NORNG, S.; JACOBS, J.; PONNAMPALAM, E. 2012. Lamb growth performance and carcass weight from rotationally grazed perennial pasture systems compared with annual pasture systems with supplements, 248-254.

BURTT, E.; HILL, G. 1990. Yield and nutritive value of spring-sown sweet lupins (Lupinus angustifolius cv. Uniharvest) for lambs grazed at four different stages of growth 1 . Dry matter production and utilisation. New Zealand Journal of Agricultural Research, 33 (3): 353-357.

CAPELLARI, A.; REVIDATTI, M.; REBAK, G.; AGUILAR, D.; FRANZ, N.; AGUIRRE, F.; ROBSON, C. 2005. Ganancia diaria de peso de corderos pesados doble propósito y triple cruza en Corrientes. En: CONGRESO ARGENTINO DE PRODUCCION ANIMALp. 19-21). 
CARVALHO, S.; VERGUEIRO, A.; KIELING, R.; TEIXEIRA, R. C.; PIVATO, J.; VIERO, R.; CRUZ, A. N. 2006. Desempenho e características da carcaça de cordeiros mantidos em pastagem de tifton-85 e suplementados com diferentes níveis de concentrado. Revista Brasileira de Agrociência, 12(3: 357-361.

CASTRO, C. 2002. Relações planta-animal em pastagem de milheto (Pennisetum americanum (L.) Leeke) manejada em diferentes alturas com ovinos. Universidade Federal do Rio Grande Do Sul. Faculdade de Agronomia.

CHURCH, D. 1984. Alimentos y alimentación del ganado. Montevideo: Hemisferio Sur. $405 \mathrm{p}$.

DE ALMEIDA. 2004. Produçao de carne de cordeiros da raça Ideal e cruzas Ideal $x$ Border Leicester terminados em campo natural suplementado ou pastagem cultivada com ou sem suplementaçao. M. Sc. Thesis. Santa María, Brasil, Universidade Federal de Santa María. $82 \mathrm{p}$.

DE NICOLO, G; MORRIS, S.; KENYON, P. 2008. A comparison of two lamb production systems in New Zealand. New Zealand Journal of Agricultural Research, 51:365-375.

DOWLING, M.; MICHALK, D.; KEMP, D.; MILLAR, G.; PRIEST, S.; TARLETON, J. 2006. Sustainable grazing systems for the Central Tablelands of New South Wales. 2 .Effect of pasture type and grazing, 457-469.

FORMOSO, D.; NORBIS, H. 2013. Uso del Riego en pasturas con destino al engorde de corderos. En: Seminario de Actualización Técnica: producción de carne ovina de calidad, INIA Treinta y Tres. Montevideo: INIA. p 113-123. (Serie Actividades de Difusión; 719).

GARIBOTTO, G.; BIANCHI, G. 2007. Alternativas nutricionales con diferente grado de intensificación y su efecto en la producción final. Capítulo 6. En: Bianchi, G. Alternativas tecnológicas para la producción de carne ovina de calidad en sistemas pastoriles. Montevideo: Hemisferio Sur p. 161-225.

GEENTY, K.; RATTRAY, P. 1987. The energy requirements of grazing sheep and cattle. En: Nicol, A. Livestock feeding on pasture. Hamilton: New Zealand Society of Animal Production. (Occasiona Publication 10). p 39-55.

GONZAGA, S.S. 2007. Produçao de carne de ovinos Corriedale terminados em pastagem de verão. PhD. Thesis. Pelotas, Brasil. Faculdade de Agronomia Eliseu Maciel, Universidade Federal de Pelotas. $104 \mathrm{p}$.

GUEDES NETO, J.; OLIVEIRA, L.; ALBUQUERQUE, F.; MEMÓRIA, H.; HOLANDA JUNIOR, E. 2012. Desempenho de cordeiros terminados em centro de terminação em pastagem cultivada e irrigada. En: Embrapa Caprinos e Ovinos-Artigo em anais de congresso (ALICE). In: Encontro de pesquisa e pos-graduaçâo da Universidade Estadual do Vale do Acaraú. 6, 2011, Sobral.[Anais...]. Sobral: UVA, 2011. $7 \mathrm{f}$.

HODGSON, J. 1990. Grazing management, science into practice. Whittemore: Longman Scientific \& Technical. 203 p.

HOLST, P.; STANLEY, D.; MILLAR, G.; RADBURN, A.; MICHALK, D.; DOWLING, P.; TARLETON, J. 2006. Sustainable grazing systems for the Central Tablelands of New South Wales. 3. Animal production response to pasture type and management. Australian Journal of Experimental Agriculture, 46 (4): 471.

HOPKINS, D.; HOLST, I.; HALL, D. 1991. Effect of grain or silage supplementation on meat quality attributes of cryptorchid lambs grazing lucerne or annual grass-clover pastures, (November), 1991-1995.

JONES, R.; KNIGHT, R.; WHITE, A. 1989. Nutrition of intensively rered lambs. En: Recent Advances in Animal Nutrition. Haresign, W.; Cole, D.(eds.) 10: 195-208.

KELMAN, W.; DOVE, H. 2007. Effects of a springsown brassica crop on lamb performance and on subsequent establishment and grain yield of dualpurpose winter wheat and oat crops. Australian Journal of Experimental Agriculture, 47 (7):815

LAMARCA, M.; BIANCHI, G. 2011. Terminación de corderos sobre un cultivo de soja suplementados con grano de sorgo. Revista Plan Agropecuario, 137:30-34. 
LEMES, J.; OSORIO; M.; GONZAGA, S.; MARTINS, L.; ESTEVES, R.; LEHMEN, R. 2014. Características da carcaça e da carne de cordeiros corriedale manejados em duas alturas de milheto. Archivos de Zootecnia, 63 (241): 161-170.

MACEDO, F.; SIQUEIRA, E.; MARTINS, E. 1999. Desempenho de cordeiros Corriedale, puros e mestiços, terminados em pastagem e em confinamento. Arq. bras. med. vet. zootec, 51(6): 583-7.

MILLER, M.; DUCKETT, S.; ANDRAE, J. 2011. The effect of forage species on performance and gastrointestinal nematode infection in lambs. Small Ruminant Research, 95 (2-3): 188-192.

NIELSEN, B. K., THAMSBORG, S. M., HANSEN, H., RANVIG, H., \& HøGH-JENSEN, H. 2009. Effects of including chicory in perennial ryegrass-white clover leys on production and health in organic lambs. Livestock Science, 125 (1), 66-73.

N.R.C. 1985. Nutrient requirements of sheep. Washington DC: National Academy Press. 2-25 p.

PIAGGIO, L. 2013. Suplementación de la recría y engorde de ovinos sobre campo natural.En: Seminario de Actualización Técnica: Producción de carne ovina de calidad, INIA Treinta y Tres. Montevideo: INIA. p 41-45. (Serie Actividades de Difusión; 719).

PIAGGIO, L.; MARICHAL, M.; PASTORIN, A. 2014. A 'protein bank' of Lotus uliginosus cv. Maku as an alternative to conventional protein supplements for weaned lambs grazing on natural pastures during summer and autumn. Animal Production Science. http://dx.doi.org/10.1071/AN13324.

POLI, C.; MONTEIRO, A.; BARROS, C.; MORAES, A.; FERNÁNDEZ, M.; PIAZZETTA, H. 2008. Produção de ovinos de corte em quatro sistemas de produção. Revista Brasileira de Zootecnia, 37(4): 666-673.

PONNAMPALAM, E.; EGAN, A.; SINCLAIR, A.; LEURY, B. 2005. Feed intake, growth, plasma glucose and urea nitrogen concentration, and carcass traits of lambs fed isoenergetic amounts of canola meal, soybean meal, and fish meal with forage based diet. Small Ruminant Research, 58 (3):245-252.

REVIDATTI, M.; CAPELLARI, A.; REBAK, G.; DOMINGUEZ, F.; AGUIRRE, F.; AGUILAR, D.; FRANZ, N. 2004. Crecimiento de corderos hasta el destete de razas doble propósito y triple cruza en la provincia de Corrientes. Comunicaciones Científicas y Tecnológicas, 57 (5):3-5.

SALMON, L.; DONNELLY, J.; MOORE, A.; FREER, M.; SIMPSON, R. 2004. Evaluation of options for production of large lean lambs in south-eastern Australia. Animal Feed Science and Technology, 112 (1-4): 195-209.

SANDERSON, I.; MCFARLANE, J.; MC MANUS, E. 1980. The growth rates of weaned lambs grazing three legume-based pastures during summer. Australian Journal of Experimental Agriculture anda Animal Husbandry, 20: 9-14.

THOMPSON, A.; KENNEDY, A.; HOLMES, J.; KEARNEY, G. 2010. Arrowleaf clover improves lamb growth rates in late spring and early summer compared with subterranean clover pastures in southwest Victoria. Animal Production Science, 50 (8): 807.

VILLAR, L. 2009. Producción de corderos pesados: una propuesta para diversificar la oferta de carne ovina. Presencia, 54: 10-14.

VOLTOLINI, T.; MOREIRA, J.; NOGUEIRA, D.; PEREIRA, L.; AZEVEDO, S.; LINS, P. 2009. Fontes proteicas no suplemento concentrado de ovinos em pastejoActa Scientiarum. Animal Sciences, 31 (1:, 61-67).

WANDER, A.; VASCONCELOS, V.; ROGÉRIO, M. 2002. Viabilidade econômica do acabamento de cordeiros em pastagens cultivadas de capim gramão e tanzânia. En: CONGRESO BRASILEÑO DE ECONOMIAE SOCIOLOGIA. (Vol. 40).

ZERVAS, G.; HADJIGEORGIOU, I.; ZABELI, G.; KOUTSOTOLIS, K.; TZIALA, C. 1999. Comparison of a grazing- with an indoorsystem of lamb fattening in Greece. Livestock Production Science, 61 (2-3): 245-251. 



\section{CAPÍTULO III. RESULTADOSY DISCUSIÓN}

\section{INTRODUCCIÓN}

Este capítulo resume los resultados experimentales de 7 ensayos de recría y engorde estival de corderos conducidos por investigadores con base en INIA Tacuarembó y en particular realizados en la Unidad Experimental Glencoe, ubicada en la región del Basalto del Uruguay. Los resultados que se presentan a continuación provienen de dos fuentes principales: a) trabajos de tesis de grado para la obtención de título de Ingeniero Agrónomo y b) otros experimentos realizados por los investigadores del INIA Tacuarembó. En todos los casos estos trabajos estuvieron alineados con los objetivos estratégicos de la Institución en cuanto a la búsqueda de alternativas tecnológicas que mejoren el ingreso y calidad de vida de los productores ganaderos y en especial de los productores de ovinos, donde el foco se centró en encontrar soluciones tecnológicas a la problemática de la producción y variabilidad estival de la producción forrajera y la mejora de la recría y engorde ovino para la región Basáltica.

En el Cuadro 1 se presenta un resumen de algunas de las características principales de los experimentos realizados.

\subsection{Materiales y métodos}

A continuación se presentan las metodologías utilizadas para la evaluación de diversos factores considerados, sobre distintas bases forrajeras de uso estival. Los factores evaluados fueron: carga animal, suplementación y el nivel de utilización de la misma, género y sistema de pastoreo. Las alternativas forrajeras utilizadas implican distintos grados de intensificación de la base forrajera; desde el uso de mejoramientos de campo (Lotus Draco) a pasturas sembradas (trébol rojo, achicoria, trébol blanco, lotus) hasta verdeos estivales como moha o sudangrás y finalmente incluyendo en los casos más intensivos la suplementación a corral.

Los animales utilizados en los experimentos fueron corderos que ingresaron a las evaluaciones post-destete con una edad en el entorno de 4-5 meses y con 20 a $25 \mathrm{~kg}$ de peso vivo inicial promedio. Se utilizaron diversos materiales genéticos, tales como: Corriedale y sus cruzas con Merino Dohne, île de France y Texel. Las evaluaciones fueron realizadas entre diciembre y mayo de cada año, entre el período comprendido entre los años 2000 y 2010.

Si bien se realizaron intensas mediciones (cantidad de variables y frecuencia), los autores del presente trabajo se centrarán en los resultados principales de pasturas y animales. Por mayor detalle en cuestiones de las metodologías y diseños aplicados se recomienda la lectura en particular de las tesis que dieron origen a estos trabajos o la lectura de otros trabajos similares realizados por este equipo de trabajo (Dighiero et al., 2013; Montossi et al., 2013).

\subsubsection{Determinaciones en pasturas $y$ animales}

Con el fin de estimar la cantidad de materia seca disponible por hectárea se realizó cortes del forraje y en todos los casos se efectuaron determinaciones tanto en el forraje ofrecido como en el forraje remanente post pastoreo.

En los mejoramientos de campo natural y en las pasturas sembradas se realizaron de 3 a 5 cortes de rectángulos para la estimación de la disponibilidad, composición botánica y valor nutritivo del forraje con una frecuencia de 7 a 14 días, dependiendo de dos factores: a) el tamaño de la parcela y b) del tipo de pastoreo. Se usaron rectángulos de 20 (ancho) $\mathrm{cm} \times 50$ (largo) cm. Para el caso de los verdeos estivales evaluados, se realizaron 5 cortes de un metro lineal cada 14 días. 
Cuadro 1. Resumen de la base forrajera utilizadas, factores evaluados y año-período de realización de los ensayos INIA sobre la recría y el engorde estival de corderos en la Unidad Experimental «Glencoe».

\begin{tabular}{|c|c|c|c|}
\hline $\begin{array}{l}\mathrm{N}^{\circ} \text { de } \\
\text { ensayo }\end{array}$ & Base Forrajera & Factores Evaluados & Año y Período \\
\hline 1 & $\begin{array}{l}\text { LOTUS DRACO } \\
\text { (Mejoramiento de } \\
\text { Campo con Lotus } \\
\text { corniculatus cV. INIA } \\
\text { Draco) }\end{array}$ & $\begin{array}{l}\text { - Carga (2): } 18 \text { y } 9 \text { corderos/ha } \\
\text { - Nivel de Suplementación (3): } \\
\text { 0\%PV (peso vivo lleno); } \\
\text { 0,75\%PV; 1,5\%PV. } \\
\text { y Género (2): machos castrados } \\
\text { y hembras }\end{array}$ & $\begin{array}{l}\text { Año } 2004-2005 \\
22 \text { de diciembre } \rightarrow 4 \\
\text { de mayo }\end{array}$ \\
\hline 2 & $\begin{array}{l}\text { TREBOL ROJO + } \\
\text { ACHICORIA } \\
\text { (Trifolium pratense cv. } \\
\text { LE } 116 \text { y Cichorium } \\
\text { intybus cv. INIA Lacerta) }\end{array}$ & $\begin{array}{l}\text { - Carga Animal (2): } 16 \text { y } 32 \\
\text { corderos/ha } \\
\text { - Sistema de Pastoreo (2): } \\
\text { Rotativo (7 días de ocupación con } \\
21 \text { días de descanso) y Alterno } \\
\text { (14 días de ocupación con } 14 \\
\text { días de descanso) } \\
\text { - Género (3): hembras, machos } \\
\text { castrados y criptorquídios }\end{array}$ & $\begin{array}{l}\text { Año } 2003 \\
29 \text { de enero } \rightarrow 27 \text { de } \\
\text { mayo }\end{array}$ \\
\hline 3 & $\begin{array}{l}\text { TREBOL ROJO + } \\
\text { ACHICORIA } \\
\text { (Trifolium pratense cv. } \\
\text { LE } 116 \text { y Cichorium } \\
\text { intybus cv. INIA Lacerta) }\end{array}$ & $\begin{array}{l}\text { - Carga Animal (2): } 10 \text { y } 20 \\
\text { corderos/ha } \\
\text { - Nivel de Suplementación (2): } \\
\text { 0\%PV y 0,75\%PV } \\
\text { - Género (2): hembras y machos } \\
\text { castrados }\end{array}$ & $\begin{array}{l}\text { Año } 2005 \\
24 \text { de enero } \rightarrow 5 \text { de } \\
\text { mayo }\end{array}$ \\
\hline 4 & $\begin{array}{c}\text { TREBOL ROJO BAJO } \\
\text { RIEGO } \\
\text { (Trifolium pratense cV. } \\
\text { LE 116) }\end{array}$ & $\begin{array}{l}\text { - Nivel de Suplementación (2): } \\
\text { 0\%PV y } 0,75 \% \text { PV }\end{array}$ & $\begin{array}{l}\text { Año } 2009 \\
2 \text { de febrero } \rightarrow 9 \text { de } \\
\text { junio }\end{array}$ \\
\hline 5 & $\begin{array}{c}\text { TREBOL } \\
\text { BLANCO+LOTUS } \\
\text { CORNICULATUS } \\
\text { (Pradera convencional } \\
\text { de } 4^{\text {to }} \text { año con Trifolium } \\
\text { repens cv. Zapicán, } \\
\text { Lotus corniculatus cv. } \\
\text { San Gabriel; Lolium } \\
\text { multiflorum espontáneo) }\end{array}$ & $\begin{array}{l}\text { - Sistema de alimentación (5): } \\
\text { 0\% ración; } 25 \% \text { ración; } 50 \% \\
\text { ración; } 74 \% \text { ración; } 100 \% \text { ración } \\
\text { (confinamiento) }\end{array}$ & $\begin{array}{l}\text { Año } 2003-2004 \\
24 \text { de octubre } \rightarrow 5 \text { de } \\
\text { febrero } 4\end{array}$ \\
\hline 6 & $\begin{array}{c}\text { MOHA } \\
\text { (Setaria italica cv. INTA } \\
\text { Carapé) }\end{array}$ & $\begin{array}{l}\text { - Nivel de Suplementación (2): } \\
\text { 0\%PV y 1\%PV } \\
\text { - Carga Animal (3): } 36.1 \\
\text { corderos/ha; } 54,2 \text { corderos/ha; } \\
72,3 \text { corderos/ha }\end{array}$ & $\begin{array}{l}\text { Año } 2000-2001 \\
12 \text { de diciembre } \rightarrow 5 \\
\text { de marzo }\end{array}$ \\
\hline 7 & $\begin{array}{c}\text { SUDANGRAS } \\
\text { (Sorghum sudanense cv. } \\
\text { Comiray) }\end{array}$ & $\begin{array}{l}\text { - Nivel de Suplementación (2): } \\
\text { 0\%PV y 1\%PV } \\
\text { - Carga Animal (3): } 37.5 \\
\text { corderos/ha; } 54,2 \text { corderos/ha; } \\
70,8 \text { corderos/ha }\end{array}$ & $\begin{array}{l}\text { Año } 2000-2001 \\
12 \text { de diciembre } \rightarrow 5 \\
\text { de marzo }\end{array}$ \\
\hline
\end{tabular}


En todos los momentos en que se realizaban cortes de forraje se efectuaban también determinaciones de altura de forraje; dentro y fuera del área de corte. En el caso de que el protocolo de trabajo impedía una alta frecuencia de muestreo y que ello no permitía realizar cortes de pasturas en todas las parcelas de pastoreo, se realizaban determinaciones de altura del forraje empleando una regla graduada que permitía estimar la disponibilidad de materia seca/ha vía el uso de ecuaciones de predicción aplicada para cada pastura y que contemplara el momento de muestreo y la situación de pastoreo (pre versus post pastoreo).

Las muestras de forraje obtenidas se procesaron con varios objetivos. Una fracción de la muestra verde obtenida de los rectángulos de corte se utilizaba para estimar la materia seca disponible por hectárea para lo cual se secaban las muestras en estufa de aire forzado hasta peso constante. Otra fracción de la muestra verde era utilizada para estimar la composición botánica pre y post pastoreo. Para esta última determinación, primero se separaba la muestra en forraje seco y verde. Dentro del forraje verde, se separaban las malezas de las especies sembradas o deseadas; dentro de las especies deseadas se separaban las distintas partes de la planta (tallo, hoja, peciolo, foliolo, inflorescencia), según metodología detallada por Montossi et al. (2000).

Todas las muestras de forraje y suplemento fueron enviadas al laboratorio de Nutrición Animal de INIA La Estanzuela donde se realizó el análisis del valor nutritivo de estas, determinando contenido de Proteína Cruda (PC) según Kjendhal (1984) Van Soest, 1982), Fibra de Detergente Acido (FDA), Fibra de Detergente Neutro (FDN) y Cenizas (C) según las metodologías descriptas por Van Soest (1982), variables a partir de las cuales se puede estimar la digestibilidad de la materia seca y digestibilidad de la materia orgánica.

En los animales de todos los experimentos se realizaron determinación de peso vivo Ileno (PVLL) y condición corporal (CC) (Russel et al., 1969) de forma periódica (cada 7 o 14 días).
En los casos en que se suplementaron los animales, se estimó el consumo grupal a través del suplemento desaparecido (ofrecido - rechazo).

En algunos casos se realizaron evaluaciones de calidad de lana así como también fueron realizadas determinaciones de conducta animal en pastoreo (tiempo de pastoreo, rumia, descanso, consumo de suplemento o agua, tasa de bocados, otros). Las metodologías empleadas se describen en el trabajo de tesis de Montossi (1995).

En los experimentos donde se faenaron los animales se realizaron mediciones con el fin de determinar el área de ojo del bife (AOB) y espesor de grasa (EG), utilizando el equipo de ultrasonido, según la metodología descripta por Russel (1995) y Brito y Pringle (2001). También fue registrado el peso de canal caliente (PCC), peso de canal fría (PCF), espesor de grasa (GR) medido en la canal sobre la $12^{\text {ava }}$ costilla a 11,5 centímetros de la columna vertebral (Kirton y Morris, 1989). Posteriormente, se determinó terne$\mathrm{za}, \mathrm{pH}$, color, etc., según lo descripto por Brito et al., 2002ab), en el laboratorio de Tecnología de la Carne de INIA Tacuarembó.

\subsubsection{Manejo de los animales}

El agua fue suministrada ad libitum a través de bebederos y en los casos en que se suplementó los animales, se realizó un período de acostumbramiento al mismo donde se comenzó con 50 g/animal/día y se incrementó a razón de 50 o $100 \mathrm{~g}$ cada 2 días hasta alcanzar el nivel de suplementación establecida por el protocolo experimental.

Respecto al manejo sanitario, los animales fueron dosificados con antihelmínticos al inicio de los experimentos y luego se realizó un monitoreo coproparasitario mediante análisis de huevos por gramo (HPG; Williamson et al., 1994) cada 28 días para determinar la necesidad de volver a tratar los animales con antihelmínticos. Se realizó la prueba de efectividad de los diferentes grupos químicos para el control de los parásitos gastrointestinales, según el protocolo «Lombritest» (Casaretto y Scremini, 1997; Castells y Pereira, 1997). En los casos que se hacía necesario vacunar contra clostridiosis por los brus- 
cos asociados a cambios de dieta, los animales fueron vacunados al inicio de los experimentos y revacunados cada 1 ó 3 meses según la situación.

\section{RECRÍA Y ENGORDE DE CORDEROS SOBRE MEJORAMIENTOS DE CAMPO}

\subsection{Evaluación de la carga, suplementación y género sobre mejoramiento de campo con Lotus corniculatus cv. INIA Draco}

El siguiente experimento fue llevado a cabo por Franco y Gutiérrez (2009) en su trabajo de tesis de grado, utilizando un mejoramiento de campo con Lotus corniculatus cV. INIA Draco, donde se evaluaron tres factores principales y sus interacciones: carga, nivel de suplementación y género. Todos los corderos eran de la raza Corriedale.

\subsubsection{Resultados en pasturas}

En el Cuadro 2 se presenta la disponibilidad y calidad del forraje ofrecido y remanente durante el período de evaluación.

El aumento de la carga animal determinó una disminución significativa en la disponibilidad y altura de forraje pre y pos pastoreo. Sin embargo, no se registraron diferencias significativas en el valor nutritivo de la pastura asociado al factor carga. Estos resultados concuerdan con: a) Arocena y Dighiero (1999) en términos de forraje ofrecido trabajando sobre una pradera mezcla de avena sativa y raigrás, b) Guarino y Pittaluga (1999) sobre una pradera mezcla de raigrás y triticale, c) De Barbieri et al. (2000) en avena byzantina, d) Azzarini et al. (2000) sobre pradera convencional en invierno, e) Correa et al. (2002) sobre raigrás y triticale, f) Iglesias y Ramos (2003) evaluando mejoramientos extensivos y g) Guerrina e Invernizzi (2002) también con mejoramiento de campo con lotus Maku. Camesasca et al. (2002), sobre una pradera convencional de alta productividad, no observaron diferencias signifi-

Cuadro 2. Disponibilidad y calidad del forraje ofrecido y remanente promedio (adaptado de Franco y Gutiérrez, 2009).

\begin{tabular}{|c|c|c|c|c|c|c|c|}
\hline & \multicolumn{3}{|c|}{ Carga (corderos/ha) } & \multicolumn{4}{|c|}{ Suplemento (\%PV) } \\
\hline & 9 & 18 & $\mathbf{P}$ & 0 & 0,75 & 1,5 & $\mathbf{P}$ \\
\hline \multicolumn{8}{|c|}{ Ofrecido } \\
\hline $\mathrm{kgMS} / \mathrm{ha}$ & $2477 \mathrm{a}$ & $2186 b$ & $\star \star$ & $2191 b$ & $2221 b$ & $2582 a$ & *夫 \\
\hline Altura (cm) & $18,8 \mathrm{a}$ & $17,2 \mathrm{~b}$ & $\star \star$ & 17,5 b & $17,7 \mathrm{~b}$ & $18,9 \mathrm{a}$ & ** \\
\hline RS (\%) & 22,5 & 21,9 & ns & 22,4 & 22,4 & 21,8 & ns \\
\hline PC (\%) & 13,5 & 14,0 & ns & 13,9 & 13,7 & 13,8 & ns \\
\hline FDA (\%) & 49,1 & 47,2 & ns & 47,6 & 48,1 & 48,8 & ns \\
\hline \multicolumn{8}{|c|}{ Remanente } \\
\hline kgMS/ha & 1739 a & 1486 b & $\star \star$ & $1504 \mathrm{~b}$ & $1533 b$ & $1801 \mathrm{a}$ & ** \\
\hline Altura (cm) & $14,7 \mathrm{a}$ & $12,9 \mathrm{~b}$ & $\star \star$ & $13,2 \mathrm{c}$ & $13,6 \mathrm{~b}$ & $14,6 \mathrm{a}$ & ** \\
\hline RS (\%) & 32,1 & 32,3 & ns & 34,3 & 32,0 & 30,2 & ns \\
\hline PC (\%) & 12,9 & 13,3 & ns & 12,7 & 13,4 & 13,2 & ns \\
\hline FDA (\%) & 50,0 & 50,4 & ns & 50,8 & 50,3 & 49,4 & ns \\
\hline
\end{tabular}

Nota: ${ }^{*}=\mathrm{P}<0,05 ;{ }^{*}=\mathrm{P}<0,01 ; \mathrm{ns}=$ no significativo $(\mathrm{P}>0,10) ;$ medias con diferentes letras entre columnas son significativamente diferentes; ${ }^{*}=\mathrm{P}<0,05 ;{ }^{*}=\mathrm{P}<0,01 ; \mathrm{kgMS} / \mathrm{ha}=$ kilos de materia seca/hectárea; $\mathrm{RS} \%=$ porcentaje de restos secos; $\mathrm{PC} \%=$ porcentaje de proteína cruda; FDA = porcentaje de fibra detergente ácido. 
cativas $(P>0,05)$ bajo los efectos de la carga animal en términos de disponibilidad de forraje ofrecido y rechazado, pero sí en la altura del mismo.

El factor carga determinó diferencias en los niveles de disponibilidad de forraje cuando se utilizan períodos de descanso iguales pero con cargas diferentes como en este experimento. Según Hodgson (1990), las cargas altas afectan la tasa de crecimiento y rebrote de la pastura debido a la reducción en el área foliar causada por la intensidad de pastoreo que conlleva a disminuciones en la actividad fotosintética.

El suministro de suplemento influyó significativamente en las características cuantitativas y cualitativas del forraje ofrecido y remanente, determinando un aumento en la disponibilidad de materia seca y la altura del forraje (Cuadro 2). Los resultados logrados en este experimento concuerdan con los resultados obtenidos por Guarino y Pittaluga (1999), De Barbieri et al. (2000) y Correa et al. (2000), manejando dos niveles de suplementación (suplementados versus no suplementados). Por otro lado, estos resultados contrastan con lo encontrado por Arocena y Dighiero (1999) y Camesasca et al. (2002), los cuales no observaron diferencias significativas de la suplementación sobre la disponibilidad del forraje ofrecido. Las diferentes condiciones experimentales, pasturas, animales y época del año, determinan diferentes interacciones pastura-animal-suplemento que resultan en diferentes respuestas a la suplementación.
Según Ganzábal (1997a), las interacciones (suplemento x pastura) dependerán del nivel de oferta y calidad del forraje, así como también del nivel y calidad de la suplementación. La sustitución de forraje por suplemento tuvo un efecto significativo en la disponibilidad de forraje ofrecido solamente para el nivel de suplementación del 1,5\% del PV.

No se observaron diferencias significativas $(P<0,05)$ para la interacción entre la carga y la suplementación en ninguno de los ciclos de pastoreo (Franco y Gutiérrez, 2009).

En la Figura 1 se puede observar la evolución de la altura de forraje disponible según los ciclos de pastoreo y las interacciones entre la carga y suplementación.

Como se puede apreciar, las curvas correspondientes a cargas menores tienden a contar con alturas mayores del forraje disponible. Asimismo, a mayor nivel de suplementación la tendencia es a tener mayores alturas del forraje disponible. Con estos datos se puede pensar en la existencia de un efecto de sustitución de forraje por suplemento. No obstante, según los resultados relacionados a la producción animal individual y total que se presentarán más adelante, se podría estar frente a la presencia de un efecto combinado adición-sustitución. En el Cuadro 3 se presenta la disponibilidad de materia verde (MV) y de hoja verde de lotus (LHv) del forraje ofrecido expresado en base seca (promedio) según la carga y el nivel de suplementación.

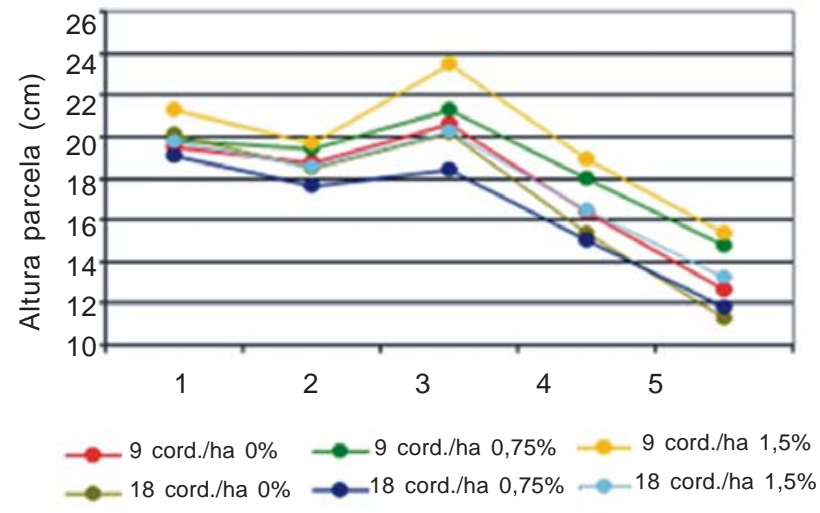

Figura 1. Evolución de la altura del forraje disponible según ciclo de pastoreo. 
Cuadro 3. Disponibilidad de forraje y de hoja de lotus verde del ofrecido (kg MS/ha), según carga (C) y nivel de suplementación (S).

\begin{tabular}{|l|ccc|cccc|}
\hline \multirow{2}{*}{ Variable } & \multicolumn{3}{|c|}{ Carga (C) } & \multicolumn{4}{c|}{ Suplementación (S) } \\
\cline { 2 - 8 } & $\mathbf{9}$ & $\mathbf{1 8}$ & $\mathbf{P}$ & $\mathbf{0}$ & $\mathbf{0 , 7 5}$ & $\mathbf{1 , 5}$ & $\mathbf{P}$ \\
\hline MV & 1837 & 1682 & $\mathrm{~ns}$ & $1624 \mathrm{~b}$ & $1675 \mathrm{~b}$ & $1981 \mathrm{a}$ & ** \\
LHV & 472 & 493 & $\mathrm{~ns}$ & 468 & 451 & 527 & ns \\
\hline
\end{tabular}

Nota: ${ }^{* *}=\mathrm{P}<0,01 ;{ }^{*}=\mathrm{P}<0,05, \mathrm{~ns}=$ no significativo $(\mathrm{P}>0,05)$. a y $\mathrm{b}=$ medias con letras diferentes entre columnas dentro de C y S son significativamente diferentes $(P<0,05)$. Referencias: MV (materia verde) y LHV (lotus hoja verde).

No se observaron diferencias significativas $(P<0,05)$ en los diferentes ciclos y el total del período experimental en ambas variables, a excepción del ciclo $4^{\text {to }}$ donde se observó una mayor disponibilidad de MV para la carga baja. Los resultados observados muestran que la MV no necesariamente presentó una relación directa con la disponibilidad de forraje (Franco y Gutiérrez, 2009).

En el caso del factor suplementación, se observaron diferencias significativas $(P<0,05)$ en cuanto a la MV para el total del período experimental, a favor de la suplementación al $1,5 \%$ del PV, coincidiendo con la mayor disponibilidad de MS observada. La variable lotus hoja verde (LHv) no presentó diferencias para ninguno de los factores evaluados en ninguno de los ciclos considerados ni el total del período experimental. Tampoco existió efecto de la interacción entre los factores evaluados para las variables mencionadas (Franco y Gutiérrez, 2009).

La carga tuvo un efecto significativo $(P<0,05)$ en la composición botánica de la pastura, a nivel de hoja de lotus ofrecida a los corderos, favorable hacia la carga alta. Esto concuerda con lo expresado por Hodgson (1990), quien señala que la disminución en la eficiencia de utilización del forraje a bajas dotaciones, provoca entre otros, una marcada reducción en la proporción de hoja verde en la pastura (Franco y Gutiérrez, 2009).

Camesasca et al. (2002), con corderos pastoreando sobre trébol blanco y lotus en invierno, encontraron diferencias significativas en el caso de hoja verde lotus a favor de la carga baja, lo cual difiere a lo observado en este experimento. Sin embargo, el com- ponente hoja verde de trébol blanco, componente dominante en dicha pastura (40 a $50 \%$ del tapiz) fue superior para la carga alta al igual que lo observado para el lotus en esta experiencia. La especie lotus según es señalado por los autores, no se adaptó al manejo de altas cargas tomando en cuenta la época del año. En dicho experimento, el lotus no fue objeto de selección animal a diferencia del trébol blanco. Por otro lado, Iglesias y Ramos (2003) manejando diversas especies de lotus y trébol blanco en los meses de invierno y primavera, no encontraron diferencias significativas de los diferentes componentes botánicos bajo los efectos de la carga, a diferencia de lo observado en este experimento. A su vez, Urrestarazú (2004) observó que la carga provocó un incremento en la proporción de los componentes del trébol rojo, a la vez de resultar en una disminución en la cantidad de restos secos y gramíneas.

El nivel de suplementación manifestó diferencias significativas $(P>0,01)$ en la composición botánica de la pastura en términos de materia verde. Esto no concuerda con lo observado por Camesasca et al. (2002) e Iglesias y Ramos (2003), quienes no encontraron diferencias en la composición botánica para ninguna de las fracciones de la misma.

En la Figura 2 se presenta la contribución relativa de los diferentes componentes botánicos de la pastura ofrecida y rechazada a lo largo del experimento. Cada columna representa un ciclo de pastoreo de 28 días de duración cada uno; representados en orden de izquierda de derecha (del $1^{\text {er }}$ al $4^{\text {to }} \mathrm{O}$ $5^{\text {to }}$ ciclo; según forraje ofrecido y rechazo, respectivamente). 

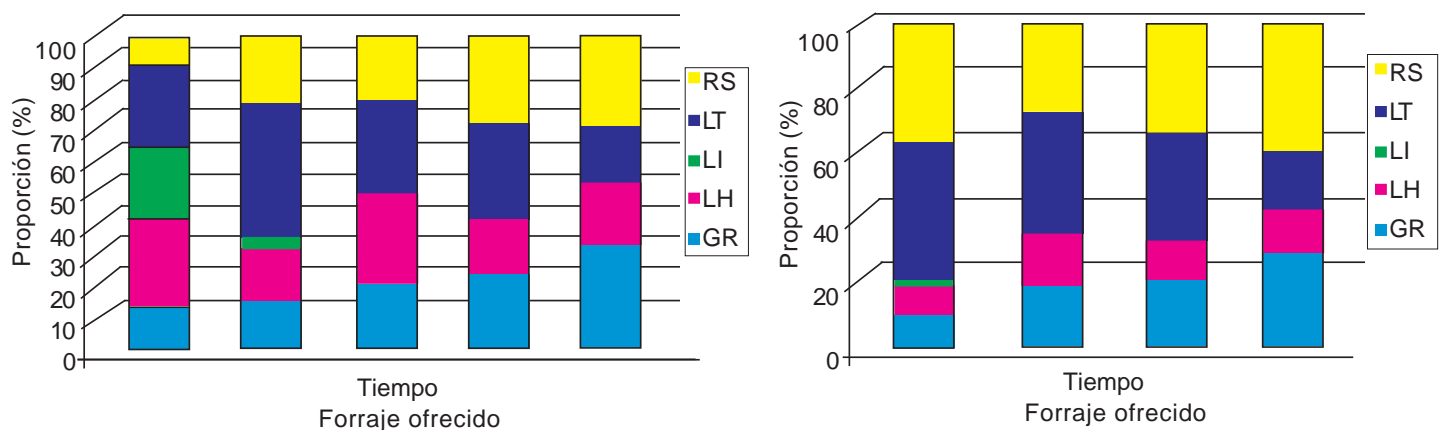

Figura 2. Composición botánica de los diferentes componentes botánicos de la pastura ofrecida y rechazada a lo largo del experimento (adaptado de Franco y Gutiérrez, 2009).

Nota: $\mathrm{RS}=$ restos secos; $\mathrm{LT}=$ tallo lotus; $\mathrm{LI}$ = inflorescencia lotus; $\mathrm{LH}=$ hoja lotus; $\mathrm{GR}$ = gramíneas.

En base a la información generada por Franco y Gutiérrez (2009) se puede apreciar un aumento en la proporción de gramíneas y restos secos en el forraje ofrecido a medida que transcurren los ciclos de pastoreo. En cuanto al forraje remanente, la tendencia fue hacia la disminución de tallos de lotus y aumento de gramíneas. La disminución del componente lotus con el correr de los ciclos se debe al efecto acumulado del pastoreo donde la selectividad animal juega un papel relevante.

En cuanto a la estructura vertical del forraje, Montossi et al. (2000) sostienen que las leguminosas no sólo deben estar en una proporción aceptable en la pastura ofrecida para tener mayores posibilidades de ser seleccionada con vistas a un incremento en la productividad animal, sino también ser ac- cesibles para el animal en pastoreo. A su vez estos mismos autores citan a Illius y Gordon (1993), quienes reafirman el rol importante y fundamental de la complejidad de la estructura y composición de la vegetación en limitar la tasa de consumo de nutrientes, asociando éstos a la necesidad de consumir una dieta variada para balancear el consumo.

Los resultados obtenidos sobre la estructura vertical del tapiz, utilizando el instrumento «Punto Cuadrado Inclinado» $(\mathrm{PCl})$, se presentan en la Figura 4 de forma porcentual y en forma absoluta (número de contactos) del $4^{\text {to }}$ ciclo de pastoreo. La información se presenta agrupándose según estado fenológico (verde y seco) y por especie forrajera y por su morfología (hoja, tallo e inflorescencia de lotus, gramíneas y malezas).

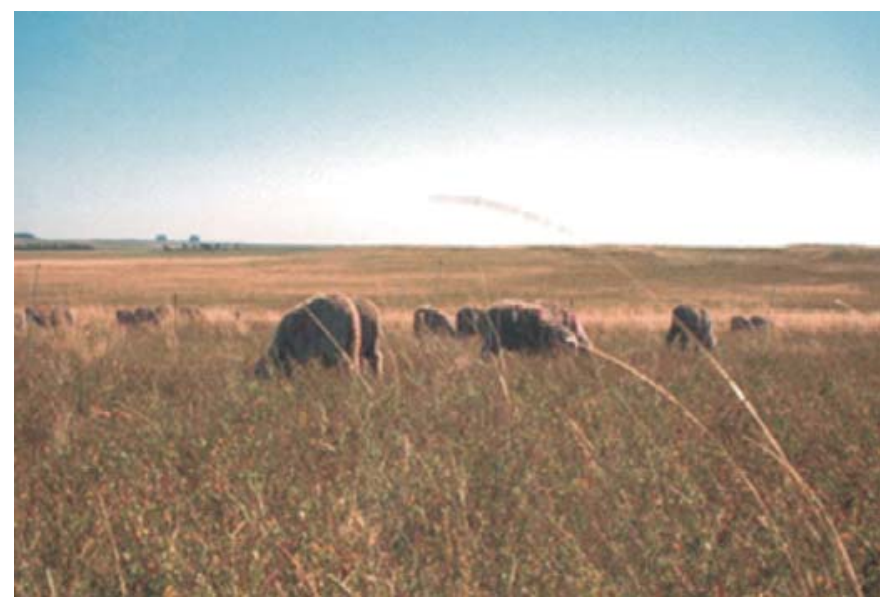

Figura 3. Corderos pastoreando mejoramiento de campo con Lotus corniculatus cv. INIA Draco. 
$9-0$

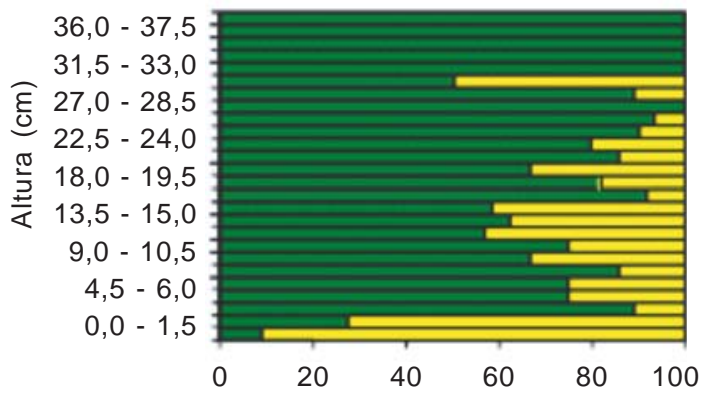

$9-0,75$

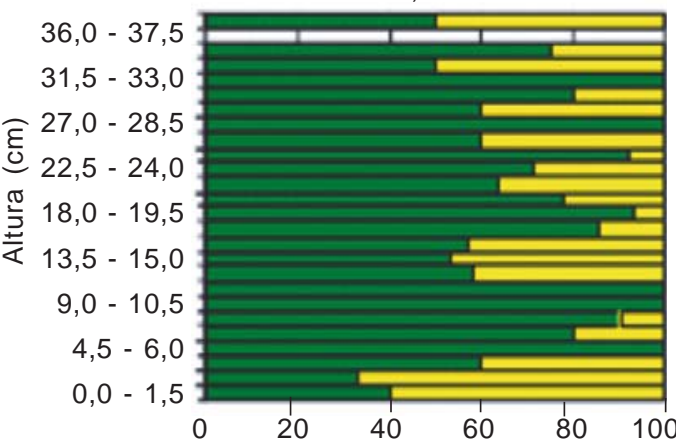

$9-1,5$

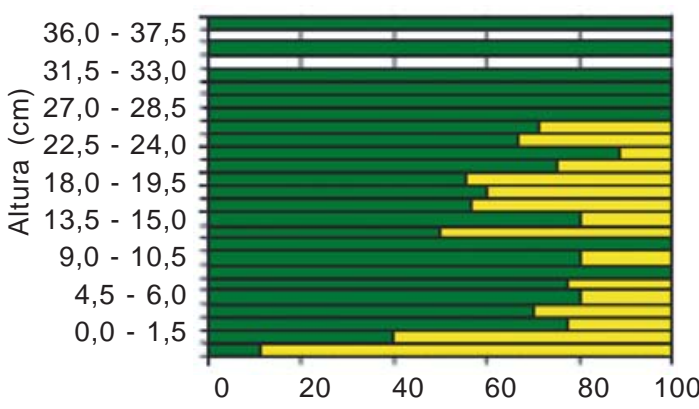

$18-0$

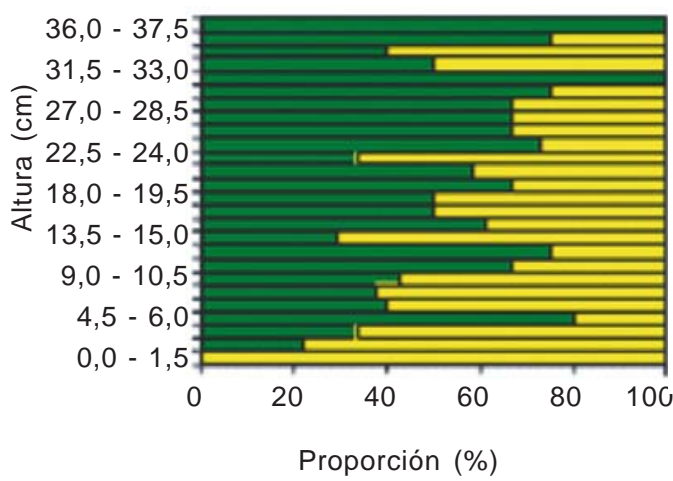

$9-0$

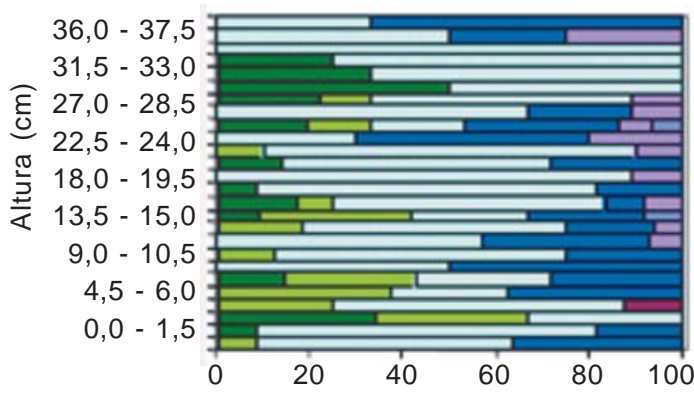

9-0,75

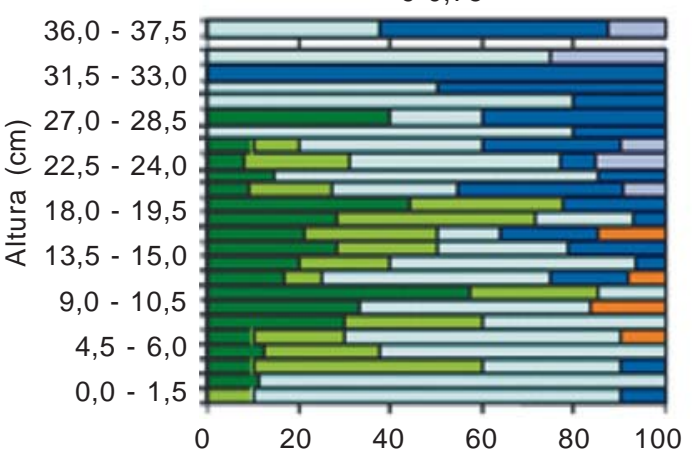

9-1,5

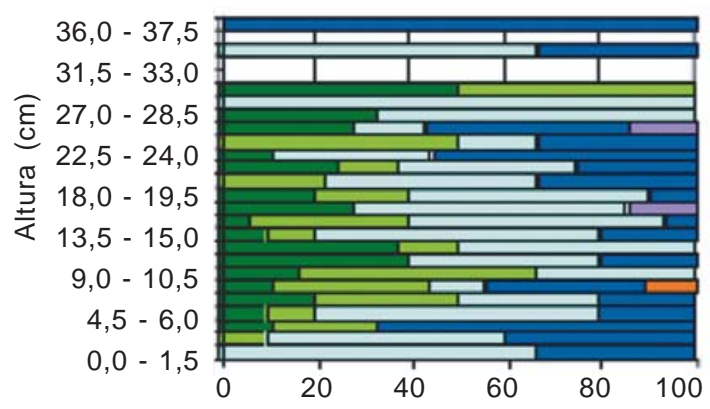

18-0

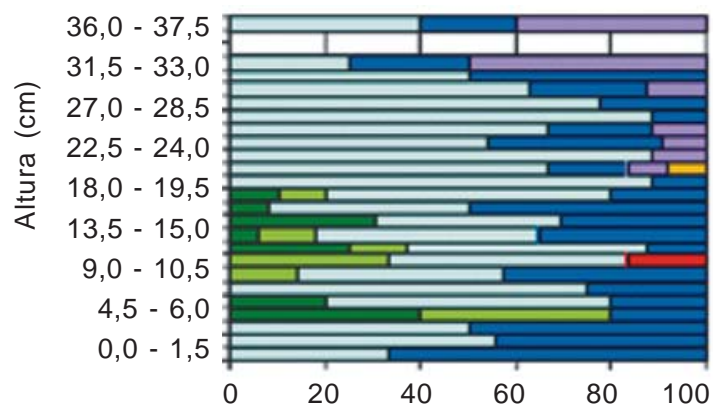

Proporción (\%) 
$18-0,75$

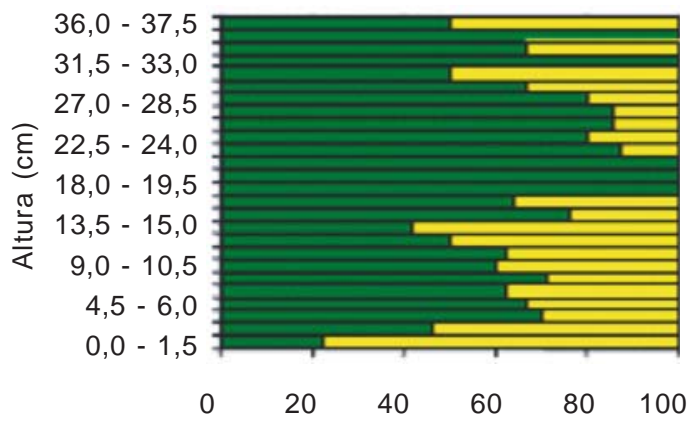

$18-1,5$

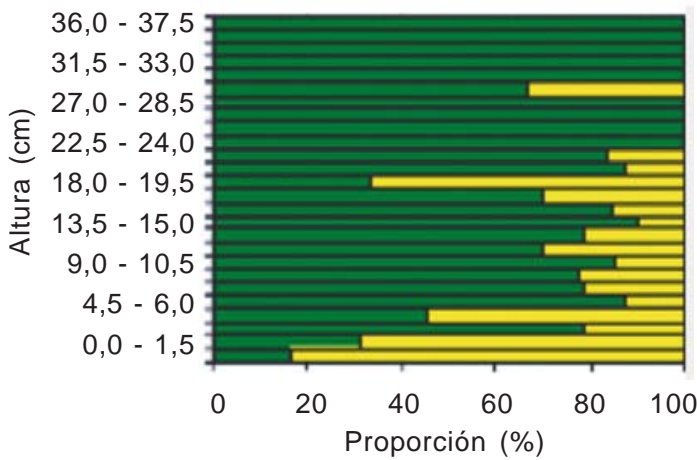

$18-0,75$

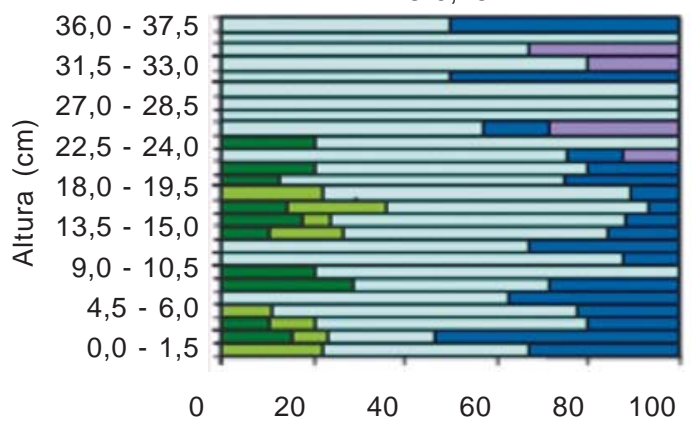

$18-1,5$

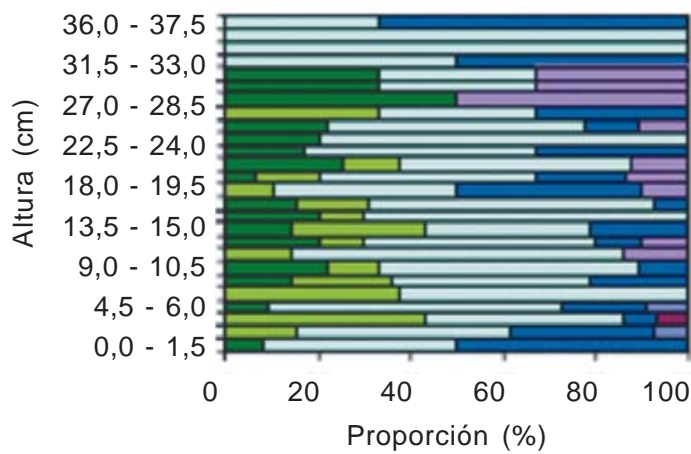

Figura 4. Composición relativa de los diferentes estratos del tapiz por tratamiento al final del ensayo ( $4^{\text {to }}$ ciclo de pastoreo), según estado fenológico y componentes de las especies (Franco y Gutiérrez, 2009).

Nota: 9-0: 9 corderos/ha - 0\% suplemento, 9-0,75: 9 corderos/ha - 0,75\% suplemento, 9-1,5: 9 corderos/ha - 1,5\% suplemento, 18-0: 18 corderos/ha - 0\% suplemento, 18-0,75: 18 corderos/ha - 0,75\% suplemento y 18-1.5: 18 corderos/ha - 1,5\% suplemento.

Franco y Gutiérrez (2009) analizaron el efecto acumulado de los tratamientos y el avance del período de maduración sobre el forraje ofrecido al final del período del experimento observando que:

a) La pastura estuvo compuesta en mayor proporción por forraje verde a lo largo de todos los ciclos de pastoreo, siendo importante en la composición de ésta la contribución del forraje seco. Las gramíneas, debido al estado fenológico de las mismas al comienzo y durante el verano, manifestaron un importante porcentaje de restos secos.

b) Las gramíneas predominaron a lo largo de los ciclos de pastoreo, principalmente en el estrato inferior y superior, siendo las hojas el componente dominante en la estructura del tapiz. c) El lotus estuvo presente principalmente en el estrato medio del tapiz, siendo compartido el mismo con las gramíneas. El lotus presentó un comportamiento variable en su proporción en el tapiz, siendo superior a las gramíneas al primer ciclo de pastoreo, disminuyendo hacia el segundo y tercer ciclo, para luego aumentar levemente su participación en el tapiz para el cuarto ciclo de pastoreo. A medida que transcurrían los ciclos, esta fracción se fue posicionando en los estratos inferiores, sobre todo para la carga alta respecto a la baja y para los animales no suplementados versus los suplementados. En ese sentido, se puede observar una mejor distribución en el perfil así como una mayor presencia relativa del componente lotus a favor de la carga baja. 
d) El forraje seco estuvo presente en todo el perfil de la pastura, predominando en el estrato inferior y superior de la pastura, correspondiendo con restos secos acumulados de hojas y tallos en el tercio inferior y tallos secos e inflorescencias en el tercio superior.

e) El aporte de forraje verde en el tapiz estuvo compartido entre el lotus y las gramíneas, predominando el lotus al comienzo del experimento (ciclo $1^{\text {ero }}$ ), para luego ir disminuyendo su aporte constantemente, pasando a dominar las gramíneas en el tapiz.

f) En cuanto al enmalezamiento, éste puede ser considerado como bajo, ya que el aporte de malezas se dio en casos puntuales y con una muy baja proporción en la composición vertical del tapiz.

g) En el caso de los corderos pastoreando a una alta asignación de forraje y sin consumo de suplemento, se observaron las menores proporciones del componente lotus a partir del segundo ciclo y hasta el cuarto ciclo de pastoreo. Esto se explica posiblemente debido a una mayor preferencia y consecuente selección de los animales, favorable hacia éste componente, lo cual asociado a el mayor tiempo de pastoreo de estos animales, determinó posiblemente un mayor consumo de ésta especie en comparación a las gramíneas presentes.

h) En el caso de los animales que fueron suplementados, se destaca un aumento en proporción del componente lotus a favor de éstos animales, para ambas cargas, siendo el tapiz pastoreado al $1,5 \%$ del PV el que presentó una mayor proporción en dicho componente. Esto puede ser explicado por el efecto de sustitución de grano por forraje, sumándose a éste el menor tiempo de pastoreo de estos corderos, por lo tanto, siendo el lotus menos seleccionado que en los tratamientos sin suplemento.

En cuanto al valor nutritivo del forraje tanto ofrecido como rechazado, el mismo se presenta en la Figura 5.

Si bien no se observaron diferencias para el forraje ofrecido ni para el remanente, existieron diferencias significativas $(P<0,05)$ al efectuar la comparación entre ambos para algunos componentes del valor nutritivo, encontrando una mayor DMS y una menor porcentaje de FDA para el forraje ofrecido.

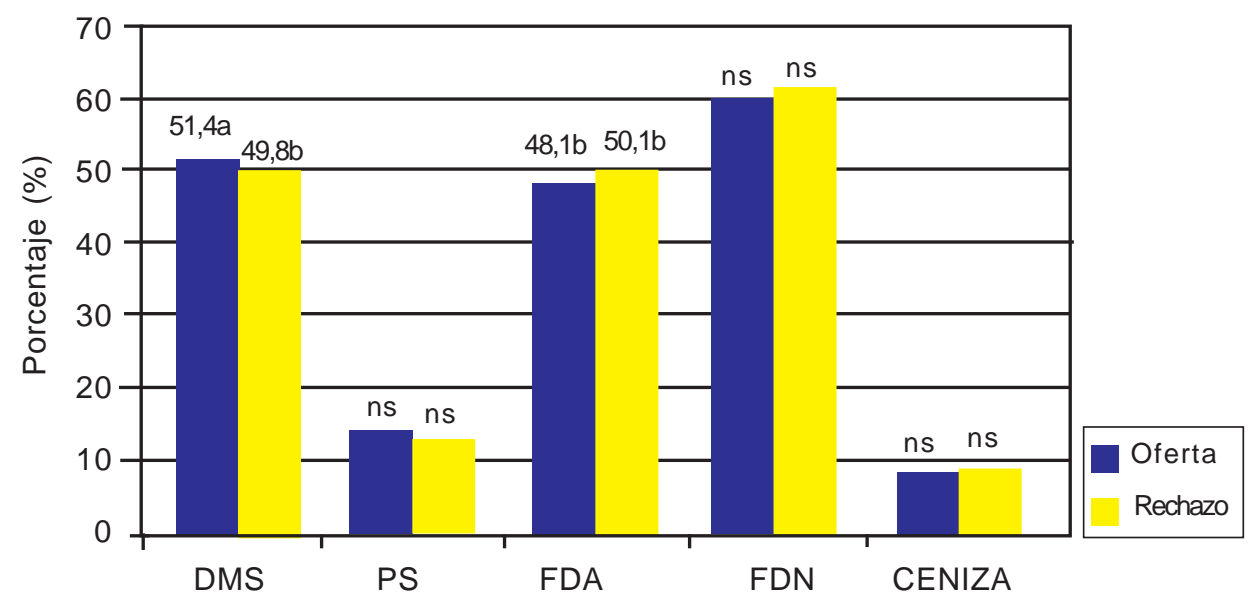

Figura 5. Valor nutritivo del forraje ofrecido y de rechazo promedio para todo el período (Franco y Gutiérrez, 2009).

Nota: $n s=$ no significativo $(P>0,05)$ a y $b=$ medias con letras diferentes son significativamente diferentes $(\mathrm{P}<0,05)$. Referencias: $P C$ (proteína cruda), FDA (fibra detergente ácida), FDN (fibra detergente neutra) y DMS (digestibilidad de la materia seca). 
Se puede apreciar que la digestibilidad del forraje ofrecido es superior al remanente lo que se corresponde con la composición botánica del forraje en cuanto a la mayor cantidad del componente lotus, el cual contribuye con un valor de digestibilidad superior. Por el mismo motivo, es significativamente diferente $(P<0,05)$ el valor de FDA, el cual aumenta en el forraje remante al disminuir el componente de mayor digestibilidad (en este caso el componente lotus) debido principalmente a la selectividad del pastoreo y a la utilización de forraje así como también un aumento relativo de los RS.

\subsubsection{Resultados en comportamiento y producción animal}

La cantidad de forraje consumida por el animal diariamente es el producto del tiempo utilizado para pastoreo y la tasa de consumo (producto de la tasa de bocado por el consumo por bocado) (Montossi et al., 1996). Según estos autores, los tres componentes del comportamiento ingestivo son principalmente afectados por la altura de la pastura. El tiempo de pastoreo raramente excede 12-13 horas por día; más allá de este tiempo, el pastoreo interferiría con actividades como la rumia y otros requerimientos de conducta (Poppi et al., 1987, citados por Montossi, 1995). A su vez, Hodgson (1990) agrega que un exceso del mismo sería indicador de condiciones de forraje limitantes.

En la Figura 6 se presenta la conducta animal promedio del período de evaluación, según factor carga y suplementación.

En ensayos nacionales sobre pasturas invernales, Arocena y Dighiero (1999) encontraron diferencias en el tiempo dedicado al pastoreo en la carga alta, tomando en cuenta 3 niveles de carga $(24,32$ y 40 cord/ha) y además registraron un mayor tiempo de descanso y rumia para las cargas media y baja (para el experimento 1). Los mismos autores en otro experimento (experimento 2) bajo 2 niveles de carga ( 25 y 35 cord/ha), encontraron menor tiempo de pastoreo en la carga baja, sin diferencias en la rumia. Estos mismos resultados fueron reportados por
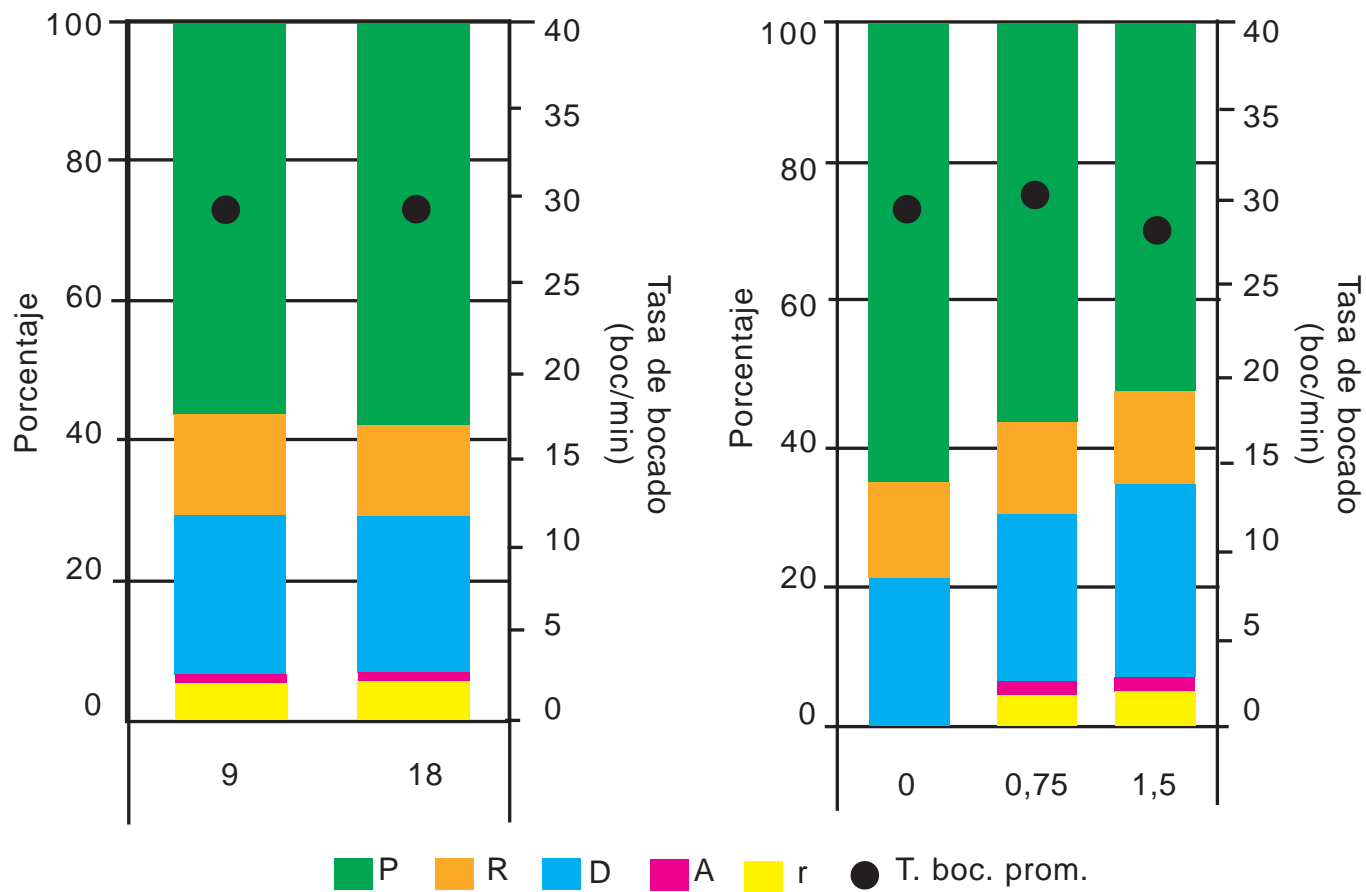

Figura 6. Conducta animal, según carga y nivel de suplementación (adaptado de Franco y Gutiérrez, 2009).

Nota: $\mathrm{P}=$ pastoreo; $\mathrm{R}=$ rumia; $\mathrm{D}=$ descanso; $\mathrm{A}=$ consumo de agua; $\mathrm{r}=$ consumo ración; $\mathrm{T}$. boc. prom. = tasa de bocado promedio. 
Camesasca et al. (2002) e Iglesias y Ramos (2003) trabajando con 2 cargas (18 versus 30 corderos/ha y 8 versus 12 corderos/ha, en experimento 1 y 2 , respectivamente), encontrando ambos autores un mayor tiempo dedicado al pastoreo para la carga alta y sin diferencias en el tiempo dedicado a la rumia. En este sentido, Camesasca et al. (2002) en el experimento 2, trabajando con 2 cargas (12 versus 24 corderos/ha) no encontraron diferencias en el tiempo dedicado al pastoreo, siendo la rumia un poco mayor para la carga alta. Por último, en un ensayo de engorde estival de corderos, Urrestarazú (2004) manejando 2 cargas (16 y 32 corderos/ha) observó efectos muy significativos $(\mathrm{P}<0,01)$ en todas las actividades de comportamiento $(P, R, D$ y $A)$ siendo el tiempo dedicado al pastoreo mayor para la carga alta y superiores a favor de la carga baja en el resto de las actividades del comportamiento evaluados.

El nivel de suplementación tuvo un efecto en el comportamiento de los animales para la mayoría de los componentes estudiados de la conducta animal. Se encontró un mayor tiempo dedicado a cosechar el forraje por parte de los animales sin suplementar, seguido por los animales suplementados al $0,75 \%$ del $\mathrm{PV}$, existiendo diferencias muy significativas $(P<0,01)$ entre los tres niveles de suplementación, tanto para el promedio como para los tres ciclos evaluados (Franco y Gutiérrez, 2009). Los mayores tiempos dedicados al pastoreo concordaron con menores disponibilidades y alturas del forraje observadas, tanto para el forraje ofrecido como para el remanente bajo los efectos de la suplementación. Estos resultados se de- berían, según señalan Camesasca et al. (2002) a un efecto de sustitución de consumo de suplemento por forraje. El efecto de la suplementación observado en el tiempo de pastoreo concuerda con los resultados obtenidos por Arocena y Dighiero (1999), Guarino y Pittaluga (1999), Correa et al. (2000), De Barbieri et al. (2000), Camesasca et al. (2002) y Silveira (2009), quienes encontraron que los corderos suplementados dedicaron menos tiempo al pastoreo que aquellos que solo tenían acceso a pasturas.

No se observaron diferencias significativas $(P>0,05)$ para el sexo y para las interacciones entre los factores, principales ni para la interacción triple entre los 3 factores (CxSxSe) en el promedio de las evaluaciones realizadas (Franco y Gutiérrez, 2009).

En el Cuadro 4 se presenta la performance animal en producción de carne, según el factor evaluado.

El incremento en el nivel de suplementación generó un aumento significativo $(P<0,01)$ en la ganancia media diaria, peso vivo y condición corporal de los animales. Asimismo, la carga menor logró pesos vivos y ganancias significativamente mayores $(P<0,01)$ que la carga mayor y lo mismo sucedió con la condición corporal $(P<0,05)$. Los machos tuvieron mejor performance en producción de carne que las hembras (Franco y Gutiérrez, 2009).

Estos resultados se corresponden con los conceptos de Carámbula (1991) y Hodgson, (1990), quienes afirman que a bajas cargas los niveles de producción por animal son altos, debido a una mayor disponibilidad y a

Cuadro 4. Performance animal en producción de carne, según factor evaluado (adaptado de Franco y Gutiérrez, 2009).

\begin{tabular}{|l|lll|lllll|lll|}
\hline \multirow{2}{*}{ Producción de carne } & \multicolumn{3}{|c|}{ Carga(corderos/ha) } & \multicolumn{4}{c|}{ Suplemento(\% PV) } & \multicolumn{3}{c|}{ Sexo } \\
\cline { 2 - 12 } & $\mathbf{9}$ & $\mathbf{1 8}$ & $\mathbf{P}$ & $\mathbf{0}$ & $\mathbf{0 , 7 5}$ & $\mathbf{1 , 5}$ & $\mathbf{P}$ & $\mathbf{M}$ & H & P \\
\hline PVV inicial $(\mathrm{kg})$ & 19,5 & 19,5 & $\mathrm{~ns}$ & 19,8 & 19,6 & 19,1 & $\mathrm{~ns}$ & 19,4 & 19,6 & $\mathrm{~ns}$ \\
PVV final (kg) & $34,8 \mathrm{a}$ & $32,8 \mathrm{~b}$ & $* *$ & $31,1 \mathrm{c}$ & $34,3 \mathrm{~b}$ & $36,2 \mathrm{a}$ & $* *$ & $34,4 \mathrm{a}$ & $33,2 \mathrm{~b}$ & $*$ \\
CC final (unidades) & $4,00 \mathrm{a}$ & $3,90 \mathrm{~b}$ & $*$ & 3,77 & $\mathrm{c}$ & $3,99 \mathrm{~b}$ & $4,09 \mathrm{a}$ & $* *$ & $4,00 \mathrm{a}$ & $3,90 \mathrm{~b}$ & $*$ \\
GMD (g/an/día) & $116 \mathrm{a}$ & $100 \mathrm{~b}$ & $* *$ & $84 \mathrm{c}$ & $110 \mathrm{~b}$ & $129 \mathrm{a}$ & $* *$ & $113 \mathrm{a}$ & $103 \mathrm{~b}$ & $*$ \\
Producción PV (kg/ha) & 117 & 195 & - & 119 & 158 & 190 & - & 167 & 148 & - \\
\hline
\end{tabular}

Nota: ${ }^{*}=P<0,05 ;{ }^{*}=P<0,01 ; n s=$ no significativo $(P>0,10)$; medias con diferentes letras entre columnas son significativamente diferentes; ${ }^{*}=\mathrm{P}<0,05 ;{ }^{*} \mathrm{P}<0,01 ; \mathrm{PVV}=$ peso vivo vacío; $\mathrm{CC}=$ condición corporal; $\mathrm{GMD}=$ ganancia media diaria; $\mathrm{PV} / \mathrm{ha}=$ peso vivo por hectárea; $\mathrm{M}=$ macho castrado; $\mathrm{H}=$ hembra. 
una mayor selectividad que los animales realizan, y por lo tanto seleccionan un forraje de mayor valor nutritivo.

Los efectos de la carga animal en la ganancia de peso vivo son concordantes con los trabajos realizados por Arocena y Dighiero (1999), Guarino y Pittaluga (1999), Correa et al. (2000), De Barbieri et al. (2000) sobre verdeos de invierno; San Julián et al. (1998), Azzarini et al. (2000), Camesasca et al. (2002) sobre praderas cultivadas; Iglesias y Ramos (2003), Guerrina e Invernizzi (2002) y Cazzuli et al. (2004) sobre mejoramientos de campo y Urrestarazú (2004) sobre una pastura de achicoria y trébol rojo en meses estivales, donde la carga alta resultó en menores ganancias de peso vivo lleno para los animales.

La carga manifestó un efecto en la condición corporal a partir del ciclo $2^{\text {do }}$ inclusive, siendo éstas diferencias estadísticamente muy significativas $(P<0,01)$, favorables hacia la carga baja, debido a los mayores pesos vivos y ganancias obtenidas. Para el final del ensayo, la diferencia siguió existiendo pero fue de menor magnitud $(P<0,05)$ (Franco y Gutiérrez, 2009). Esto concuerda con la performance lograda en la carga baja, ya que la misma presentó mayores tasas de ganancia al igual que mayores pesos.
Arocena y Dighiero (1999), Guarino y Pittaluga (1999), De Barbieri et al. (2000), Camesasca et al. (2002) y Urrestarazú (2004), coinciden con estos resultados encontrando diferencias significativas a favor de la carga baja. Sin embargo, Correa et al. (2000), Iglesias y Ramos (2003) y Cazzuli et al. (2004), no evidenciaron diferencias en la condiciones corporales entre las diferentes cargas evaluadas.

En la Figura 7 se presenta el efecto de cada factor evaluado sobre la evolución del peso vivo.

La evolución del peso es notoriamente menor en los tratamientos sin suplementación, especialmente con carga alta. El tratamiento con menor carga y mayor suplementación es el que terminó con mayor peso vivo final (Franco y Gutiérrez, 2009).

El nivel de suplementación tuvo un efecto considerable sobre las ganancias obtenidas, siempre a favor de la suplementación del $1,5 \%$ del PV, siendo las diferencias muy significativas $(P<0,01)$. Los pesos vivos finales logrados por los animales tuvieron un incremento de 4,8 kg comparando animales sin suplemento versus suplementados al 1,5\% del PV. Diferentes experiencias a nivel nacional no encontraron efectos de la suplementación en todos los ciclos de pas-

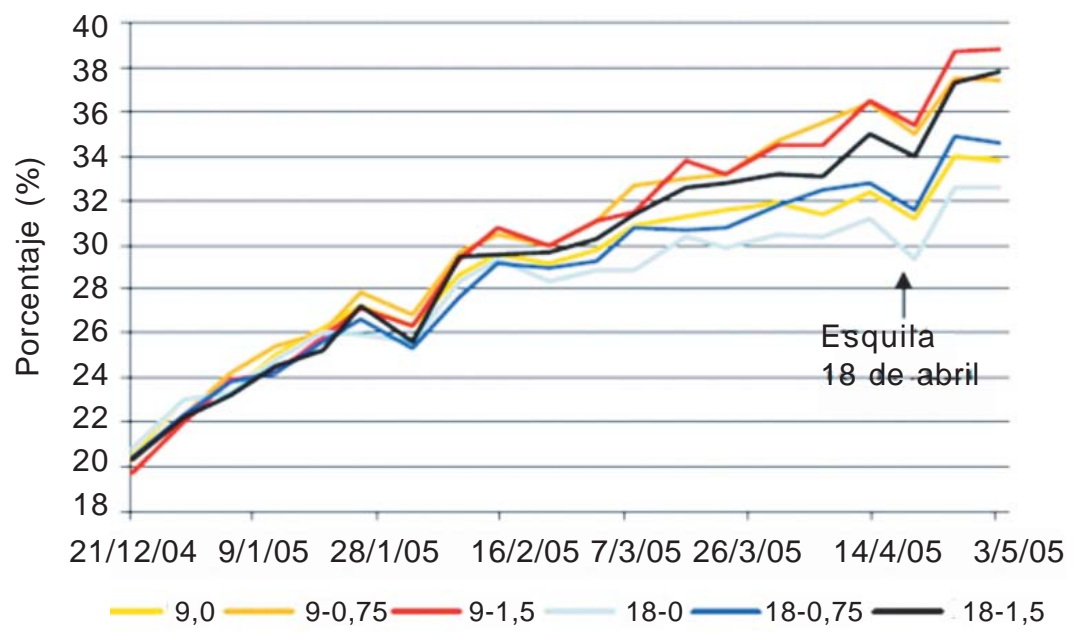

Figura 7. Evolución del PV en función del tiempo, según factor evaluado (Franco y Gutiérrez, 2009).

Nota: $9-0=9 \mathrm{cord} / \mathrm{ha}+$ 0\% PV suplementación; 9-0,75 = $9 \mathrm{cord} / \mathrm{ha}+$ 0,75\% PV suplementación; = 9-1,5 = 9 cord/ha $+1,5 \% \mathrm{PV}$ suplementación; 18-0 = $18 \mathrm{cord} / \mathrm{ha}+0 \% \mathrm{PV}$ suplementación; 18-0,75 = 18 cord/ha + 0,75\% PV suplementación; 18-1,5 = 18 cord/ha + 1,5\% PV suplementación. 
toreo (de 28 días cada uno), lo cual difiere de lo observado en este ensayo, en que consistentemente las diferencias fueron generadas en todos los ciclos. En este sentido, Arocena y Dighiero (1999) y De Barbieri et al. (2000) encontraron además diferencias en el total experimental, mientras que Guarino y Pittaluga (1999) y Camesasca et al. (2002) no observaron diferencias significativas en el total del período experimental $(P>0,05)$. Por otra parte, Correa et al. (2000) no encontraron diferencias significativas entre los animales suplementados versus no suplementados para los diferentes ciclos y ni para el total experimental.

La respuesta animal a la suplementación es explicada por los conceptos desarrollados mencionados por De Barbieri et al. (2000), quienes sostienen que por un lado existe una respuesta a la suplementación cuando no existen limitantes de calidad y disponibilidad en el forraje por lo que el consumo sustitutivo de suplemento implica un aumento en la selectividad animal en el pastoreo, con un consecuente aumento del consumo de forraje de mayor valor nutritivo. También existe respuesta a la suplementación en aquellos casos en que el valor nutricional de la pastura fuera limitante para una buena performance animal y la suplementación cumple un proceso de adición en el consumo de materia seca. Esto concuerda con lo señalado por López Da Silva (2001) quien señala que en pasturas de baja calidad disminuye el aprovechamiento del forraje (digestibilidad) y el nivel de consumo. En este sentido se sugiere que la adición de concentrados energéticos y proteicos colaborarían al menos en parte a superar las limitantes para el crecimiento de los animales. Al final del período experimental (avanzado el período reproductivo de la leguminosa) el valor nutritivo del Lotus inferior al comienzo del experimento (inicio del verano).

Además de otros factores, como las características del propio suplemento, la estación del año sería un factor importante que estaría incidiendo en las diferencias en calidad y/o cantidad del alimento base implicando diferentes respuestas a la suplementación en esta experiencia respecto a ensayos invernales.
Ayala y Bermúdez (2005), hallaron ganancias en corderos pesados durante el período estival similares a las encontradas en este ensayo. Esas ganancias fueron de $144 \mathrm{~g} / \mathrm{an} /$ día sobre Lotus corniculatus cv. INIA Draco (13 corderos/ha), $129 \mathrm{~g} / \mathrm{an} /$ día sobre Trifolium pratense cv. INIA Mizar (9 corderos/ha) y 97 g/an/día sobre una mezcla de trébol rojo-achicoria.

No existieron diferencias significativas $(P>0,05)$ para el sexo y entre la interacción carga $x$ sexo durante todo el período de engorde y el promedio total, al igual que para la interacción triple (carga x suplementación $x$ sexo). Sin embargo, existieron diferencias significativas $(P<0,05)$ en la interacción entre la carga y el sexo a partir del tercer ciclo, tornándose la misma muy significativa $(P<0,01)$ para el cuarto ciclo de pastoreo. Esta diferencia se dio a favor del peso vivo lleno de los machos en la carga alta mientras que en la carga baja los pesos vivos no se diferenciaron según el sexo (Franco y Gutiérrez, 2009). Urrestarazú (2004) utilizando machos criptorquídeos, castrados y hembras también observó interacción entre la carga y el sexo, obteniendo diferencias significativas entre machos castrados y hembras en la carga alta (32 corderos/ha), no así en la carga baja (16 corderos/ha).

En el Cuadro 5 se presentan las características de la canal y la carne, según carga y nivel de suplementación. Las hembras no fueron faenadas.

En la comparación del factor sexo en las determinaciones realizadas in vivo (AOB y $P C$ ), se destaca que ambos parámetros fueron significativamente mayores $(P<0,01)$ en los machos que en las hembras (Franco y Gutiérrez, 2009).

Brito et al. (2002) citados por Luzardo et al. (2013) realizaron una recopilación de registros de calidad de canal y carne de 246 corderos machos y hembras de diferentes genotipos, con una edad menor a los 12 meses y provenientes de distintos regímenes alimenticios. Si se comparan los resultados obtenidos por Franco y Gutiérrez (2009) con los obtenidos por Brito et al. (2002) citados por Luzardo et al. (2013), se puede apreciar que en la presente experiencia las canales resultaron con menor PCC (promedio 
Cuadro 5. Características de la canal y la carne, según carga y nivel de suplementación (adaptado de Franco y Gutiérrez, 2009).

\begin{tabular}{|l|lll|llll|}
\hline Producción de carne & \multicolumn{2}{|c|}{ Carga (corderos/ha) } & \multicolumn{5}{|c|}{ Suplemento (\% PV) } \\
& $\mathbf{9}$ & $\mathbf{1 8}$ & $\mathbf{P}$ & $\mathbf{0}$ & $\mathbf{0 , 7 5}$ & $\mathbf{1 , 5}$ & P \\
\hline AOB in vivo $\left(\mathrm{cm}^{2}\right)$ & $12,9 \mathrm{a}$ & $11,8 \mathrm{~b}$ & $*$ & $11,5 \mathrm{~b}$ & $12,6 \mathrm{ab}$ & $13,2 \mathrm{a}$ & * \\
Punto C in vivo $(\mathrm{mm})$ & 4,3 & 4,1 & $\mathrm{~ns}$ & $3,2 \mathrm{~b}$ & $4,4 \mathrm{a}$ & $4,9 \mathrm{a}$ & $* *$ \\
PCC $(\mathrm{kg})$ & $14,5 \mathrm{a}$ & $13,7 \mathrm{~b}$ & $*$ & $12,4 \mathrm{~b}$ & $14,5 \mathrm{a}$ & $15,4 \mathrm{a}$ & $* *$ \\
PCF $(\mathrm{kg})$ & 14,0 & 13,4 & $\mathrm{~ns}$ & $11,7 \mathrm{c}$ & $14,1 \mathrm{~b}$ & $15,2 \mathrm{a}$ & $*$ \\
GR $(\mathrm{mm})$ & $6,9 \mathrm{a}$ & $5,6 \mathrm{~b}$ & $*$ & $4,1 \mathrm{c}$ & $6,5 \mathrm{~b}$ & $8,1 \mathrm{a}$ & $*$ \\
Terneza 2 Días $(\mathrm{kgF})$ & 3,97 & 3,49 & $\mathrm{~ns}$ & 3,78 & 3,60 & 3,82 & $\mathrm{~ns}$ \\
Terneza 10 Días $(\mathrm{kgF})$ & 2,32 & 2,25 & $\mathrm{~ns}$ & $2,63 \mathrm{~b}$ & $2,05 \mathrm{a}$ & $2,20 \mathrm{a}$ & $\mathrm{ns}$ \\
\hline
\end{tabular}

Nota: ${ }^{*}=P<0,05 ;{ }^{*}=P<0,01 ; n s=$ no significativo $(P>0,10)$; medias con diferentes letras entre columnas son significativamente diferentes; ${ }^{*}=\mathrm{P}<0,05 ;{ }^{* *}=\mathrm{P}<0,01 ; \mathrm{AOB}=$ área ojo de bife; $\mathrm{PCC}=$ peso canal caliente; $\mathrm{PCF}$ = peso canal fría; GR = espesor de grasa sobre la $12^{\text {ava }}$ costilla a $11,5 \mathrm{~cm}$ de la línea media de la canal.

$19,78 \mathrm{~kg}$ ) y GR (promedio $9,26 \mathrm{~mm}$ ). Sin embargo, las ternezas medidas a los 10 días aquí presentadas resultaron mejores, es decir con valores menores en términos generales (promedio 2,55 kgF); el único caso en donde la terneza no presentó valores menores a los reportados por la bibliografía fue en el tratamiento sin suplementación $(2,63 \mathrm{kgF})$.

El nivel de suplementación tuvo un efecto significativo en todos los parámetros que midieron la calidad de canal, donde se generaron canales con mayor peso y grado de engrasamiento, debido al aumento de aporte energético del suplemento (Soeparno y Davies, 1982).
En el Cuadro 6 se resume la performance animal en producción y calidad de lana, según factor carga y nivel de suplementación.

El nivel de suplementación fue el único factor evaluado que influyó significativamente en el crecimiento de lana y diámetro de la fibra. El resto de los parámetros de producción y calidad de lana no fueron afectados por ningún tratamiento (Franco y Gutiérrez, 2009).

\subsubsection{Comentarios y conclusiones}

Aquellos tratamientos sin suplementar y utilizando cargas de 18 corderos/ha, no per-

Cuadro 6. Características de producción y calidad de lana, según carga y nivel de suplementación (adaptado de Franco y Gutiérrez, 2009).

\begin{tabular}{|c|c|c|c|c|c|c|c|}
\hline \multirow[t]{2}{*}{$\begin{array}{l}\text { Producción y } \\
\text { calidad de lana }\end{array}$} & \multicolumn{3}{|c|}{ Carga (corderos/ha) } & \multicolumn{4}{|c|}{ Suplemento (\% PV) } \\
\hline & 9 & 18 & $\mathbf{P}$ & 0 & 0,75 & 1,5 & $\mathbf{P}$ \\
\hline $\begin{array}{l}\text { Producción lana vellón } \\
(\mathrm{kg} / \mathrm{cordero})^{1}\end{array}$ & 2,28 & 2,18 & ns & 2,15 & 2,19 & 2,33 & ns \\
\hline $\begin{array}{l}\text { Crecimiento lana limpia } \\
\left(\mu \mathrm{g} / \mathrm{cm}^{2} / \mathrm{d} \text { lía) }\right.\end{array}$ & 1491 & 1356 & ns & $1270 \mathrm{~b}$ & $1414 \mathrm{a}$ & $1865 \mathrm{a}$ & ** \\
\hline $\mathrm{DF}(\mu \mathrm{m})$ & 25,7 & 25,2 & ns & $24,9 \mathrm{~b}$ & $24,9 \mathrm{~b}$ & $26,6 \mathrm{a}$ & ** \\
\hline Rendimiento (\%) & 83,1 & 83,5 & ns & 82,4 & 84,1 & 83,5 & ns \\
\hline LM (cm) & 8,1 & 8,0 & ns & 8,0 & 7,8 & 8,2 & ns \\
\hline
\end{tabular}

Nota: ${ }^{1}=$ corregido por lana inicial; $n s=$ no significativo $(P>0,10)$; medias con diferentes letras entre columnas son significativamente diferentes; ${ }^{*}=\mathrm{P}<0,05 ;{ }^{*}=\mathrm{P}<0,01$; DF = diámetro de la fibra; $\mathrm{LM}=$ largo de mecha; Rendimiento $(\%)=$ rendimiento al lavado. 
mitieron finalizar el engorde de los corderos en el período considerado. Sin embargo, la inclusión de la suplementación resultó ser muy importante para mejorar la performance animal y de la canal trabajando con esta carga sobre una pastura de Lotus Corniculatus cv. INIA Draco durante el período estival.

La carga alta permitió incrementar la producción de peso vivo por unidad de superficie en detrimento de menor performance individual. Por otro lado, la inclusión de suplementación, especialmente a razón de $1,5 \% \mathrm{PV}$, permitió terminar animales obteniendo los mayores valores de productividad por hectárea. Este experimento demuestra la conveniencia tecnológica del uso de Lotus corniculatus CV. INIA Draco como pastura especializada en la recría y engorde de corderos pesados durante el período estival. Con ello se podría lograr descentralizar la oferta de corderos pesados del Uruguay, en particular de aquellos que provienen de la región de Basalto.

Cargas animales de aproximadamente 10 corderos/ha, son sustentables en cuanto a la productividad del Lotus corniculatus y de la producción animal. La suplementación durante el período estival sobre pasturas de Lotus aparece como una excelente tecnología para acelerar el proceso de crecimiento, aumentar la capacidad de carga del sistema de engorde y mejorar la calidad del producto final (canal y carne) de corderos durante el período estival.

\section{RECRÍA Y ENGORDE DE CORDEROS SOBRE PRADERAS ARTIFICIALES DE CICLO CORTO}

\subsection{Evaluación de la carga, sistema de pastoreo y género sobre pastura de trébol rojo y achicoria}

En el presente experimento llevado a cabo por Urrestarazú (2004) en su trabajo de tesis, utilizando una pastura mezcla de trébol rojo y achicoria, se evaluaron tres factores: carga, sistema de pastoreo y género. Los corderos eran de las razas île de France $x$ Corriedale y Texel x Corriedale.

\subsubsection{Resultados en pasturas}

El Cuadro 7 presenta la disponibilidad y calidad del forraje ofrecido y remanente durante el período de evaluación.

El incremento de la carga animal, produjo reducciones en los parámetros de disponibilidad y altura del forraje ofrecido y remanente, alterando el valor nutritivo y la composición botánica de la pastura (Urrestarazú, 2004), lo cual se evidencia más claramente en el forraje remanente. Hodgson (1990) plantea que incrementos en la carga animal aumentan la severidad y frecuencia de la defoliación. En la medida que aumenta la

Cuadro 7. Disponibilidad y calidad del forraje ofrecido y remanente promedio (adaptado de Urrestarazú, 2004).

\begin{tabular}{|c|c|c|c|c|c|c|c|c|c|c|c|c|}
\hline & \multicolumn{6}{|c|}{ Ofrecido } & \multicolumn{6}{|c|}{ Remanente } \\
\hline & \multicolumn{3}{|c|}{ Carga (corderos/ha) } & \multicolumn{3}{|c|}{ Sist. Pastoreo } & \multicolumn{3}{|c|}{ Carga (corderos/ha) } & \multicolumn{3}{|c|}{ Sist. Pastoreo } \\
\hline & 16 & 32 & $\mathbf{P}$ & Rot & Alt & $\mathbf{P}$ & 16 & 32 & $\mathbf{P}$ & Rot & Alt & $\mathbf{P}$ \\
\hline $\mathrm{kgMS} / \mathrm{ha}$ & 2553 & 2232 & ns & 2378 & 2406 & ns & 2055 a & $1374 \mathrm{~b}$ & ** & $1573 \mathrm{~b}$ & $2856 a$ & * \\
\hline Altura $(\mathrm{cm})$ & $19,7 \mathrm{a}$ & $13,0 \mathrm{~b}$ & ** & $17,4 \mathrm{a}$ & $15,2 \mathrm{~b}$ & ** & $13,3 \mathrm{a}$ & $6,8 \mathrm{~b}$ & ** & 10,3 & 9,8 & ns \\
\hline RS (\%) & $37,0 \mathrm{~b}$ & $46,2 \mathrm{a}$ & ** & $38,1 \mathrm{~b}$ & $45,1 \mathrm{a}$ & * & $40,5 \mathrm{~b}$ & $57,7 \mathrm{a}$ & $\star \star$ & $43,5 \mathrm{~b}$ & $54,7 \mathrm{a}$ & ** \\
\hline PC (\%) & 21,0 & 19,6 & ns & 20,8 & 19,8 & ns & $19,1 \mathrm{a}$ & $15,1 \mathrm{~b}$ & ** & 16,4 & 17,8 & ns \\
\hline FDA (\%) & 42,1 & 45,4 & ns & 43,2 & 44,3 & ns & $46,4 \mathrm{~b}$ & 53,9 a & $\star \star$ & 49,3 & 51,0 & ns \\
\hline
\end{tabular}

Nota: ${ }^{*}=\mathrm{P}<0,05 ;{ }^{*}=\mathrm{P}<0,01 ; \mathrm{ns}=$ no significativo $(\mathrm{P}>0,10)$; medias con diferentes letras entre columnas son significativamente diferentes $(*=P<0,05 ; * *=P<0,01)$; Rot $=$ rotativo $(7$ ocupación $/ 21$ descanso); Alt = alterno (14 ocupación/14 descanso); kgMS/ha = kilos de materia seca/hectárea; RS\% = porcentaje de restos secos; $\mathrm{PC} \%=$ porcentaje de proteína cruda; FDA = porcentaje de fibra detergente ácido. 
presión de pastoreo (altas cargas) el sistema de pastoreo comienza a tener una mayor importancia.

El sistema de pastoreo no afectó la disponibilidad del forraje ofrecido, pero sí lo hizo en el forraje remanente, resultando en este caso en una mayor disponibilidad de forraje bajo pastoreo alterno. Los restos secos fueron significativamente mayores bajo sistema de pastoreo alterno, tanto en el forraje ofrecido $(P<0,05)$ como en el remanente $(P<0,01)$. A la luz de los datos obtenidos, se observa que el sistema de pastoreo no incidió en gran medida sobre el valor del forraje remanente; en todo caso el sistema alterno de pastoreo permitió a los animales rechazar un forraje de mayor valor nutritivo, lográndose una dieta de mayor calidad también.

En cuanto a la asociación entre la altura y la disponibilidad del forraje, Urrestarazú (2004) encontró que ésta es lineal y positiva $\left(R^{2}=0,41\right)$. No obstante, en términos generales no se encontraron diferencias significativas en disponibilidades de forraje, pero sí se encontraron con las alturas entre tratamientos. Las alturas de forraje en varios ensayos de cargas instantáneas han demostrado ser más sensibles que la disponibilidad de forraje para detectar efectos diferenciales de la intensidad de pastoreo, aunque al aplastamiento del forraje por los animales puede llevar a efectos confundidos.

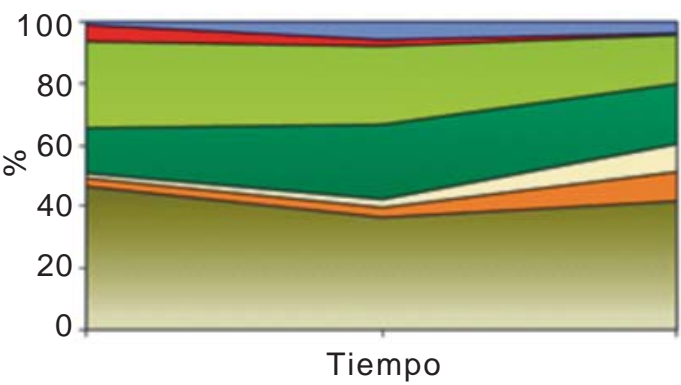

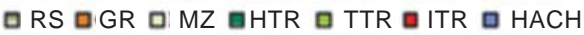
Forraje ofrecido
En los trabajos de Arocena y Dighiero (1999), Correa et al. (2000) y Camesasca et al. (2002) no se encontraron ventajas favorables a los sistemas de pastoreo más controlados. Por otro lado, Ganzábal (1997b) sostiene que en condiciones intensivas de alimentación sobre pasturas sembradas donde se pretenda maximizar el uso de los recursos disponibles, los pastoreos controlados deberían formar parte de las estrategias de manejo, dado que estas especies desarrollan un mejor comportamiento con tiempos de descanso prolongados, fundamentalmente durante los meses secos, con manejos que minimizan el consumo inmediato de rebrotes. El nivel de utilización de forraje y los días de descanso del sistema de pastoreo alterno versus los del sistema semanal, fueron más adecuados para este tipo de pastura, durante esta época del año, presentando una mayor disponibilidad de materia seca total y material verde y altura del forraje ofrecido y remanente, lo cual no se transformó en un mayor valor nutritivo del forraje ofrecido y remanente.

La Figura 8 presenta la contribución relativa de los diferentes componentes botánicos de la pastura ofrecida y rechazada.

La fracción predominante en el forraje ofrecido son los restos secos, siempre por encima del 35\%. Rattray et al. (1987) mencionan que la producción animal es afectada cuando los restos secos superan el 15-20\%. Por otro lado, lo mismo ocurre con los restos secos del forraje rechazado, si bien a

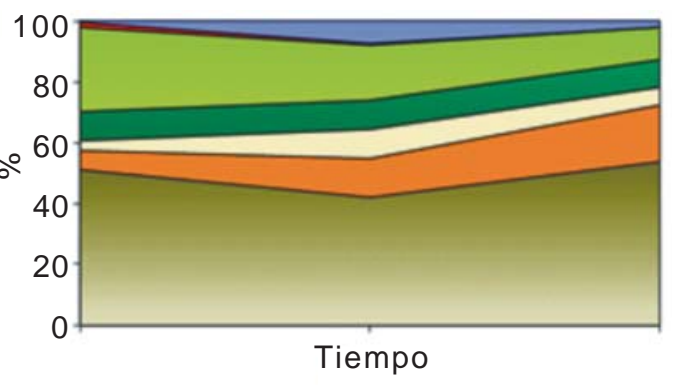

๑RS a GR a MZ EHTR aTTR aITR a HACH Forraje ofrecido

Figura 8. Composición botánica según factor evaluado (adaptado de Urrestarazú, 2004). Nota: $\mathrm{RS}$ = restos secos; GR = gramíneas; $\mathrm{MZ}$ = malezas; HTR = hoja trébol rojo; TTR = tallo trébol rojo; ITR = inflorescencia trébol rojo; $\mathrm{HACH}=$ hoja achicoria. 
niveles por encima del 40\%. Beattie y Thomson (1989) sostienen que la performance animal es el producto de la cantidad de forraje ofrecido y la calidad del mismo. Los restos secos reducen la digestibilidad y limitan el consumo a causa de una menor palatabilidad y una mayor dificultad de acceso al forraje verde. Consecuentemente, la acumulación de restos secos afecta negativamente la producción animal.

Langlands y Sanson (1976) y Birrell (1981), citados por Birrell (1989) demostraron que el incremento en la proporción de forraje muerto en el tapiz disminuye la oportunidad de los animales de seleccionar materiales altamente digestibles. Por lo tanto, puede decirse que en este ensayo, la selectividad animal pudo haberse limitado en cierta medida.

Con respecto a las otras fracciones, a mitad del período experimental las gramíneas comienzan a acentuar su proporción en el forraje, especialmente en el forraje rechazado (Urrestarazú, 2004). La proporción total (hoja + tallo) de leguminosa descendió para el forraje disponible y remanente, a medida que transcurría el tiempo experimental. La proporción de hoja de achicoria siempre fue baja en relación de los demás componentes de la pastura, pero esto fue más marcado en el forraje disponible. Se puede decir entonces que la achicoria no representó una fracción de relevancia en la dieta de los corderos (menos del 10\%).

\subsubsection{Resultados en comportamiento y producción animal}

La conducta animal fue evaluada solamente para los dos últimos ciclos de pastoreo de los cuatro que se registraron, pero aquí solamente se presentan los datos del tercer ciclo. Esto se explica porque al llegar al cuarto ciclo de pastoreo los tratamientos con carga alta tuvieron que ser suspendidos, por falta en cantidad y calidad de disponibilidad de forraje.

La Figura 9 presenta la conducta animal promedio del período de evaluación, según los factores evaluados.

La carga animal tuvo un efecto muy significativo $(P<0,01)$ sobre todas las variables del comportamiento animal estudiadas. Los animales correspondientes a los tratamientos de carga alta dedicaron mayor tiempo a la rumia, el descanso y el consumo de agua, en un intento de por compensar las disponibilidades limitantes del forraje ofrecido. Este intento de compensación también se ve reflejado en las diferencias entre tasas de bocado $(P<0,01)$, donde los corderos de carga alta intentaron compensar la disminución en el peso de bocado, con un incremento en la tasa.

Arocena y Dighiero (1999) registraron mayores tiempos de pastoreo en los tratamientos con cargas altas (40 corderos/ha), comparadas a las cargas medias (32 corde-

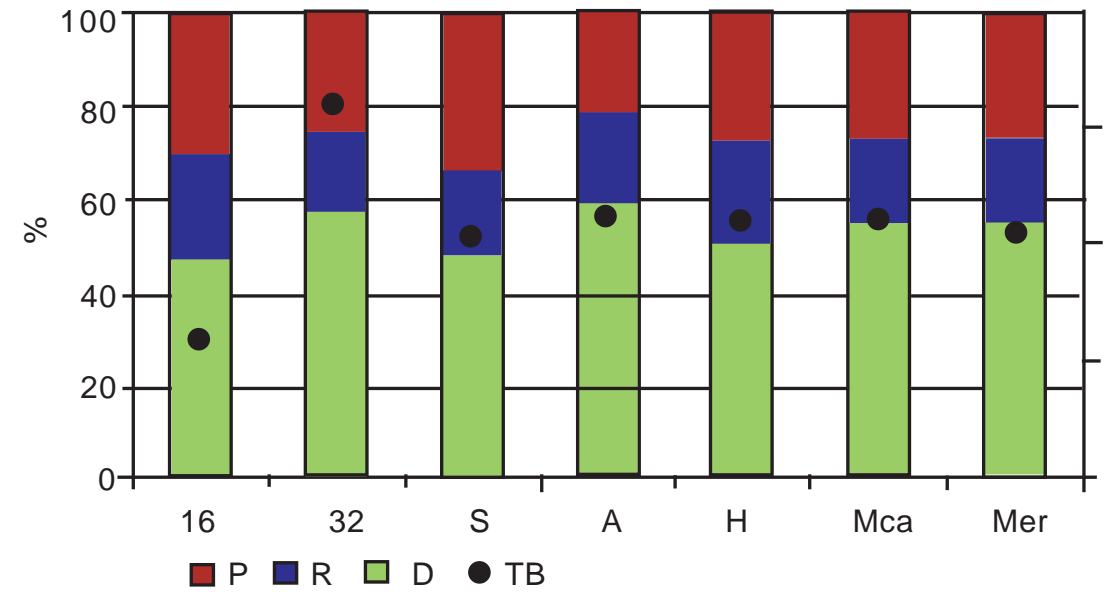

Figura 9. Conducta animal, según factor evaluado (adaptado de Urrestarazú, 2004). Nota: $\mathrm{P}=$ pastoreo; $\mathrm{R}=$ rumia; $\mathrm{D}$ = descanso; $\mathrm{TB}$ = tasa de bocado. 
ros/ha) y bajas (24 corderos/ha). Resultados similares fueron obtenidos por Correa et al. (2000) con 35 y 25 corderos/ha, así como los obtenidos por Iglesias y Ramos (2003) con 8 y 12 corderos/ha.

El sistema de pastoreo afectó significativamente $(P<0,01)$ el tiempo dedicado al pastoreo, rumia, descanso y consumo de agua. Los animales bajo sistema de pastoreo alterno destinaron mayor tiempo al pastoreo y al consumo de agua y menos tiempo al descanso que los corderos asignados al pastoreo semanal. Asimismo, la tasa de bocado no se vio afectada, lo que sugiere un mayor consumo realizado por los animales del sistema alterno, presentando probablemente mayores posibilidades de selección al realizar una menor utilización del forraje ofrecido.

El factor sexo no afectó prácticamente ninguno de los parámetros asociados a la conducta animal, lo que coincide con los resultados obtenidos por Camesasca et al. (2002) y Franco y Gutiérrez (2009).

El Cuadro 8 resume la performance animal en producción de carne, según el factor evaluado.

La carga fue el factor evaluado con mayor influencia en el peso vivo final, condición corporal y ganancia media diaria. Si bien no es posible comparar estadísticamente la producción de PV/ha, se destaca que la producción total de carne fue mayor con la carga más baja. Dicha productividad, sumado al resto de los valores presentados de performance animal, que sí pueden compararse estadísticamente, relativizan la utilidad de trabajar a cargas tan altas como 32 corderos/ha.

Las diferencias que se manifiestan en el peso vivo de los animales coinciden con las mayores asignaciones de forraje que se dan en los tratamientos con carga baja a una misma disponibilidad. Esto se explica porque el consumo de forraje por animal y performance individual declinó progresivamente a medida que aumenta la carga animal (Mott, 1960 y Hodgson, 1990). En este ensayo, la carga elevada no permitió sostener la performance individual, resultando en menores producciones totales. En tal sentido, los resultados de este trabajo sugieren que la carga alta está por encima de la carga óptima, para la región basáltica, durante el período estival y las especies forrajeras involucradas en el estudio (Urrestarazú, 2004).

La carga menor resultó en una mejor condición corporal de los animales al final del período, como consecuencia de mayores ganancias individuales y pesos finales. Esto es coincidente con lo hallado por Arocena y Dighiero (1999), Guarino y Pittaluga (1999), De Barbieri et al. (2000) y Camesasca et al. (2002). En contraste, Correa et al. (2000) e Iglesias y Ramos (2003) no encontraron diferencias significativas en la condición corporal entre las diferentes cargas evaluadas.

El sistema de pastoreo no determinó ninguna diferencia significativa en la performance animal. De cualquier forma, se destaca que la producción total de peso vivo/ha fue un $13 \%$ superior para el pastoreo alterno.

Cuadro 8. Performance animal en producción de carne, según factor evaluado (adaptado de Urrestarazú, 2004).

\begin{tabular}{|c|c|c|c|c|c|c|c|c|c|c|}
\hline \multirow[t]{2}{*}{ Producción de carne } & \multicolumn{3}{|c|}{ Carga (cord/ha) } & \multicolumn{3}{|c|}{ Sistema Pastoreo } & \multicolumn{4}{|c|}{ Género } \\
\hline & 16 & 32 & $\mathbf{P}$ & Rot & Alt & $\mathbf{P}$ & $\mathbf{H}$ & Mcast & Mcrp & $\mathbf{P}$ \\
\hline PVV inicial (kg) & 19,6 & 19,1 & ns & 19,6 & 19,1 & ns & 19,3 & 19,2 & 19,5 & ns \\
\hline PVV final (kg) & $29,8 \mathrm{a}$ & $23,8 b$ & * & 26,6 & 27,0 & ns & 26,3 & 26,5 & 27,7 & ns \\
\hline CC final (unidades) & $3,6 \mathrm{a}$ & $2,8 b$ & ** & 3,1 & 3,2 & ns & 3,2 & 3,2 & 3,1 & ns \\
\hline GMD (g/an/día) & $124 \mathrm{a}$ & $54 \mathrm{~b}$ & ** & 85 & 92 & ns & 82 & 85 & 99 & ns \\
\hline Producción PV (kg/ha) & 163 & 150 & - & 168 & 190 & - & 168 & 175 & 197 & - \\
\hline
\end{tabular}

Nota: ${ }^{*}=\mathrm{P}<0,05 ;{ }^{*}=\mathrm{P}<0,01 ; \mathrm{ns}=$ no significativo $\left.\mathrm{P}>0,10\right)$; medias con diferentes letras entre columnas son significativamente diferentes $(\mathrm{P}<0,01) ; \mathrm{PVV}=$ peso vivo vacío; $\mathrm{CC}=$ condición corporal; $\mathrm{GMD}=$ ganancia media diaria; PV/ha = peso vivo por hectárea; Rot = rotativo (7 ocup/21 desc); Alt = alterno (14ocup/14 desc); $\mathrm{H}=$ hembra; Mcast = Macho castrado; Mcrp = macho criptorquídio. 
Ninguna de las variables medidas registró diferencias significativas comparando los géneros de animales utilizados. Azzarini et al. (2001), Montossi et al. (2002) y Pereira y Azzarini (2003) afirman que la criptorquídea inducida para la producción de corderos pesados de razas carniceras presenta ventajas productivas en comparación con el uso de machos castrados o hembras. Sin embargo, se sostiene que para utilizar al máximo esta tecnología, deben presentarse condiciones adecuadas de disponibilidad y valor nutritivo del forraje ofrecido (Urrestarazú, 2004).

La Figura 10 muestra el efecto de cada factor evaluado sobre la evolución del PV.
La carga es el factor evaluado que más influyó en la performance animal a lo largo del experimento. En el factor género, si bien los machos critporquídeos figuran con una evolución de PV por arriba de las hembras y los machos castrados, las diferencias no son significativas. Se observa que la carga baja comenzó a mostrar diferencias notorias y favorables en la evolución del peso vivo, a partir del primer tercio del período experimental. Los otros dos factores evaluados no tuvieron similar comportamiento (Urrestarazú, 2004).

El Cuadro 9 resume la performance animal en producción y calidad de lana, según el factor evaluado.
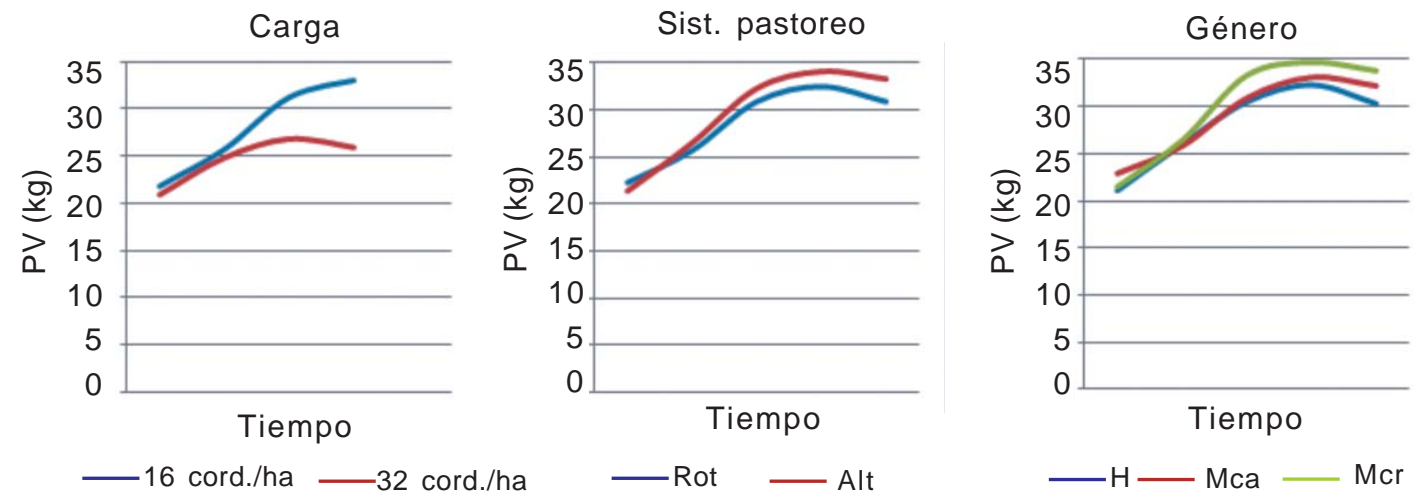

Figura 10. Evolución del PV en función del tiempo, según factor evaluado (adaptado de Urrestarazú, 2004).

Nota: Rot $=$ rotativo $(7$ ocup/21 desc $) ;$ Alt = alterno $(140$ cup $/ 14 \mathrm{desc}) ; \mathrm{H}=$ hembra; Mca = Macho castrado; Mcr = macho criptorquídio.

Cuadro 9. Performance animal en producción y calidad de lana, según factor evaluado (adaptado de Urrestarazú, 2004).

\begin{tabular}{|c|c|c|c|c|c|c|c|c|}
\hline \multirow{2}{*}{$\begin{array}{l}\text { Producción y calidad } \\
\text { de lana }\end{array}$} & \multicolumn{3}{|c|}{ Sistema Pastoreo } & \multicolumn{4}{|c|}{ Género } & \multirow{2}{*}{$\begin{array}{l}\text { Sistema } \\
\text { Pastoreo } \\
\text { x Género }\end{array}$} \\
\hline & Rot & Alt & $\mathbf{P}$ & $\mathbf{H}$ & Mcast & Mcrp & $\mathbf{P}$ & \\
\hline $\begin{array}{l}\text { Producción lana vellón } \\
(\mathrm{kg} / \text { cordero })^{1}\end{array}$ & 1,56 & 1,62 & ns & 1,64 & 1,68 & 1,46 & ns & ns \\
\hline $\begin{array}{l}\text { Crecimiento lana } \\
\text { limpia }\left(\mu \mathrm{g} / \mathrm{cm}^{2} / \mathrm{día}\right)\end{array}$ & 1163 & 1186 & ns & 1185 & 1214 & 1124 & ns & ns \\
\hline $\mathrm{DF}(\mu \mathrm{m})$ & 30,8 & 30,2 & ns & 31,0 & 29,5 & 31,1 & ns & ns \\
\hline Rendimiento (\%) & 82,4 & 83,8 & ns & 83,7 & 85,5 & 80,1 & ns & ns \\
\hline LM (cm) & 3,9 & 4,4 & ns & 3,9 & 4,4 & 4,0 & ns & ns \\
\hline
\end{tabular}

Nota: ${ }^{1}=$ corregido por $\mathrm{PV}$ final; $\mathrm{ns}=$ no significativo $(\mathrm{P}>0,10)$; medias con diferentes letras entre columnas son significativamente diferentes $(P<0,05) ; D F=$ diámetro de la fibra; $L M=$ largo de mecha; Rot = rotativo $(7$ ocupación/21 descanso); Alt = alterno (14 ocupación/14 descanso); $\mathrm{H}=$ hembra; Mcast = Macho castrado; Mcrp = macho criptorquídio; Sistema pastoreo $\mathrm{x}$ género = interacción entre sistema pastoreo y género. 
El factor carga no se incluye en el análisis porque se realizó una única esquila y los animales de la carga alta se retiraron 28 días antes del final del período experimental (1 ciclo de pastoreo), período suficiente como para compensar o minimizar las diferencias generadas durante el experimento.

Los datos de producción y crecimiento de lana individual no fueron afectados por el sistema de pastoreo, lo cual es coincidente con los resultados de los trabajos de Cazzuli et al. (2004), Camesasca et al. (2002), Correa et al. (2000) y Arocena y Dighiero (1999). El factor sexo tampoco afectó estos valores, coincidente con los trabajos de Camesasca et al. (2002), Iglesias y Ramos (2003) y Franco y Gutiérrez (2009). Algorta et al. (1989), citando a Langlands y Donald (1977), Nagorcka (1979), Allden (1979) y Rodríguez (1987), afirman que el crecimiento de la lana es uno de los procesos que se ve afectado por el nivel nutricional, por lo que, en este caso, la diferencia que pudiera existir en el plano nutricional entre tratamientos no fue suficientemente importante como para ser trasladada al crecimiento de lana.

Los parámetros medidos en calidad de lana no fueron afectados por el sistema de pastoreo (coincidente con Iglesias y Ramos, 2003), ni por el sexo (coincidente con Franco y Gutiérrez (2009).

En general, no se observaron diferencias significativas $(P<0,05)$ o fueron de escasa magnitud para la interacción entre los diferentes factores evaluados a nivel de pasturas o animales, por lo tanto, no se presentan o desarrollan los resultados inherentes a estos.

\subsubsection{Comentarios y conclusiones}

Para las condiciones presentes en el experimento, en el caso de la carga animal baja y con los niveles de disponibilidad y calidad de forraje ofrecido, no se justificaría biológica y económicamente el uso de un sistema de pastoreo más controlado (semanal) para aumentar la productividad de dicho forraje y de los corderos, aunque el uso de estos sistemas, podría ser más seguro fren- te a condiciones climáticas más rigurosas que las ocurridas durante el transcurso de este período experimental (Urrestarazú, 2004). Este efecto contraproducente de la intensificación en el manejo del pastoreo concuerda con lo hallado por Akiki et al. (1992) y Arocena y Dighiero (1999).

La carga alta resultó inapropiada para el período estival considerado, con este tipo de pastura, sin tener en cuenta el sistema de pastoreo utilizado (Urrestarazú, 2004).

La producción y calidad de lana no fue afectada por el sistema de pastoreo ni por el género.

Ganzábal (1997b) definió la carga óptima como aquella que permite el mejor aprovechamiento del recurso forrajero, tanto para el cumplimiento de los objetivos propuestos como pata la generación de los mejores índices económicos de la explotación ganadera. Se puede concluir que la carga alta utilizada en esta experiencia se encuentra por encima de la óptima para las condiciones planteadas.

Por su parte, el manejo benéfico del género para incrementar la productividad animal, requiere mejores niveles de alimentación para ser considerado una variable de manejo influyente, aún superiores a los ofrecidos por la carga baja utilizada en el presente experimento (Urrestarazú, 2004).

De acuerdo a los resultados de este experimento, la utilización de la mezcla trébol rojo y achicoria durante el período estival, no permitió alcanzar los requerimientos mínimos impuestos por la industria frigorífica dentro del contexto del Operativo Cordero Pesado del Uruguay. Las cargas utilizadas en este ensayo fueron excesivas para los objetivos inicialmente planteados. Sin embargo, puede ser considerada como una buena alternativa para su uso en proceso de recría ovina durante el verano en la región de Basalto, sobre suelos de mediana profundidad y alta fertilidad, si se manejan cargas moderadas y sistemas de pastoreo controlado, que no comprometan la productividad futura de la pastura (Urrestarazú, 2004). 


\subsection{Evaluación de la carga, suplementación y género sobre pastura de trébol rojo y achicoria}

En base al ensayo anteriormente presentado, se diseñó el siguiente experimento. Se utilizó la misma base forrajera (trébol rojo y achicoria) para la evaluación de tres factores: carga, suplementación y género. El sistema de pastoreo utilizado fue alterno (14 días de ocupación y de descanso). El suplemento suministrado era mezcla de grano de maíz (72\%) y expeller se soja (28\%). Los corderos eran de la raza Corriedale.

\subsubsection{Resultados en pasturas}

El Cuadro 10 muestra la disponibilidad y calidad del forraje ofrecido y remanente durante el período de evaluación.

Respecto a la pastura, se hallaron diferencias en las variables de disponibilidad de materia seca y altura del forraje, tanto para forraje disponible como remanente, para los factores carga y suplementación.

En el caso de la carga alta, la disponibilidad del forraje ofrecido pudo haber sido limitante para el consumo animal $(<1500$ $\mathrm{kgMS} / \mathrm{ha}$ ), según lo manifestado por Milne (1990), citado por Montossi (1995).

La carga afectó la disponibilidad del forraje ofrecido y remanente. De Barbieri et al. (2000), Arocena y Dighiero (1999), Guarino y Pittaluga (1999), Correa et al. (2000), Urrestarazú (2004), Guerrina e Invernizzi
(2002) y Franco y Gutiérrez (2009) obtuvieron resultados similares en cuanto a que ante el aumento de la carga animal, se constató un descenso de la disponibilidad del forraje. Por otra parte, Cazzuli et al. (2004) evaluando cargas de 14 y 17 corderos/ha sobre mejoramientos de campo con lotus Maku y trébol blanco, no registraron diferencias entre la disponibilidad ni la altura del forraje disponible y remanente. Camesasca et al. (2002) tampoco encontraron diferencias en las disponibilidades de forraje ofrecido ni remanente al evaluar distintas cargas (18 y 30 corderos/ha).

Por otro lado, no se registraron prácticamente diferencias para las variables de composición botánica y calidad del forraje (RS, PC y FDA). Esto es coincidente con lo encontrado por De Barbieri et al. (2000), Franco y Gutiérrez (2009), Iglesias y Ramos (2003), Camesasca et al. (2002).

Esto concuerda con la afirmación de Hodgson (1990) que manifiesta que un aumento en la proporción de hojas en la pastura, debido a una alta dotación, no necesariamente se traduce en una mayor digestibilidad de la misma, ya que se reduce la oportunidad de selección.

Evaluando el factor suplementación aisladamente y según los datos de las pasturas y de la evolución del PV, existió un fenómeno de sustitución del concentrado durante las primeras etapas del ensayo y luego pasó a registrarse un fenómeno de adición del suplemento a la base forrajera. Franco y Gutiérrez (2009), Guarino y Pittaluga (1999),

Cuadro 10. Disponibilidad y calidad del forraje ofrecido y remanente promedio.

\begin{tabular}{|c|c|c|c|c|c|c|c|c|c|c|c|c|}
\hline & \multicolumn{6}{|c|}{ Ofrecido } & \multicolumn{6}{|c|}{ Remanente } \\
\hline & \multicolumn{3}{|c|}{$\begin{array}{c}\text { Carga } \\
\text { (corderos/ha) }\end{array}$} & \multicolumn{3}{|c|}{$\begin{array}{c}\text { Suplementación } \\
(\% \mathrm{PV})\end{array}$} & \multicolumn{3}{|c|}{$\begin{array}{c}\text { Carga } \\
\text { (corderos/ha) }\end{array}$} & \multicolumn{3}{|c|}{$\begin{array}{c}\text { Suplementación } \\
\text { (\%PV) }\end{array}$} \\
\hline & 10 & 20 & $\mathbf{P}$ & 0 & 0,75 & $\mathbf{P}$ & 10 & 20 & $\mathbf{P}$ & 0 & 0,75 & $\mathbf{P}$ \\
\hline $\mathrm{kgMS} / \mathrm{ha}$ & $1412 \mathrm{a}$ & $1067 \mathrm{~b}$ & ** & $1125 b$ & $1354 \mathrm{a}$ & ** & $1359 a$ & $914 \mathrm{~b}$ & ** & 997 b & $1276 \mathrm{a}$ & ** \\
\hline Altura $(\mathrm{cm})$ & $10,1 \mathrm{a}$ & $6,6 \mathrm{~b}$ & ** & $6,7 \mathrm{~b}$ & $10,0 \mathrm{a}$ & $\star \star$ & $7,8 \mathrm{a}$ & $3,8 \mathrm{~b}$ & $\star \star$ & $4,5 \mathrm{~b}$ & $7,1 \mathrm{a}$ & ** \\
\hline RS (\%) & 19,0 & 23,0 & ns & 20,8 & 21,2 & ns & 23,7 & 31,2 & ns & 27,8 & 27,1 & ns \\
\hline PC (\%) & 14,5 & 14,9 & ns & 14,2 & 15,2 & ns & 14,5 & 16,0 & ns & 15,8 & 14,7 & ns \\
\hline FDA (\%) & 41,7 & 44,1 & ns & $45,3 a$ & $40,5 \mathrm{~b}$ & * & $42,6 \mathrm{~b}$ & $48,3 a$ & * & 46,9 & 44,0 & ns \\
\hline
\end{tabular}

Nota: ${ }^{*}=\mathrm{P}<0,05 ;{ }^{* *}=\mathrm{P}<0,01 ; \mathrm{ns}=$ no significativo $(\mathrm{P}>0,10)$; medias con diferentes letras entre columnas son significativamente diferentes; ${ }^{*}=\mathrm{P}<0,05 ; * \star=\mathrm{P}<0,01 ; \mathrm{kgMS} / \mathrm{ha}=$ kilos de materia seca/hectárea; $\mathrm{RS} \%=$ porcentaje de restos secos; $\mathrm{PC} \%=$ porcentaje de proteína cruda; FDA = porcentaje de fibra detergente ácido. 


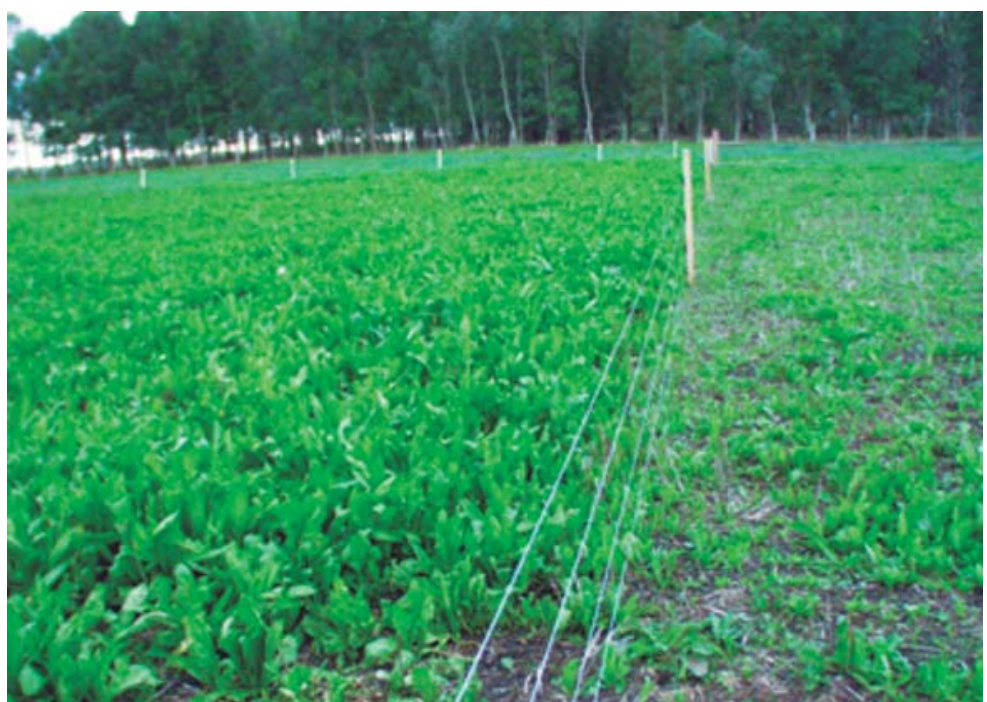

Figura 11. Diferencia de disponibilidades de forraje debido al efecto de la carga animal.

Correa et al. (2000), De Barbieri et al. (2000) también detectaron diferencias en la disponibilidad de forraje al contrastar niveles distintos de suplementación. Por otro lado, Arocena y Dighiero (1999) y Camesasca et al. (2002) no registraron diferencias significativas de la suplementación sobre la disponibilidad del forraje ofrecido. No obstante, Camesasca et al. (2002) sí hallaron diferencias en el forraje remanente al comparar tratamientos suplementados versus no suplementados, a favor del tratamiento suplementado.

Las diferencias en disponibilidad y altura del forraje ofrecido y remanente de los tratamientos con carga baja y suplementación eran claramente observables a nivel de campo (ver Figura 7), en contraste con los tratamientos con carga alta y sin suplementación.

\subsubsection{Resultados en producción animal}

El Cuadro 11 presenta la performance animal en producción de carne, según el factor evaluado.

La carga y la suplementación tuvieron efecto sobre la performance animal, sin interacción entre ambos factores.

Las diferencias en disponibilidades de pasturas guardan relación con las mayores ganancias y pesos vivos finales alcanzados en los tratamientos con menor carga y presencia de suplementación.

Acorde con Carámbula (1996) y Stuth (1991), la menor disponibilidad de forraje por animal que se da en la carga alta podría deberse a la reducción del tamaño de bocado por ser el componente más sensible a las

Cuadro 11. Performance animal en producción de carne, según factor evaluado.

\begin{tabular}{|c|c|c|c|c|c|c|c|c|c|c|}
\hline \multirow[t]{2}{*}{ Producción de carne } & \multicolumn{3}{|c|}{$\begin{array}{c}\text { Carga (C) } \\
\text { (corderos/ha) }\end{array}$} & \multicolumn{3}{|c|}{$\begin{array}{c}\text { Suplemento (S) } \\
\text { (\%PV) }\end{array}$} & \multicolumn{3}{|c|}{ Género } & \multirow{2}{*}{$C * S$} \\
\hline & 10 & 20 & $\mathbf{P}$ & 0\%PV & 1\%PV & $\mathbf{P}$ & $\mathbf{H}$ & M & $\mathbf{P}$ & \\
\hline PVLL inicial (kg) & 22,3 & 21,8 & ns & 22,1 & 22,0 & ns & $24,1 \mathrm{a}$ & $20,0 \mathrm{~b}$ & ** & ns \\
\hline PVLL final (kg) & $40,8 \mathrm{a}$ & $34,3 \mathrm{~b}$ & $\star \star$ & $35,5 \mathrm{~b}$ & $39,6 \mathrm{a}$ & $\star *$ & 37,4 & 37,7 & ns & ns \\
\hline CC final (unidades) & $4,4 \mathrm{a}$ & $3,6 \mathrm{~b}$ & ** & $3,7 \mathrm{~b}$ & $4,3 \mathrm{a}$ & * & 4,1 & 3,9 & ns & ns \\
\hline GMD (g/an/día) & $126 \mathrm{a}$ & $77 \mathrm{~b}$ & ** & $85 b$ & $118 \mathrm{a}$ & $\star \star$ & 95 & 108 & ns & ns \\
\hline
\end{tabular}

Nota: * $=\mathrm{P}<0,05 ; * *=\mathrm{P}<0,01 ; \mathrm{ns}=$ no significativo $(\mathrm{P}>0,10)$; medias con diferentes letras entre columnas son significativamente diferentes; ${ }^{*}=\mathrm{P}<0,05 ; * \star=\mathrm{P}<0,01$; $\mathrm{PVLL}=$ peso vivo Ileno; CC = condición corporal; GMD = ganancia media diaria . 
variaciones en la pastura. Con respecto a la carga los resultados de esta experiencia, éstos son coincidentes con los trabajos de Arocena y Dighiero (1999), Correa et al. (2000), Guarino y Pittaluga (1999), Franco y Gutiérrez (2009) y Camesasca et al. (2002). Iglesias y Ramos (2003), encontraron diferencias en términos de ganancias y pesos vivos, pero no fue así con la condición corporal, la cual no fue estadísticamente distinta entre tratamientos.

En cuanto a la suplementación, Arocena y Dighiero (1999), Correa et al. (2000) y Franco y Gutiérrez (2009) también obtuvieron diferencias significativas en los parámetros de pesos vivos, ganancias medias diarias y condiciones corporales entre tratamientos.

Sin embargo, Guarino y Pittaluga (1999) no detectaron diferencias entre tratamientos con y sin suplementación en términos de ganancias medias y de condición corporal de los corderos. Camesasca et al. (2002) tampoco encontraron efecto de la suplementación sobre los pesos finales y las ganancias, pero sí hallaron que la suplementación resultaba en condiciones corporales significativamente $(\mathrm{P}<0,01)$ mayores que los tratamientos no suplementados.

El factor sexo no afecto ninguna de las variables evaluadas, concordantemente con los resultados de Urestarazú (2004).

Esto no concuerda con Franco y Gutiérrez (2009) quienes sí detectaron diferencias significativas para los parámetros de producción mencionados, si bien es posible que en este caso las diferencias que se encontraron podrían deberse a que los machos fueron esquilados y luego de este período estos animales aumentaron sus ganancias. Camesasca et al. (2002) también detectaron diferencias en parámetros productivos de los animales entre sexos, a favor de los machos.

La Figura 12 presenta el efecto de cada uno de los factores evaluados sobre la evolución de PV.

La suplementación comienza a mostrar su efecto a partir del cuarto ciclo de pastoreo, momento en que comienza a disminuir la disponibilidad y altura del forraje ofrecido, evidenciando el efecto aditivo de la suplementación. Este es un comportamiento esperado en función de los mecanismos de sustitución de concentrado por pastura, donde las mayores respuestas al uso de suplementos deben esperarse cuando la disponibilidad de forraje es limitante, es decir cuando la tasa de sustitución es mínima (Ganzábal, 1997a).

El factor sexo mantuvo la diferencia de peso vivo inicial entre sexos hasta el final del experimento, no hallándose diferencias en ganancia de peso vivo.

El efecto de la mayor presión de pastoreo en la carga alta comenzó a evidenciarse a partir del tercer ciclo de pastoreo, momento en el cual la disponibilidad de pastura de la carga alta disminuye respecto a la baja
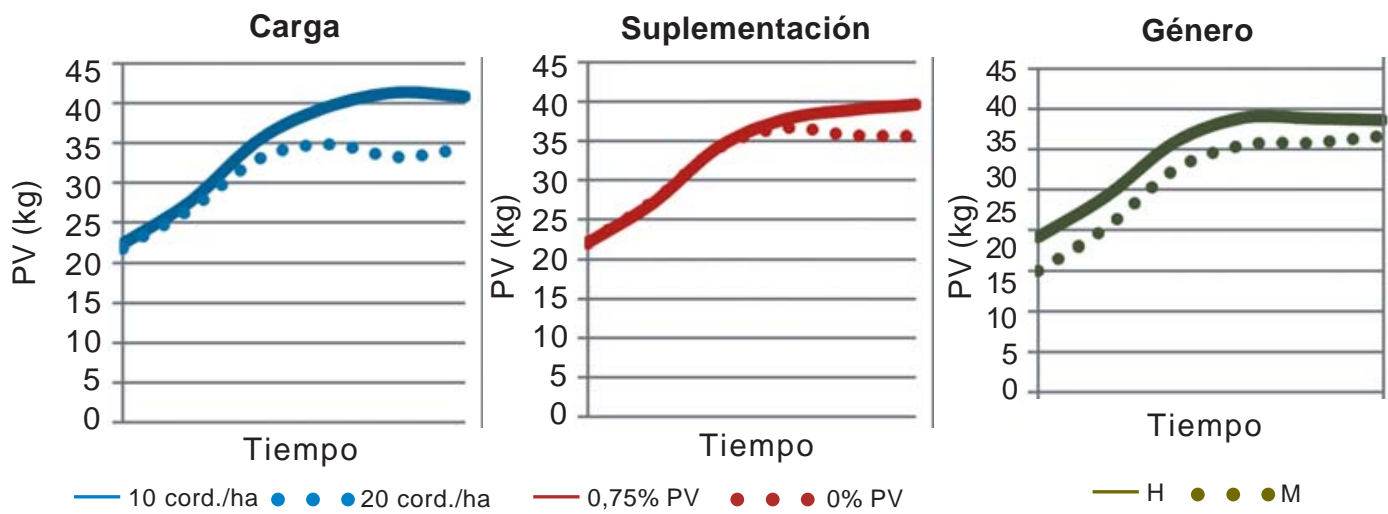

Figura 12. Evolución del PV en función del tiempo, según factor evaluado. Nota: $0 \% \mathrm{PV}=$ sin suplementar; $0,75 \% \mathrm{PV}=$ suplementados al $0,75 \%$ del $\mathrm{PV} ; \mathrm{H}=$ hembra; $\mathrm{M}=$ macho. 
Cuadro 12. Características de la canal y la carne, según carga y nivel de suplementación.

\begin{tabular}{|l|ccc|ccc|c|}
\hline \multirow{2}{*}{$\begin{array}{c}\text { Producción de } \\
\text { carne }\end{array}$} & \multicolumn{3}{|c|}{$\begin{array}{c}\text { Carga (C) } \\
\text { (corderos/ha) }\end{array}$} & \multicolumn{3}{c|}{$\begin{array}{c}\text { Suplementación (S) } \\
\text { (\%PV) }\end{array}$} & \multirow{2}{*}{ C*S } \\
\cline { 2 - 7 } & $\mathbf{1 0}$ & $\mathbf{2 0}$ & $\mathbf{P}$ & $\mathbf{0}$ & $\mathbf{0 , 7 5}$ & $\mathbf{P}$ & \\
\hline AOB in vivo $\left(\mathrm{cm}^{2}\right)$ & $12,3 \mathrm{a}$ & $9,9 \mathrm{~b}$ & $*$ & $10,0 \mathrm{~b}$ & $12,2 \mathrm{a}$ & $*$ & $\mathrm{~ns}$ \\
PCC $(\mathrm{kg})$ & $17,6 \mathrm{a}$ & $13,9 \mathrm{~b}$ & $* *$ & $14,4 \mathrm{~b}$ & $17,2 \mathrm{a}$ & $*$ & $\mathrm{~ns}$ \\
PCF $(\mathrm{kg})$ & $17,2 \mathrm{a}$ & $13,6 \mathrm{~b}$ & $* *$ & $14,1 \mathrm{~b}$ & $16,6 \mathrm{a}$ & $*$ & $\mathrm{~ns}$ \\
GR $(\mathrm{mm})$ & 7,7 & 8,6 & $\mathrm{~ns}$ & $6,8 \mathrm{~b}$ & $9,5 \mathrm{a}$ & $*$ & $*$ \\
Terneza 2 días $(\mathrm{kgF})$ & 3,05 & 3,75 & $\mathrm{~ns}$ & 3,31 & 3,46 & $\mathrm{~ns}$ & $\mathrm{~ns}$ \\
Terneza 10 días $(\mathrm{kgF})$ & 2,68 & 2,67 & $\mathrm{~ns}$ & 2,68 & 2,67 & $\mathrm{~ns}$ & $\mathrm{~ns}$ \\
\hline
\end{tabular}

Nota: * $=P<0,05 ;{ }^{*}=P<0,01 ; n s=$ no significativo $(P>0,10)$; medias con diferentes letras entre columnas son significativamente diferentes; * $=\mathrm{P}<0,05 ;{ }^{* *}=\mathrm{P}<0,01 ; \mathrm{AOB}=$ área ojo de bife; $\mathrm{PCC}=$ peso canal caliente; PCF = peso canal fría; $\mathrm{GR}=$ espesor de grasa sobre la $12^{\mathrm{va}}$. costilla a $11 \mathrm{~cm}$ de la línea media de la canal.

(2000 versus $1000 \mathrm{kgMS} / \mathrm{ha}$ ) manifestándose en un descenso de la ganancia de peso vivo (Mott, 1960 y Hodgson, 1990).

El Cuadro 12 presenta las características de la canal y la carne, según carga y nivel de suplementación. Solo fueron faenados los machos.

Los parámetros de calidad de canal (AOB, PCC y PCF) presentaron el mismo comportamiento que la performance in vivo: mayores pesos en corderos suplementados y manejados a baja carga, aunque en todos los casos se alcanzaron los pesos de canal requeridos por el Operativo Cordero Pesado. La estimación de la cobertura de grasa (GR) fue mayor para los corderos que recibieron suplemento, posiblemente debido a un mayor contenido de energía en la dieta (Soeparn y Davies, 1987).

Los resultados obtenidos en esta experiencia son menores a los promedios presentados por Brito et al. (2002) citados por Luzardo et al. (2013), en términos de PCC y GR para todos los tratamientos (a excepción de GR del tratamiento con $0,75 \% \mathrm{~S}$ ). Asimismo, la terneza medida a los 10 días es presenta resultados mayores (carne menos tierna) aquí para todos los tratamientos.

Cazzuli et al. (2004) encontraron efecto de la carga en PCF de los corderos pastoreando lotus Maku y en PCC de los corderos pastoreando trébol blanco. Camesasca et al. (2002) encontraron diferencias entre cargas a favor de la carga baja para AOB, PCC y GR. Por otro lado, Iglesias y Ramos (2003) no encontraron efecto de la carga sobre el AOB, pero sí sobre PCC y PCF. En contraste, Guarino y Pittaluga (1999) sí encontraron efecto significativo de la carga sobre el AOB. Arocena y Dighiero (1999) y Correa et al. (2000) encontraron efecto de la carga en AOB, PCC, PCF y GR.

Ninguno de los autores mencionados encontró diferencias significativas entre las distintas cargas en la terneza de la carne. Iguales resultados fueron hallados por Franco y Gutiérrez (2009) quienes tampoco detectaron diferencias significativas entre distintas cargas y niveles de suplementación.

Por otra parte, en un ensayo llevado a cabo por San Julián et al. (2007) con corderos pastoreando un mejoramiento de campo con Lotus corniculatus cv. INIA Draco de $4^{\text {to }}$ año, que fueron sometidos a distintos niveles de suplementación con concentrados $(0,6 \% \mathrm{PV}$, $1,2 \%$ PV y ad libitum), sí se encontraron diferencias significativas en la terneza evaluada con 20 días de maduración. La carne de los corderos suplementados al 1,2\% PV o ad libitum fue significativamente $(\mathrm{P}<0,05)$ más tierna que los animales solamente alimentados a forraje o con niveles de suplementación del 0,6\% PV.

Con respecto a la suplementación, Arocena y Dighiero (1999) y Correa et al. (2000) encontraron además diferencias significativas entre tratamientos suplementados y no suplementados en PCC, PCF y AOB.

En general, no se observaron diferencias significativas $(P<0,05)$ o fueron de escasa magnitud para la interacción entre los diferentes factores evaluados a nivel de pasturas 
o animales, por lo tanto, no se presentan o desarrollan los resultados inherentes a éstos.

\subsubsection{Comentarios y conclusiones}

Tanto la carga como la suplementación tuvieron un efecto significativo en la performance animal, así como en los parámetros de calidad de canal. De acuerdo a los resultados de este experimento, la utilización de la mezcla trébol rojo y achicoria durante el período estival a las cargas consideradas, es una opción forrajera válida para engorde estival de corderos. Las cargas utilizadas en este ensayo fueron adecuadas para los objetivos inicialmente planteados (llegar a PV de faena según requisitos del Operativo Cordero Pesado), permitiendo en el caso de la carga baja y la suplementación terminar con todos los animales y llegar más temprano al mercado.

A su vez, teniendo como objetivo alternativo al Operativo Cordero Pesado, la recría de hembras, esta base forrajera permite alcanzar pesos en torno a los $35 \mathrm{~kg}$ con 6 meses de edad.

\subsection{Evaluación de}

\section{suplementación sobre} pastura irrigada de trébol rojo

En el marco de los proyectos de evaluación de pasturas bajo riego se introdujo la evaluación de la respuesta animal. El objetivo fue evaluar el potencial productivo (producción de carne y lana) de una pastura de trébol rojo bajo riego, con y sin suplementación energética de los animales.

La carga promedio fue de 22,5 corderos por hectárea. Se inició el experimento a principios de febrero con 20 corderos/ha y al culminar el primer ciclo de pastoreo (30 días) se ajustó la carga a 25 corderos/ha para una mejor utilización de la pastura. Cuando la altura del rechazo fue inferior a $6 \mathrm{~cm}$ (tercer ciclo de pastoreo) se ajustó nuevamente la carga a 20 corderos/ha.

La suplementación se realizó con grano de maíz entero. Los corderos eran de las razas Merino Dohne x Corriedale y Corriedale.

\subsubsection{Resultados en pasturas}

En el Cuadro 13 se presenta la disponibilidad y calidad del forraje ofrecido y remanente durante el período evaluado.

Los tratamientos no tuvieron efecto en ninguno de los parámetros evaluados de la pastura. Para ambos tratamientos, el contenido de restos secos se encuentra por encima de las recomendaciones de Rattray et al. (1987) para potencializar la ganancia de peso de corderos.

En cuanto a la producción de forraje en los mismos suelos de Basalto en donde se desarrolló el presente experimento, Giorello et al. (2013) reportaron crecimientos de $2695 \mathrm{kgMS} / \mathrm{ha}$ para el período estival, producciones algo más elevadas que las del presente experimento.

En cuanto a la altura de la pastura ofreci$\mathrm{da}$, se puede decir que éstas son suficientes para no limitar la productividad animal, por encontrarse por encima de los valores

Cuadro 13. Disponibilidad y calidad del forraje ofrecido y remanente promedio.

\begin{tabular}{|l|ccc|ccc|}
\hline \multirow{2}{*}{} & \multicolumn{4}{|c|}{ Ofrecido } & \multicolumn{4}{c|}{ Remanente } \\
\cline { 2 - 7 } & \multicolumn{4}{|c|}{ Suplementación (\%PV) } \\
\cline { 2 - 7 } & 0\%PV & 1\%PV & P & 0\%PV & 1\%PV & P \\
\hline kgMS/ha & 2418 & 2640 & ns & 2011 & 2352 & ns \\
Altura (cm) & 15,7 & 16,8 & ns & 7,6 & 9,0 & ns \\
RS (\%) & 29,0 & 27,6 & ns & 44,0 & 37,2 & ns \\
\hline
\end{tabular}

Nota: $\mathrm{ns}=$ no significativo $(\mathrm{P}>0,10) ; \mathrm{kgMS} / \mathrm{ha}=$ kilos de materia seca/hectárea; $\mathrm{RS} \%=$ porcentaje de restos secos. 
mencionados por Hodgson (1990), de $6-8 \mathrm{~cm}$ para ovinos. Por debajo de estos valores, la ingesta diaria de forraje se vería restringida principalmente el consumo por bocado y un eventual aumento en el tiempo de pastoreo o la tasa de bocado no podrían ser suficientes para evitar la disminución de consumo. En la misma línea de razonamiento, Hughes (1983) y Gordon y Lascano (1993) afirman que la profundidad del bocado en ovinos está positivamente relacionada a la altura de la superficie de la pastura y negativamente relacionada a la densidad de la misma, mientras que el área de bocado decrece linealmente con ésta y se incrementa cuadráticamente con la altura del tapiz.

Guy (1979), Van Dyne et al. (1980) y Geenty (1983), citados por Hughes (1983) opinan que los animales en general y los ovinos en particular seleccionan consistentemente más material verde que muerto, es decir, restos secos. Tomando las recomendaciones de Rattray et al. (1987), la proporción de restos secos del forraje ofrecido estaría por encima de los niveles a partir de los cuales la producción animal se resiente (valores mayores a 15-20\%). Los mismos autores sostienen que los restos secos del forraje remanente deberían situarse por debajo del $40 \%$ para no afectar la performance animal; en este sentido solo los tratamientos con suplementación entrarían en la categoría recomendada.

\subsubsection{Resultados en producción animal}

En el Cuadro 14 se presenta la performance animal en términos de peso vivo, condición corporal y ganancias medias, así como también en calidad de canal y carne.

A diferencia de lo registrado en las determinaciones en las pasturas en donde no se registraron diferencias significativas $(P>0,10)$, todos los parámetros de producción de carne y calidad de canal fueron afectados positiva y significativamente por la inclusión de la suplementación. En ambos tratamientos, el promedio de los animales alcanzaron pesos superiores al mínimo requerido para cumplir con los requisitos del Operativo Cordero Pesado.

La suplementación determinó diferencias en los atributos de calidad de canal, lo cual es coherente con los resultados encontrados por Arocena y Dighiero (1999) y Correa et al. (2000). Los mayores pesos de canal logrados con el tratamiento suplementado se deberían a la mayor concentración energética en la dieta (Soeparno y Davies, 1982).

La calidad de carne en términos de terneza no fue afectada por la suplementación. En este sentido, con tiempos de maduración de 2 y 10 días los resultados son coherentes con lo hallado en el ensayo presentado anteriormente sobre una pastura de achicoria y trébol rojo con y sin suplementación,

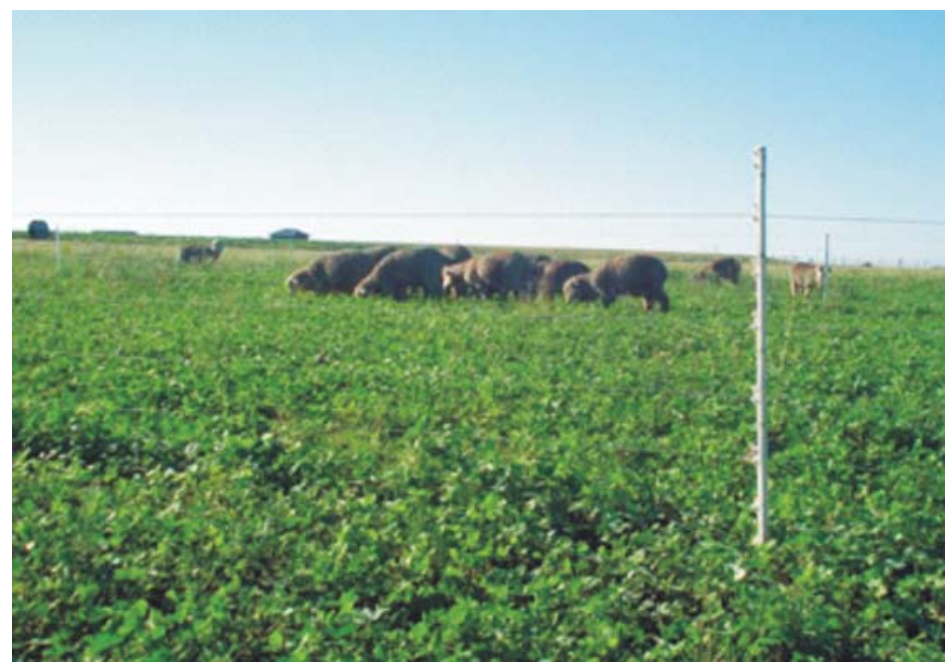

Figura 13. Corderos pastoreando trébol rojo bajo riego. 
Cuadro 14. Performance animal en producción y calidad de carne y canal, según nivel de suplementación.

\begin{tabular}{|l|lll|}
\hline \multirow{2}{*}{ Producción carne } & \multicolumn{3}{|c|}{$\begin{array}{c}\text { Suplementación } \\
\text { (\%PV) }\end{array}$} \\
\cline { 2 - 4 } & 0\%PV & 1\%PV & P \\
\hline PV LI inicial (kg) & 24,5 & 24,7 & $\mathrm{~ns}$ \\
PV LI final (kg) & $38,7 \mathrm{~b}$ & $42,9 \mathrm{a}$ & $\star \star$ \\
CC final (unidades) & $3,3 \mathrm{~b}$ & $3,8 \mathrm{a}$ & $* \star$ \\
GMD (g/an/día) & $101 \mathrm{~b}$ & $136 \mathrm{a}$ & $\star \star$ \\
\hline
\end{tabular}

\begin{tabular}{|l|lll|}
\hline \multirow{2}{*}{ Calidad canal y carne } & \multicolumn{3}{|c|}{ Suplementación (\%PV) } \\
\cline { 2 - 4 } & 0\%PV & 1\%PV & P \\
\hline AOB in vivo $\left(\mathrm{cm}^{2}\right)$ & $9,2 \mathrm{~b}$ & $10,6 \mathrm{a}$ & $\star \star$ \\
PCC $(\mathrm{kg})$ & $15,9 \mathrm{~b}$ & $19,3 \mathrm{a}$ & $\star \star$ \\
PCF $(\mathrm{kg})$ & $15,4 \mathrm{~b}$ & $18,5 \mathrm{a}$ & $\star \star$ \\
GR $(\mathrm{mm})$ & $3,5 \mathrm{~b}$ & $8,4 \mathrm{a}$ & $\star \star$ \\
Terneza 2 días $(\mathrm{kgF})$ & 3,4 & 3,1 & $\mathrm{~ns}$ \\
Terneza 10 días $(\mathrm{kgF})$ & 2,6 & 2,4 & $\mathrm{~ns}$ \\
\hline
\end{tabular}

Nota: ${ }^{* *}=P<0,01 ; n s=$ no significativo $(P>0,10)$; medias con diferentes letras entre columnas son significativamente diferentes; ${ }^{*}=\mathrm{P}<0,05 ;{ }^{* *}=\mathrm{P}<0,01$; $\mathrm{PVLI}=$ peso vivo lleno; $\mathrm{CC}=$ condición corporal; $\mathrm{GMD}=$ ganancia media diaria; $\mathrm{AOB}=$ área ojo de bife; $\mathrm{PCC}=$ peso canal caliente; $\mathrm{PCF}=$ peso canal fría; $\mathrm{GR}$ = espesor de grasa sobre la $12^{\text {va }}$ costilla a $11 \mathrm{~cm}$ de la línea media de la canal.

así como con los resultados de Franco y Gutiérrez (2009).

Por otro lado, las PCC y GR fueron menores, al igual que lo que sucedió con los valores de terneza a los 10 días de madura- ción en los que los valores fueron menores o iguales a los registrados por Brito et al. (2002) citados por Luzardo et al. (2013).

La Figura 14 presenta el efecto de la suplementación sobre la evolución del PV.

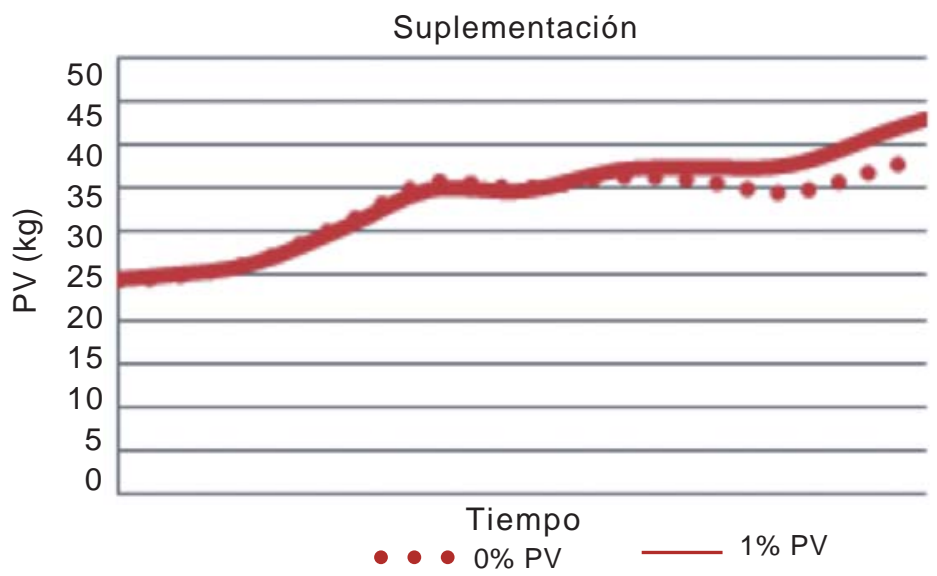

Figura 14. Evolución del $\mathrm{PV}$ en función del tiempo, según suplementación.

Nota: $0 \% \mathrm{PV}=$ sin suplementación; 1\%PV = suplementación al 1\% del PV. 
Las diferencias en peso vivo debido a la suplementación comienzan a evidenciarse a partir del tercer ciclo de pastoreo a pesar de que no se hallaron diferencias significativas en la pastura, como ya se presentó en la sección anterior.

\subsubsection{Comentarios y conclusiones}

A partir del tercer ciclo de pastoreo el forraje rechazado comenzó a ser inferior a $1500 \mathrm{kgMS} / \mathrm{ha}$ y el forraje ofrecido comenzó a registrar valores de restos secos (\%) del entorno de 35\%. Esto pudo haber resultado en un efecto aditivo de la suplementación a la dieta total (Ganzábal, 1997a), lo cual se tradujo en mayores ganancias de peso vivo para los animales que recibieron suplemento. Según Coop (1986), una disponibilidad del forraje remanente del orden de 1200$1400 \mathrm{kgMS} /$ ha para corderos destetados se correspondería con ganancias de 160-200 g/ animal/día, performances que no se dieron estas circunstancias, en ninguno de los dos tratamientos. Si bien las disponibilidades del forraje ofrecido fueron aceptables, la proporción de restos seco fue elevada (30\%), lo cual podría explicar que las ganancias no hayan sido mayores.

Los antecedentes nacionales del comportamiento del trébol rojo con riego en la región de basalto, reportan respuestas en producción de forraje de $17 \mathrm{kgMs} / \mathrm{ha} / \mathrm{mm}$ (Pérez Gomar et al., 2008) lo cual es muy alentador. Esta información demuestra el potencial del uso del trébol rojo bajo riego como una pastura especializada en el engorde de corderos pos destete en el período estival.

\subsection{Comentarios y conclusiones de praderas de ciclo corto}

Se evaluó la mezcla forrajera de secano de trébol rojo y achicoria en dos años distintos, obteniendo como mejor resultado el manejo de cargas moderadas (10-16 corderos/ha). En general, el sistema de pastoreo alterno resultó muy adecuado para este tipo de pasturas en lo productivo y como «seguro» para favorecer la producción animal frente a potenciales problemas climáticos que se presenten en este período estival.
En ambos casos presentados de opciones forrajeras, la calidad de la pastura no fue afectada por la carga animal en términos de contenido de PC\% y FDA\%. Sin embargo, en términos de disponibilidad y altura del forraje ofrecido, se detectaron diferencias significativas entre las distintas cargas evaluadas. La carga animal es determinante para la productividad de las pasturas frente al sistema de pastoreo, y eventualmente en la persistencia.

La producción de corderos sobre pasturas regadas, en este caso trébol rojo, se plantea como una alternativa promisoria debido a los resultados obtenidos en producción de materia seca en experimentos sin pastoreo. La información inédita generada para el engorde de corderos en el Basalto sobre esta opción forrajera irrigada y con la inclusión de suplementación, demuestra su alto potencial para ser explorado. Debido a la escasa información, nacional e internacional, es necesario continuar investigando sobre el comportamiento de la pastura regada bajo pastoreo para este objetivo de mejora de la recría y engorde ovino.

\section{RECRÍA Y ENGORDE DE CORDEROS SOBRE PRADERAS ARTIFICIALES PERMANENTES}

\subsection{Evaluación del nivel de suplementación sobre pastura de trébol blanco, lotus corniculatus y raigrás}

En el presente trabajo de tesis realizado por Silveira (2009) se evaluaron 5 niveles diferentes de suplementación, hasta llegar al confinamiento: T1) 0\% ración (testigo, 100\% pastura); T2) 25\% ración (75\% pastura); T3) $50 \%$ ración (50\% pastura); T4) $75 \%$ ración (25\% pastura); T5) 100\% ración (confinamiento, ración compuesta por $80 \%$ ración comercial y $20 \%$ fardo alfalfa).

La pradera utilizada fue una mezcla de trébol blanco y lotus cv. San Gabriel de cuarto año y con raigrás espontáneo. La carga ani- 
mal utilizada fue 6,3 corderos/ha en los tratamientos con pastoreo. Las corderas eran todas hembras y de las razas île de France $x$ Corriedale y Texel x Corriedale.

\subsubsection{Resultados en pasturas}

El Cuadro 15 presenta la disponibilidad y calidad del forraje ofrecido y remanente durante el período de evaluación.

Ninguno de los niveles de suplementación evaluados afectó la cantidad o calidad de la pastura, en los tratamientos con acceso a pasturas. Esta información está en total coincidencia con los resultados de Arocena y Dighiero (1999). De igual forma, en los experimentos presentados más arriba con trébol rojo y achicoria, en términos de contenido de restos secos y proteína cruda, la suplementación tampoco afectó estos parámetros. Por el contrario, la disponibilidad y altura del forraje ofrecido y remanente sí fueron afectadas por este factor.

Camesasca et al. (2002) tampoco encontraron efecto de la suplementación sobre todos los parámetros evaluados en el forraje ofrecido, pero sí en la disponibilidad y altura en el forraje remanente, lo que coincide en términos generales por lo hallado por Correa et al. (2000). De Barbieri et al. (2000) y Franco y Gutiérrez (2009), los que encontraron diferencias en las disponibilidades y alturas del forraje ofrecido y remanente, pero no en la calidad del forraje. Guarino y Pittaluga (1999) encontraron diferencias atribuibles a la suplementación en todos los parámetros de cantidad y calidad de pastura ofrecida y rechazada.

En este caso, con los resultados de la pastura analizados, se puede destacar que no se estaría registrando un fenómeno de sustitución de pastura por suplemento, ya que en todos los tratamientos el forraje ofrecido y remanente no fueron afectados por la suplementación. La Figura 15 presenta la contribución relativa de los diferentes componentes botánicos de la pastura ofrecida y rechazada.

En el forraje ofrecido, la fracción malezas fue aumentando a medida que avanzaba el período de evaluación. Si bien los restos secos fueron aumentando con el tiempo, en un momento la proporción empezó a decaer, lo que en parte se explica por el aumento en la proporción de malezas. Por otro lado, en el forraje de rechazo, las malezas también fueron en aumento a medida que avanzaba el ensayo, en detrimento de todo el resto de los componentes de la pastura.

Hodgson (1990) sostiene que la composición botánica de la pastura puede ejercer un efecto directo sobre el consumo de forraje de animales en pastoreo, además de la composición química y el contenido de nutrientes. Por tanto, es dable esperar que con la evolución de la composición botánica de la pastura que se registró en el período, el consumo de los animales se haya visto afectado por la presencia creciente de las malezas de menor valor nutricional que las pasturas sembradas.

Cuadro 15. Disponibilidad y calidad del forraje ofrecido y remanente promedio (adaptado de Silveira, 2009).

\begin{tabular}{|c|c|c|c|c|c|c|c|c|c|c|}
\hline \multirow[t]{2}{*}{ Pasturas } & \multicolumn{5}{|c|}{ Ofrecido } & \multicolumn{5}{|c|}{ Remanente } \\
\hline & $\begin{array}{l}0 \% \\
\text { ración }\end{array}$ & $\begin{array}{c}25 \% \\
\text { ración }\end{array}$ & $\begin{array}{l}50 \% \\
\text { ración }\end{array}$ & $\begin{array}{l}75 \% \\
\text { ración }\end{array}$ & $\mathbf{P}$ & $\begin{array}{c}0 \% \\
\text { ración }\end{array}$ & $\begin{array}{l}25 \% \\
\text { ración }\end{array}$ & $\begin{array}{l}50 \% \\
\text { ración }\end{array}$ & $\begin{array}{l}75 \% \\
\text { ración }\end{array}$ & $\mathbf{P}$ \\
\hline kgMS/ha & 2547 & 2476 & 2550 & 2473 & ns & 2164 & 1979 & 1975 & 1875 & ns \\
\hline Altura $(\mathrm{cm})$ & 9,5 & 8,7 & 9,2 & 8,6 & ns & 6.0 & 5.6 & 6.1 & 6.3 & ns \\
\hline RS (\%) & 50,4 & 45,0 & 52,8 & 51,0 & ns & 54.2 & 51.3 & 51.0 & 51.9 & ns \\
\hline PC (\%) & 13,1 & 13,3 & 12,8 & 13,4 & ns & 13.2 & 12.8 & 12.3 & 12.0 & ns \\
\hline FDA (\%) & 28,0 & 27,8 & 28,2 & 27,7 & ns & 30.6 & 29.6 & 28.7 & 29.9 & $\mathrm{~ns}$ \\
\hline
\end{tabular}

Nota: $\mathrm{ns}=$ no significativo $(\mathrm{P}>0,10) ; \mathrm{kgMS} / \mathrm{ha}=$ kilos de materia seca/hectárea; $\mathrm{RS} \%=$ porcentaje de restos secos; PC \% = porcentaje de proteína cruda; FDA = porcentaje de fibra detergente ácido. 


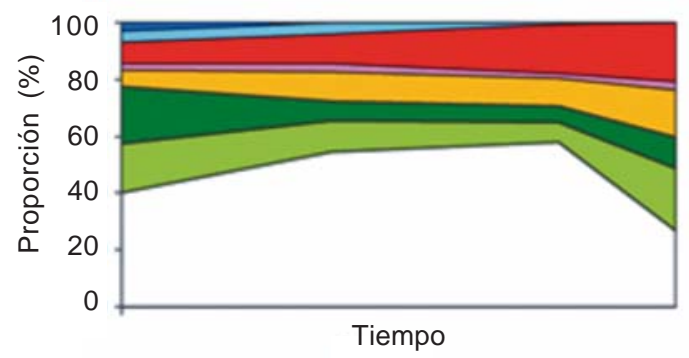

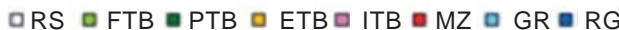

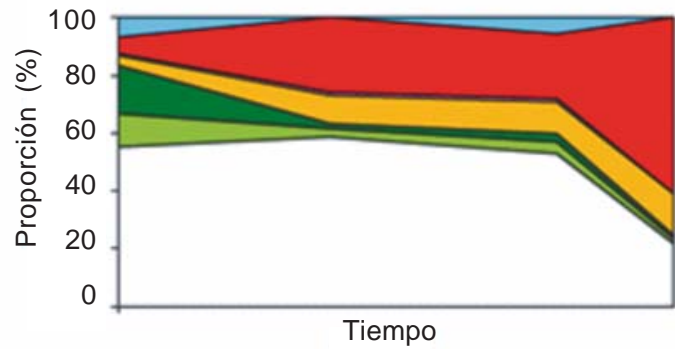

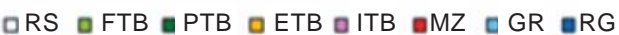

Figura 15. Composición botánica según nivel de suplementación (adaptado de Silveira, 2009). Nota: RS = restos secos; FTB = folíolo de trébol blanco; PTB = pecíolo de trébol blanco; ETB = estolón de trébol blanco; ITB = inflorescencia de trébol blanco; GR = gramíneas; $\mathrm{MZ}=$ malezas.

\subsubsection{Resultados en comportamiento y producción animal}

La Figura 16 presenta la conducta animal promedio del período de evaluación según el nivel de suplementación.

A medida que se disminuía la proporción de la pastura en la dieta, las actividades de pastoreo disminuían, en los tratamientos con acceso a pasturas. Asimismo, la actividad dedicada a consumo de suplemento aumentaba a mayor proporción de suplementación en la dieta. En cuanto a las tasas de bocado, este parámetro fue medido solamente en los tratamientos con acceso a pasturas y fue en aumento a mayor contenido de pastura en la dieta, salvo en el tratamiento con $25 \%$ pastura (T4) en donde de hecho, se registró la menor tasa de bocado.

En las experiencias de Correa et al. (2000), Arocena y Dighiero (1999) y Franco y Gutiérrez (2009) el tiempo de pastoreo fue significativamente menor $(P<0,01)$ en los tratamientos suplementados que en los no su-

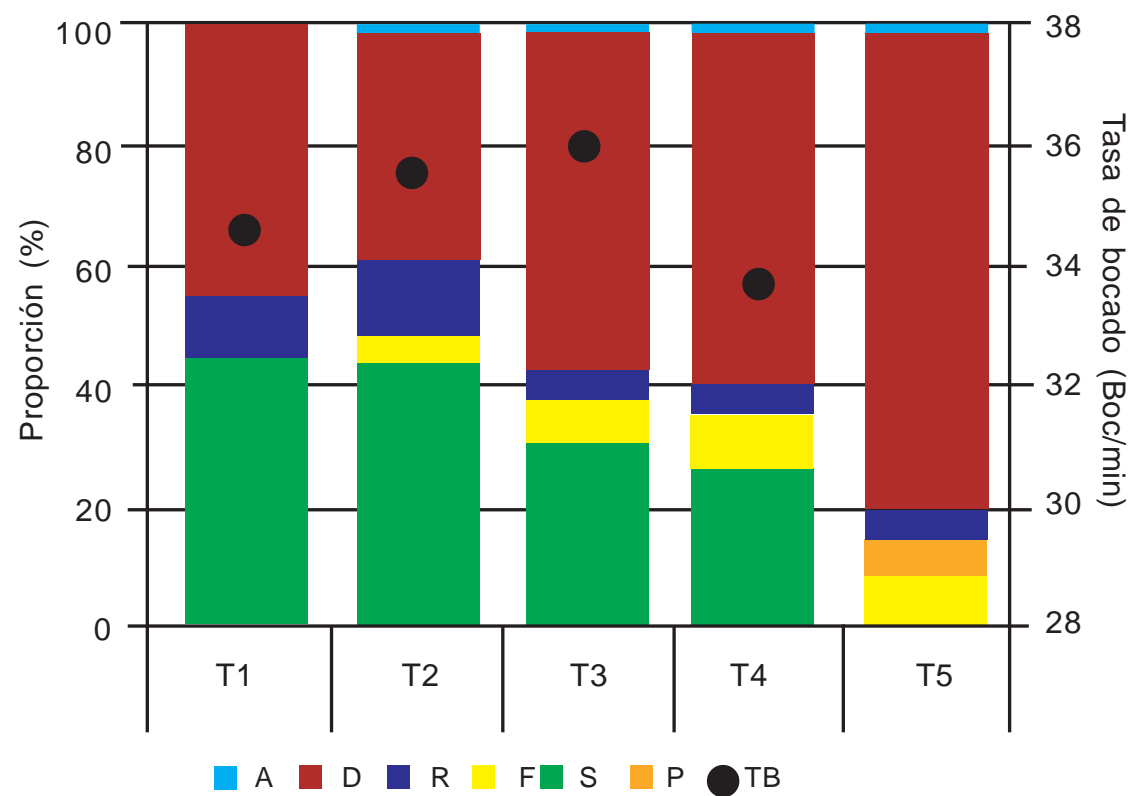

Figura 16. Conducta animal, según factor evaluado (adaptado de Silveira, 2009).

Nota: $\mathrm{P}=$ pastoreo; $\mathrm{S}=$ consumo suplemento; $\mathrm{F}=$ consumo fardo; $\mathrm{R}=$ rumia $; \mathrm{D}$ = descanso; $\mathrm{A}$ = consumo de agua; $\mathrm{TB}=$ tasa de bocado. 
Cuadro 16. Performance animal en producción de carne, según nivel de suplementación (adaptado de Silveira, 2009).

\begin{tabular}{|l|cccccc|}
\hline $\begin{array}{l}\text { Producción } \\
\text { de carne }\end{array}$ & 0\% ración & 25\% ración & 50\% ración & 75\% ración & 100\% ración & P \\
\hline PVV inicial $(\mathrm{kg})$ & 31,3 & 29,8 & 30,4 & 30,8 & 30,0 & $\mathrm{~ns}$ \\
PVV final $(\mathrm{kg})$ & $46,3 \mathrm{ab}$ & $49,3 \mathrm{a}$ & $49,0 \mathrm{a}$ & $49,6 \mathrm{a}$ & $44,5 \mathrm{~b}$ & $* *$ \\
CC final (unidades) & $4,33 \mathrm{~b}$ & $4,56 \mathrm{a}$ & $4,44 \mathrm{ab}$ & $4,53 \mathrm{a}$ & $4,42 \mathrm{ab}$ & $*$ \\
GMD (g/an/día) & $152 \mathrm{ab}$ & $182 \mathrm{a}$ & $179 \mathrm{a}$ & $184 \mathrm{a}$ & $100 \mathrm{ab}$ & $* *$ \\
\hline
\end{tabular}

Nota: ${ }^{*}=\mathrm{P}<0,05 ;{ }^{*}=\mathrm{P}<0,01 ; \mathrm{ns}=$ no significativo $(\mathrm{P}>0,10)$; medias con diferentes letras entre columnas son significativamente diferentes; ${ }^{*}=\mathrm{P}<0,05 ;{ }^{* *}=\mathrm{P}<0,01 ; \mathrm{PVV}=$ peso vivo vacío; $\mathrm{CC}=$ condición corporal; $\mathrm{GMD}=$ ganancia media diaria .

plementados, lo que coincide con estos resultados.

El Cuadro 16 resume la performance animal en producción de carne, según el nivel de suplementación.

El nivel de suplementación tuvo efecto significativo sobre el peso vivo final, condición corporal y ganancia media diaria. El peso final y las ganancias fueron menores en el tratamiento con confinamiento (100\% ración), debido a las dificultades halladas en el periodo de acostumbramiento (Silveira, 2009).

Estos resultados coinciden con lo hallado por Franco y Gutiérrez (2009), Arocena y Dighiero (1999), De Barbieri et al. (2000) y las experiencias presentadas en las secciones anteriores.

Camesasca et al. (2002) y Correa et al. (2000), sin embargo, no encontraron diferencias entre los tratamientos suplementados.
La Figura 17 presenta el efecto del nivel de suplementación sobre la evolución del PV.

Se observa que el tratamiento con confinamiento presentó menores ganancias en los primeros días -coincidente con el período de acostumbramiento- diferencia que se mantuvo hasta finalizar el experimento. Las mayores ganancias se obtuvieron sobre pastura con mayor nivel de concentrado $(75 \%$ ración), siendo estadísticamente iguales todos los tratamientos que recibieron concentrado.

El Cuadro 17 presenta las características de la canal y la carne, según nivel de suplementación.

La menor performance obtenida por el tratamiento en confinamiento se reflejó en los pesos de canal fría y caliente. El resto de las características de calidad y de carne no tuvo efecto de los niveles de suplementación.

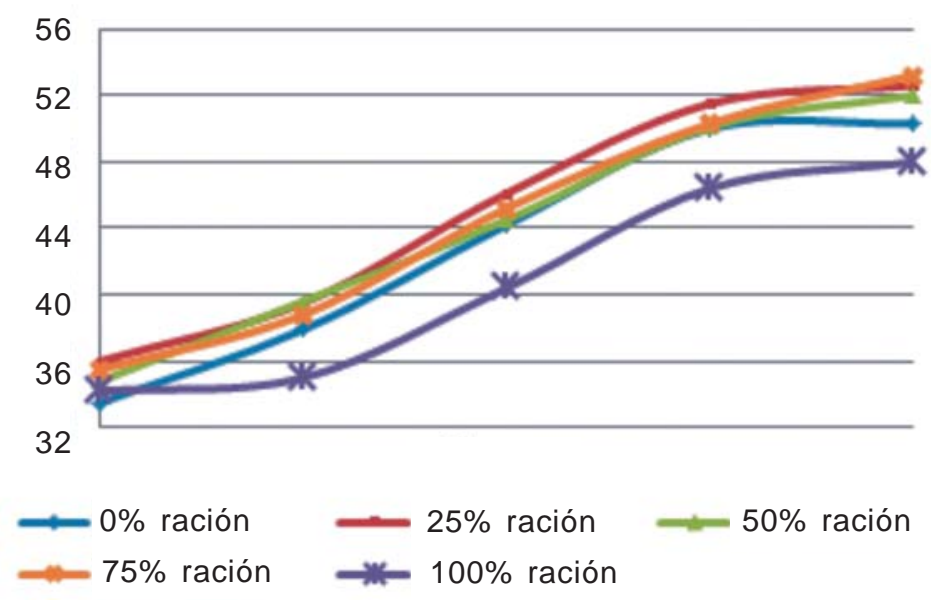

Figura 17. Evolución del PV en función del tiempo, según nivel de suplementación (adaptado de Silveira, 2009). 
Cuadro 17. Características de la canal y la carne, según nivel de suplementación (adaptado de Silveira, 2009).

\begin{tabular}{|l|cccccc|}
\hline $\begin{array}{l}\text { Producción } \\
\text { de carne }\end{array}$ & 0\% ración & 25\% ración & 50\% ración & 75\% ración & 100\% ración & P \\
\hline AOB in vivo $\left(\mathrm{cm}^{2}\right)$ & 15,85 & 16,27 & 17,44 & 17,36 & 15,88 & $\mathrm{~ns}$ \\
Punto C in vivo $(\mathrm{mm})$ & 9,06 & 9,78 & 10,25 & 11,10 & 9,11 & $\mathrm{~ns}$ \\
AOB post mortem $\left(\mathrm{cm}^{2}\right)$ & 15,20 & 15,34 & 15,63 & 15,19 & 14,48 & $\mathrm{~ns}$ \\
PCC $(\mathrm{kg})$ & $23,1 \mathrm{~b}$ & $24,8 \mathrm{ab}$ & $25,7 \mathrm{ab}$ & $26,3 \mathrm{a}$ & $22,5 \mathrm{~b}$ & $\star *$ \\
PCF $(\mathrm{kg})$ & 22,8 ab & $24,6 \mathrm{ab}$ & $25,3 \mathrm{a}$ & $25,7 \mathrm{a}$ & $21,8 \mathrm{~b}$ & $\star *$ \\
GR $(\mathrm{mm})$ & 18,9 & 21,4 & 21,7 & 22,8 & 20,0 & $\mathrm{~ns}$ \\
Terneza 2 días $(\mathrm{kgF})$ & 4,14 & 3,10 & 3,19 & 3,56 & 4,17 & $\mathrm{~ns}$ \\
Terneza 10 días $(\mathrm{kgF})$ & 2,99 & 2,69 & 2,40 & 2,77 & 2,59 & $\mathrm{~ns}$ \\
\hline
\end{tabular}

Nota: ${ }^{* *}=\mathrm{P}<0,01 ; \mathrm{ns}=$ no significativo $(\mathrm{P}>0,10)$; medias con diferentes letras entre columnas son significativamente diferentes; ${ }^{*}=\mathrm{P}<0,05 ;{ }^{* *}=\mathrm{P}<0,01 ; \mathrm{AOB}=$ área ojo de bife; $\mathrm{PCC}=$ peso canal caliente; $\mathrm{PCF}=$ peso canal fría; $\mathrm{GR}=$ espesor de grasa sobre la 12va costilla a $11 \mathrm{~cm}$ de la línea media de la canal.

Se destacan especialmente los valores de terneza, que se encuentran por debajo (efecto positivo) de los exigidos por los mercados de Nueva Zelandia (Bickerstaffe, 1996, citado por Silveira, 2009) y Australia (Montossi et. al., 2002, citados por Silveira, 2009).

En el mismo sentido y a diferencia con la tendencia encontrada para los demás ensayos presentados previamente, todos los tratamientos registraron valores mayores de PCC, GR y terneza que los obtenidos por Brito et al. (2002) citados por Luzardo et al. (2013). En este caso, los valores más elevados responden al uso de genotipos netamente carniceros de los animales evaluados (île de France y Texel en cruzamiento con Corriedale), así como por los elevados pesos finales y engrasamiento que el potencial genético de las corderas les permitió alcanzar.
En este caso, solo los PCC y PCF fueron significativamente distintos $(P<0,01)$ por efecto de los tratamientos, mientras que Franco y Gutiérrez (2009), Arocena y Dighiero (1999) y Correa et al. (2000) encontraron diferencias en todos los atributos de calidad de canal entre tratamientos suplementados. Algo similar ocurrió con la experiencia presentada en esta misma publicación, con los corderos pastoreando trébol rojo irrigado.

El Cuadro 18 resume la performance animal en producción y calidad de lana, según el nivel de suplementación.

Ninguno de los niveles de suplementación afectó la producción, crecimiento o calidad de la lana de los corderos. Resultados similares fueron hallados por Arocena y Dighiero (1999), De Barbieri et al. (2000), Camesasca et al. (2002) y Correa et al. (2000).

Cuadro 18. Performance animal en producción y calidad de lana, según nivel de suplementación (adaptado de Silveira, 2009).

\begin{tabular}{|c|c|c|c|c|c|c|}
\hline $\begin{array}{l}\text { Producción } \\
\text { de lana }\end{array}$ & 0\% ración & $25 \%$ ración & $50 \%$ ración & $75 \%$ ración & $100 \%$ ración & $\mathbf{P}$ \\
\hline $\begin{array}{l}\text { Producción lana vellón } \\
\text { (kg/cordero) }^{1}\end{array}$ & 2,04 & 2,19 & 2,08 & 1,98 & 1,81 & ns \\
\hline $\begin{array}{l}\text { Crecimiento lana limpia } \\
\left(\mu \mathrm{g} / \mathrm{cm}^{2} / \mathrm{d} i ́ \mathrm{a}\right)\end{array}$ & 1177 & 1332 & 1265 & 1135 & 1158 & ns \\
\hline $\mathrm{DF}(\mu \mathrm{m})$ & 31,9 & 34,6 & 33,8 & 32,4 & 33,1 & ns \\
\hline Rendimiento (\%) & 82 & 80 & 80 & 77 & 790 & ns \\
\hline LM (cm) & 4,1 & 3,7 & 3,7 & 3,4 & 3,3 & ns \\
\hline
\end{tabular}

Nota: ${ }^{1}=$ corregido por lana inicial; $n s=$ no significativo $(P>0,10) ;$ medias con diferentes letras entre columnas son significativamente diferentes; DF = diámetro de la fibra; $L M=$ largo de mecha; Rendimiento (\%) = rendimiento al lavado. 
Sin embargo, Guarino y Pittaluga (1999) encontraron mayores pesos de vellón y menores rendimientos para los tratamientos suplementados. Por otra parte, Franco y Gutiérrez (2009) encontraron mayores crecimientos de lana limpia y diámetros más gruesos en los tratamientos suplementados.

\subsubsection{Comentarios y conclusiones}

Desde el momento en que la decisión de suplementar está muy asociada a los beneficios económicos que esperan obtenerse (Orcasberro, 1997) y que el objetivo de la misma es alcanzar determinados objetivos productivos (Pigurina, 1997), hay que poner en consideración múltiples factores a la hora de optar por suplementar y en qué proporción hacerlo en un sistema de engorde de corderos pesados. En esta experiencia en concreto, desde el punto de vista estrictamente productivo, la suplementación sobre una pradera dominada por trébol blanco durante el período estival significó aumentos significativos de la producción animal, lo que no ocurrió con los tratamientos con exclusión del forraje.

Dentro de los factores a considerar en una estrategia de suplementación creciente, deben mencionarse los relativos al animal, a la pastura, al suplemento y a la interacción de todos estos factores (Pigurina, 1997). Los efectos del suplemento sobre el forraje y el tipo de interacción resultante también depende de otros factores, a saber: estructura del tapiz, disponibilidad y calidad del forraje, tipo de suplemento, nivel de suplementación, procesamiento del suplemento, procesamiento del forraje, frecuencia de alimentación, fotoperíodo, características del animal (especie y categoría) (Mieres, 1997). Lo mencionado por estos dos autores explica por qué los diversos resultados experimentales en producción animal y pasturas no siempre son coincidentes entre sí, a pesar de contar con muchas similitudes entre niveles de suplementación y/o tipo de suelo y/o condiciones climáticas durante el período de evaluación.

En este experimento se observó como una pradera sobre Basalto, dominada principalmente por trébol blanco en su último ve- rano, puede ser utilizada para el engorde o recría de ovinos obteniéndose muy buenas ganancias. En el caso de la recría, las ganancias obtenidas permitirían llegar a la primera encarnerada con pesos muy superiores a los requeridos (Silveira, 2009).

El tratamiento en confinamiento merece consideraciones a parte de los tratamientos de base pastoril. Para obtener buenos resultados productivos en los sistemas de confinamiento, es necesario realizar un adecuado proceso de acostumbramiento de los animales al consumo de suplemento. Si esto no se cumple, pueden lograrse objetivos productivos por debajo de lo esperado y por lo tanto no se volvería rentable la actividad.

En esta experiencia se detectaron problemas de acidosis durante el período de acostumbramiento y esto resultó en menores ganancias de peso desde el inicio del experimento. La diferencia en los pesos generada durante el período de acostumbramiento se mantuvo hasta la finalización del ensayo. Las dificultades encontradas en dicho período se presentan comúnmente cuando los corderos inician el consumo de dietas basadas en granos de cereales debido a un brusco consumo de excesivas cantidades de éstos (Seymour, 2000, citado por Silveira, 2009 e Easton, 1994).

Easton (1994) recomienda introducir el grano en la dieta en forma gradual para prevenir desórdenes digestivos. Los animales de este ensayo se encontraban en sistemas de alimentación pastoriles. A esto se le suma lo mencionado por Bell et al. (2003) en referencia a que aún tomando todos los recaudos, un $5-10 \%$ de los corderos no se adaptan al sistema de confinamiento.

\section{RECRÍA Y ENGORDE DE CORDEROS SOBRE VERDEOS ESTIVALES}

Con el objetivo de evaluar opciones forrajeras estivales de alto rendimiento y ciclo corto se realizaron evaluaciones en dos cultivos anuales estivales: moha y sudangrás, ambos en el mismo verano (años 2000-2001). En ambos casos se evaluaron dos factores en pastoreo 
directo: suplementación con expeller de girasol molido y distintas intensidades de pastoreo (cargas).

\subsection{Evaluación de la suplementación y carga sobre cultivo de moha}

En este trabajo se evaluó el efecto de la carga y suplementación sobre la performance animal sobre un cultivo de moha (Setaria italica cv. INTA Carapé). El cultivo se sembró en noviembre a $30 \mathrm{~kg} / \mathrm{ha}$ de semilla y fue fertilizado con $100 \mathrm{~kg} / \mathrm{ha}$ de N:P:K (21:40:0). Se realizó un pastoreo directo y alterno (cada 7 días), con corderos de la raza Corriedale.

\subsubsection{Resultados en pasturas}

El Cuadro 19 presenta la disponibilidad y calidad del forraje ofrecido y remanente durante el período de evaluación.

Ninguno de los factores evaluados afectaron la disponibilidad o calidad del forraje disponible o rechazado, salvo por la altura del remanente, que resultó algo mayor en las cargas más bajas.

Devoto y González (1999) reportaron producciones totales de $6152 \mathrm{kgMS} / \mathrm{ha}$ en un cultivo de moha con un corte al macollaje, valores superiores a los encontrados aquí. Las producciones obtenidas en este ensayo se comprenden dentro del rango reportado por Bruno et al. (1983), citados por Carámbula (2007) las que oscilan entre 811 y 7862 $\mathrm{kgMS} / \mathrm{ha}$, desde etapas de macollaje del cultivo hasta estadio correspondiente a grano duro (máximo 98-81 días de ciclo).
Las características morfológicas de las plantas de moha, con sistemas radiculares poco profundos, porte erecto y poco macolladoras, limitan a esta especie en su capacidad de uso para pastoreo directo, ya que presenta una recuperación muy lenta luego de cada defoliación. A pesar de esto, se trata de una especie muy palatable (Carámbula, 2007 y Terra et al., 2000).

Oelke (1990), Croissant y Shanahan (1992) y PROVA (1997), citados por Terra et al. (2000) y Carámbula (2007) sostienen que la moha presenta la misma calidad que el sudangrás o el sorgo forrajero. En términos de contenido de PC (\%) éste sería de 7.7$14,1 \%$. Por lo tanto, se puede destacar que este cultivo está por debajo de la calidad reportada, salvo por el forraje ofrecido para las cargas más elevadas, que de cualquier manera se ubican cerca del límite inferior.

En general, no se observaron diferencias significativas $(P<0,05)$ o fueron de escasa magnitud para la interacción entre los diferentes factores evaluados a nivel de pasturas, por lo tanto, no se presentan o desarrollan los resultados inherentes a éstos.

\subsubsection{Resultados en producción animal}

El Cuadro 20 presenta la performance animal en producción de carne, según el factor evaluado.

Tanto la carga como la suplementación presentaron efectos sustanciales sobre las ganancias obtenidas, a favor de las cargas más bajas y de la suplementación. No se hallaron interacciones entre los factores eva-

Cuadro 19. Disponibilidad y calidad del forraje ofrecido y remanente promedio.

\begin{tabular}{|c|c|c|c|c|c|c|c|c|c|c|c|c|c|c|}
\hline & \multicolumn{7}{|c|}{ Ofrecido } & \multicolumn{7}{|c|}{ Remanente } \\
\hline & 36,1 & 54,2 & 72,3 & $\mathbf{P}$ & $0 \% \mathrm{PV}$ & $1 \% \mathrm{PV}$ & $\mathbf{P}$ & 36,1 & 54,2 & 72,3 & $\mathbf{P}$ & 0\%PV1 & $\%$ PV & $\mathbf{P}$ \\
\hline kgMS/ha & 2337 & 2086 & 1976 & ns & 1875 & 2391 & ns & 1743 & 1669 & 1144 & ns & 1292 & 1745 & ns \\
\hline Altura (cm) & 39 & 39 & 37 & ns & 35 & 41 & ns & $29 \mathrm{a}$ & $27 a b$ & $19 \mathrm{~b}$ & * & 22 & 28 & ns \\
\hline FDA (\%) & 40,6 & 39.9 & 40,0 & ns & 39,7 & 40,7 & ns & 41,8 & 43,3 & 45,1 & ns & 43,3 & 43,5 & ns \\
\hline
\end{tabular}

Nota: * $=\mathrm{P}<0,05 ; \mathrm{ns}=$ no significativo $(\mathrm{P}>0,05) ; 0 \% \mathrm{PV}=$ sin suplementación; $1 \% \mathrm{PV}=$ suplementación al $1 \%$ del PV; kgMS/ha = kilos de materia seca/hectárea; RS\% = porcentaje de restos secos; PC \% = porcentaje de proteína cruda; FDA = porcentaje de fibra detergente ácido. 
Cuadro 20. Performance animal en producción de carne, según factor evaluado.

\begin{tabular}{|c|c|c|c|c|c|c|c|c|}
\hline \multirow{2}{*}{ Producción de carne } & \multicolumn{4}{|c|}{ Carga (C) (corderos/ha) } & \multicolumn{3}{|c|}{ Suplemento (S)(\%PV) } & \multirow{2}{*}{$\mathrm{C} * \mathrm{~S}$} \\
\hline & 36,1 & 54,2 & 72,3 & $\mathbf{P}$ & 0\%PV & $1 \% \mathrm{PV}$ & $\mathbf{P}$ & \\
\hline PV LL inicial (kg) & 21,3 & 21,4 & 21,4 & ns & 21,3 & 21,4 & ns & ns \\
\hline PV LL final (kg) & 30,1 a & $27,6 \mathrm{~b}$ & $26,4 \mathrm{~b}$ & ** & $26,9 \mathrm{~b}$ & $29,1 \mathrm{a}$ & * & ns \\
\hline CC final (unidades) & 3,7 & 3,6 & 3,5 & ns & $3,4 b$ & $3,8 \mathrm{a}$ & * & ns \\
\hline GMD (g/an/día) & $103 \mathrm{a}$ & $75 \mathrm{~b}$ & $58 \mathrm{c}$ & $\star \star$ & $65 \mathrm{~b}$ & 93 a & ** & * \\
\hline
\end{tabular}

Nota: * $=\mathrm{P}<0,05 ;{ }^{*}=\mathrm{P}<0,01 ; \mathrm{ns}=$ no significativo $(\mathrm{P}>0,10)$; medias con diferentes letras entre columnas son significativamente diferentes; ${ }^{*}=\mathrm{P}<0,05 ;{ }^{* *}=\mathrm{P}<0,01 ; \mathrm{PVLL}=$ peso vivo lleno; $\mathrm{CC}=$ condición corporal; $\mathrm{GMD}$ = ganancia media diaria; $\mathrm{C}{ }^{\star} \mathrm{S}=$ interacción entre carga y suplemento.

luados. Es de destacar que con ninguno de los tratamientos se obtuvieron pesos de faena de acuerdo a los requerimientos del Operativo de Corderos Pesados del Uruguay al final del periodo de utilización del verdeo.

Utilizando sudangrás, Ayala et al. (2013) publicaron ganancias de corderos en un rango de 103-132 g/an/día, lo cual está por encima de los valores obtenidos aquí. Por otro lado, Magallanes y Paiva (2007), Ayala y Bermúdez (2005) y Parma (1997), citado por Ayala et al. (2013) también con sudangrás obtuvieron ganancias en promedio debajo de

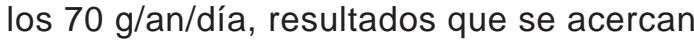
más a lo obtenido aquí con las dos cargas más elevadas sobre cultivo de moha.

De cualquier forma, dada la poca adaptabilidad del cultivo al pastoreo directo (Carámbula, 2007), es de destacarse el hecho de registrarse ganancias similares a al-

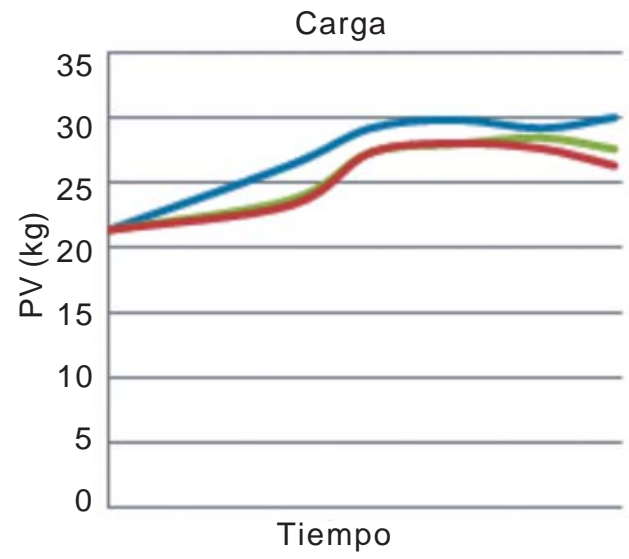

-31,6 cord./ha $-72,3$ cord./ha $-54,2$ cord./ha gunas obtenidas sobre sudangrás, especie que sí se adapta muy bien al pastoreo.

La Figura 18 muestra el efecto de cada factor evaluado sobre la evolución del PV.

La carga más baja y la suplementación al 1\%PV se destacan en su mejor evolución del PV en función del tiempo. Las cargas media y alta no tuvieron mucha diferencia entre sí en general, si bien al final del período de estudio los PV de la carga alta finalizaron por debajo de los de carga media.

\subsubsection{Comentarios y conclusiones}

La inclusión de expeler de girasol (PC\% $=31,6)$ en la dieta al 1\% PV determinó un incremento significativo en las ganancias medias diarias, explicado por un aumento en el valor nutritivo de la dieta total. Asimismo y a pesar de no registrarse diferencias signifi-

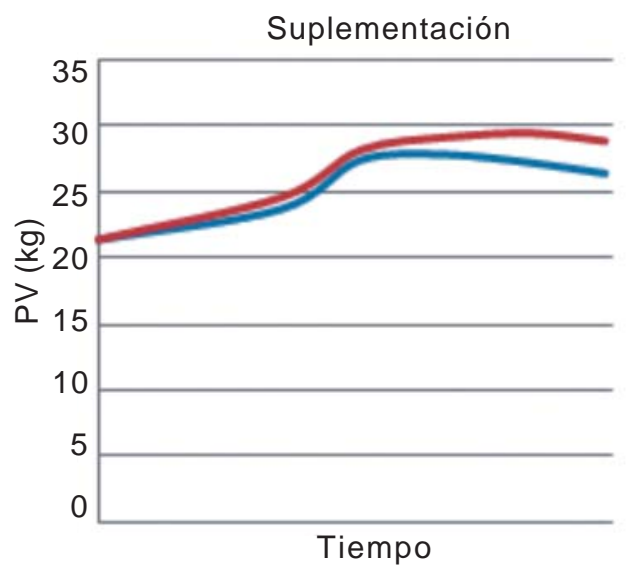

$-0 \% \mathrm{PV}-1 \% \mathrm{PV}$

Figura 18. Evolución del PV en función del tiempo, según factor evaluado.

Nota: $\operatorname{cord} /$ ha $=$ corderos/ha; $0 \% \mathrm{PV}=$ sin suplementación; $1 \% \mathrm{PV}=$ suplementación al 1\% del PV. 
cativas, puede observarse una tendencia a un efecto de sustitución de suplemento por forraje, ya que en el tratamiento suplementado los valores de disponibilidad de forraje remanente tienden a ser mayores.

Se observa en la evolución de peso vivo que al avanzar el estado fisiológico de esta especie forrajera y al bajar la calidad nutritiva de la misma, el peso mejora con la suplementación mejorando a su vez las ganancias de peso vivo, demostrando la conveniencia de esta práctica. Según lo reportado por Vaz Martins e Ibáñez (2003) el porcentaje de proteína de la moha disminuye a partir de los 40 días de sembrada (14\%) para situarse en torno al $7 \%$ a los 70 días: este momento coincide con el momento en que los animales de todos los tratamientos dejan de ganar peso.

A pesar de que las ganancias de peso obtenidas son positivas para mejorar la producción de corderos, las ganancias obtenidas durante el período considerado de 83 días de pastoreo de la moha y con pesos iniciales del entorno de $21 \mathrm{kgPV}$, no fueron suficientes para alcanzar pesos mínimos para faena como corderos pesados según los requerimientos del mercado. Igualmente, se destacan las ganancias obtenidas en los primeros 45 días del ensayo (mediados de diciembre a fines de enero) las cuales se encontraron en torno a los 140-180 g/an/d dependiendo de la carga y la suplementación. Es por ello, que esta opción aparece interesante para mejorar la recría en «bancos verde» que permiten mantener altas cargas por un período de aproximadamente 2 a 3 meses, con un uso estratégico de la suplementación particularmente después de dos meses de utilización este cultivo cuando el mismo pierde valor nutritivo.

\subsection{Evaluación de la suplementación y carga sobre cultivo de sudangrás}

Al igual que en el ensayo anterior utilizando moha, en este trabajo se evaluó el efecto de la suplementación y la carga sobre un cultivo de sudangrás (Sorghum sudanense cv. Comiray). El mismo fue sembrado a una den- sidad de $25 \mathrm{~kg} / \mathrm{ha}$ de semilla. Se realizó pastoreo directo y alterno (cada 7 días), con corderos de la raza Corriedale.

\subsubsection{Resultados en pasturas}

El Cuadro 21 presenta la disponibilidad y calidad del forraje ofrecido y remanente durante el período de evaluación.

El sistema de pastoreo no afectó los parámetros medidos en la pastura al igual que en la experiencia con moha, mientras que la carga sí afectó significativamente varios de los parámetros, especialmente en el forraje ofrecido. Las menores cargas permitieron una mayor disponibilidad y altura de forraje ofrecido, en comparación con la carga mayor. Sin embargo, esto derivó en un peor valor nutritivo del forraje para los tratamientos con cargas menores, reflejado en los valores significativamente menores $(P<0,01)$ de proteína y restos secos.

Según Carámbula (2007), bajo condiciones ambientales favorables los cultivos del género Sorghum sp. pueden rendir entre 13000 y $20000 \mathrm{kgMS} / \mathrm{ha}$ con pastoreo directo. Específicamente, el promedio mencionado para crecimiento de sudangrás por dicho autor fue de $9000 \mathrm{kgMS} / \mathrm{ha}$. Según Vaz Martins (2000), citado por Carámbula (2007), el manejo del cultivo es el elemento más importante a la hora de la utilización del sorgo para pastoreo directo. El mismo autor sostiene que dada la alta velocidad de crecimiento, muchas veces es difícil utilizar rápidamente el forraje y evitar que las plantas alcancen una altura mayor a la recomendable para la producción animal e incluso entren en la fase reproductiva con los efectos negativos que ello tiene para promover el crecimiento animal. Un buen manejo comprende altas dotaciones en superficies limitadas con ganancias moderadas, de forma tal que los animales utilicen el forraje disponible en el menor tiempo posible.

Carámbula (2007) sostiene que una altura de plantas de $80 \mathrm{~cm}$ pre pastoreo rinde más forraje que $40 \circ 60 \mathrm{~cm}$. Las alturas de forraje ofrecido de esta experiencia fueron iguales o inferiores a $51 \mathrm{~cm}$, lo cual está por debajo de los valores que maneja el mencionado investigador. Este mismo autor recomienda ingresar 
Cuadro 21. Disponibilidad y calidad del forraje ofrecido y remanente promedio.

\begin{tabular}{|c|c|c|c|c|c|c|c|}
\hline & \multicolumn{4}{|c|}{ Carga (C) (corderos/ha) } & \multicolumn{3}{|c|}{ Suplementación (S) (\%PV) } \\
\hline & 37,5 & 54,2 & 70,8 & $\mathbf{P}$ & 0\%PV & $1 \% \mathrm{PV}$ & $\mathbf{P}$ \\
\hline \multicolumn{8}{|c|}{ Ofrecido } \\
\hline kgMS/ha & 2959 a & 2495 a & $1607 \mathrm{~b}$ & ** & 2338 & 2369 & ns \\
\hline Altura (cm) & $51 \mathrm{a}$ & $46 \mathrm{a}$ & $29 \mathrm{~b}$ & ** & 43 & 41 & ns \\
\hline RS (\%) & $81 \mathrm{a}$ & $80 \mathrm{a}$ & $64 \mathrm{~b}$ & $\star \star$ & 78 & 72 & ns \\
\hline $\mathrm{PC}(\%)$ & $7.9 \mathrm{~b}$ & $7.1 \mathrm{~b}$ & $10.1 \mathrm{a}$ & *夫 & 8.0 & 9.3 & ns \\
\hline FDA (\%) & 42.2 & 43.1 & 42.0 & ns & 43.1 & 41.8 & ns \\
\hline \multicolumn{8}{|c|}{ Remanente } \\
\hline kgMS/ha & 3097 a & 1598 b & 1043 b & ** & 2190 & 1883 & ns \\
\hline Altura (cm) & $44 \mathrm{a}$ & $27 b$ & $18 \mathrm{~b}$ & ** & 29 & 30 & ns \\
\hline RS (\%) & 81 & 73 & 75 & ns & 78 & 75 & ns \\
\hline $\mathrm{PC}(\%)$ & 6.6 & 6.9 & 6.8 & ns & 5.7 & 7.8 & * \\
\hline FDA (\%) & 43.3 & 47.1 & 51.5 & ns & 47.9 & 46.7 & ns \\
\hline
\end{tabular}

Nota: ${ }^{*}=\mathrm{P}<0,05 ;{ }^{*}=\mathrm{P}<0,01 ; \mathrm{ns}=$ no significativo $(\mathrm{P}>0,10)$; medias con diferentes letras entre columnas son significativamente diferentes; ${ }^{*}=\mathrm{P}<0,05 ; * \star=\mathrm{P}<0,01 ; 0 \% \mathrm{PV}=$ sin suplementación; $1 \% \mathrm{PV}=$ suplementación al $1 \%$ del PV;kgMS/ha = kilos de materia seca/hectárea; RS $\%=$ porcentaje de restos secos; $\mathrm{PC} \%=$ porcentaje de proteína cruda; FDA = porcentaje de fibra detergente ácido.

a pastorear el cultivo con alturas no mayores a los $45 \mathrm{~cm}$, lo cual se cumple en todos los tratamientos, salvo por el de menor carga.

En cuanto al contenido de PC\%, Carámbula (2007) reporta valores entre 14,1 y $7,7 \%$ para el cultivo de sudangrás. El forraje ofrecido en esta instancia en términos generales, se encuentra dentro del rango mencionado.

\subsubsection{Resultados en producción animal}

El Cuadro 22 presenta la performance animal en producción de carne, según el factor evaluado.
Al igual que en el ensayo sobre moha, tanto la carga como la suplementación presentaron efectos importantes sobre las ganancias medias diarias y peso vivo final, a favor de las cargas menores y la utilización de suplementación. No se presentaron interacciones entre los factores evaluados.

Al comparar estos resultados con experiencias anteriores de engorde de corderos sobre sudangrás, en términos generales se puede decir que las ganancias obtenidas en esta oportunidad son menores que en los trabajos de Parma (1997) citado por Ayala et al. (2013) y Ayala y Bermúdez (2005), Magallanes y Paiva (2007) y Ayala et al.

Cuadro 22. Performance animal en producción de carne, según factor evaluado.

\begin{tabular}{|c|c|c|c|c|c|c|c|c|}
\hline \multirow{2}{*}{ Producción de carne } & \multicolumn{4}{|c|}{ Carga (C) (corderos/ha) } & \multicolumn{3}{|c|}{ Suplemento (S) (\%PV) } & \multirow{2}{*}{$C * S$} \\
\hline & 37,5 & 54,2 & 70,8 & $\mathbf{P}$ & 0\%PV & $1 \% \mathrm{PV}$ & $\mathbf{P}$ & \\
\hline PVLL inicial (kg) & 21,4 & 21,5 & 21,2 & ns & 21,4 & 21,3 & ns & ns \\
\hline PVLL final (kg) & $28,6 \mathrm{a}$ & $26,1 \mathrm{~b}$ & $22,9 \mathrm{a}$ & $\star \star$ & $23,5 b$ & $28,2 \mathrm{a}$ & ** & ns \\
\hline CC final (unidades) & $3,6 \mathrm{a}$ & $3,3 \mathrm{~b}$ & $2,8 \mathrm{c}$ & ** & $3,0 \mathrm{~b}$ & $3,5 \mathrm{a}$ & ** & ns \\
\hline GMD (g/an/día) & $46 \mathrm{a}$ & $-6 b$ & $-20 b$ & ** & $-30 b$ & $43 \mathrm{a}$ & ** & ns \\
\hline
\end{tabular}

Nota: ${ }^{*}=\mathrm{P}<0,05$; ${ }^{*}=\mathrm{P}<0,01 ; \mathrm{ns}=$ no significativo $(\mathrm{P}>0,10)$; medias con diferentes letras entre columnas son significativamente diferentes; ${ }^{*}=\mathrm{P}<0,05 ;{ }^{*}=\mathrm{P}<0,01 ; \mathrm{PVLL}=$ peso vivo lleno; $\mathrm{CC}=$ condición corporal; $\mathrm{GMD}=$ ganancia media diaria; $\mathrm{C} * \mathrm{~S}=$ interacción carga por suplemento. 
(2013). No obstante, las cargas utilizadas en esta oportunidad pudieron ser excesivas en comparación con los mencionados antecedentes y esa podría ser la causa de las diferencias encontradas entre trabajos.

Por otra parte, trabajos similares pero sobre sorgo forrajero llevados adelante por Piaggio (2013) y Montossi et al. (2004), citados por Ayala et al. (2013) reportan ganancias moderadas, en un amplio rango que va de 20 a 149 g/an/día. En comparación, esta experiencia solamente registró ganancias bajas con carga baja o con suplementación al $1 \% \mathrm{PV}$, mientras que los demás valores son todos negativos.

En ninguno de los tratamientos se obtuvieron ganancias que permitieran alcanzar pesos de faena al final del período de acuerdo a los requisitos de corderos pesados.

La Figura 19 muestra el efecto de cada factor evaluado sobre la evolución del PV.

Al igual que lo que sucedió con la moha, la carga menor generó una mejor evolución de PV en el tiempo. La carga mayor directamente provocó una reducción en la ganancia de peso a la mitad del período evaluado. Por otra parte, la presencia de suplementación resultó en una evolución del PV mejor que en el tratamiento sin suplementación, que de hecho va disminuyendo consistentemente

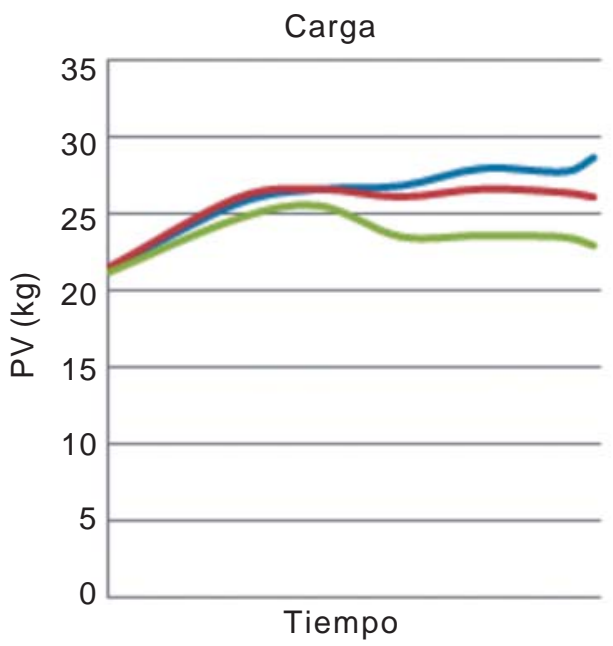

-37,5 cord./ha $-54,2$ cord./ha $-70,8$ cord./ha luego de transcurrido aproximadamente un tercio del período de evaluación.

\subsubsection{Comentarios y conclusiones}

Las ganancias obtenidas sobre sudangrás en los ensayos recién descriptos (-30 a 46 g/an/día) son, en general inferiores a las reportadas en igual base forrajera por Parma (1997), citado por Ayala et al. (2013) (34 g/an/día a 40 corderos/ha); Ayala y Bermúdez (2005), citados por Ayala et al. (2013) (63 g/an/día a 88 corderos/ha); Ayala et al. (2013) (117 g/an/día a 48 corderos/ha); Magallanes y Paiva (2007) citados por Ayala et al. (2013) (67 g/an/día a 41 corderos/ha).

En la carga más alta y en los lotes sin suplementación se obtuvieron pérdidas de peso. Estas pérdidas se pueden explicar por la baja calidad promedio del forraje para la categoría, no cubriendo los requerimientos de la misma. Al incluir el expeller de girasol se registró un incremento significativo de la ganancia ya que aumenta el valor nutritivo de la dieta.

Los resultados obtenidos en este trabajo mostraron que el manejo del pastoreo directo del sudangrás a altas cargas y/o sin suplementación llevó a pérdidas de peso vivo.

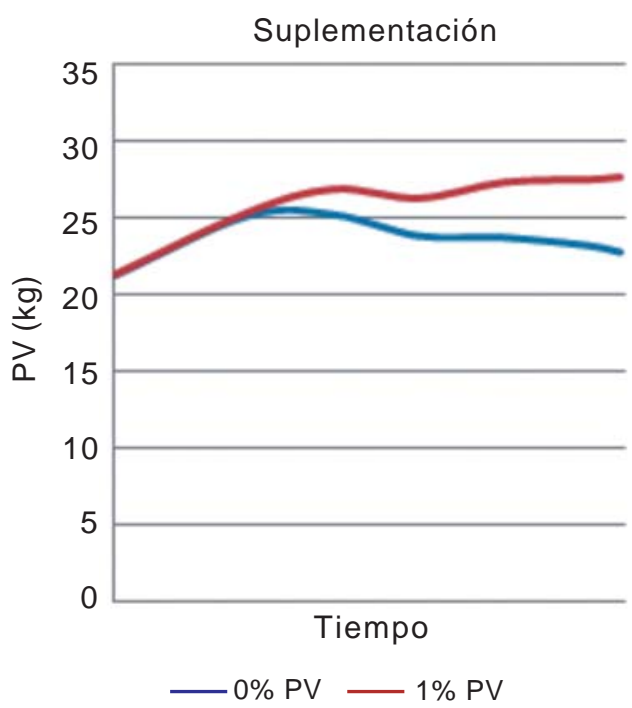

Figura 19. Evolución del PV en función del tiempo, según factor evaluado.

Nota: $\operatorname{cord} /$ ha $=$ corderos/ha; $0 \% \mathrm{PV}=$ sin suplementación; $1 \% \mathrm{PV}=$ suplementación al 1\% del PV. 
El período en que los animales se mantuvieron con ganancias sostenidas de peso vivo fue muy corto -menos de 30 días- por lo que, para las condiciones evaluadas, el sudangrás no se presenta como una alternativa forrajera para engorde de corderos durante todo el período estival. Sin embargo, al igual que para la moha, el sudangrás puede considerarse como una opción válida para mejorar la recría en «bancos de verde» que permiten mantener altas cargas por un período de aproximadamente 2 a 3 meses, con un uso estratégico de la suplementación particularmente después de dos meses de utilización este cultivo cuando el mismo pierde valor nutritivo.

\subsection{Comentarios y conclusiones de verdeos anuales estivales}

Los efectos de los factores evaluados se comenzaron a notar más tempranamente sobre el cultivo sudangrás que sobre la moha. El efecto de la suplementación se comenzó a notar a los 28 días de iniciado el experimento sobre sudangrás, mientras que la carga lo hizo entre los 28 y 42 días. El sudangrás posee niveles iniciales de proteína cruda menores al 14\% (Carámbula, 1977), calidad que se pierde rápidamente en los primeros 40 a 60 días (Milford y Haydock, 1965, citados por Fassio et al., 2002).

La moha resultó ser una alternativa interesante a considerar para obtener ganancias adecuadas para colaborar en la recría mejorada de corderos en la región de $\mathrm{Ba}$ salto, pero la limitante podría estar en el corto período de pastoreo que la misma ofrece, que en este caso fue insuficiente, al menos para el engorde de corderos pesados. A pesar del mayor período de utilización en pastoreo, a las cargas consideradas y con suplementación, el sudangrás presentaría restricciones de relevancia para obtener ganancias por encima de 50 g/an/día.

Con estas dos bases forrajeras no se lograron los objetivos productivos de engorde de corderos pesados. Estos resultados estuvieron principalmente asociados al bajo contenido de proteína, particularmente cuan- do se alcanzan los 60 - 70 días de sembrado el cultivo, donde la suplementación solamente permitió mantener el peso de los animales. Estas podrían ser alternativas para su utilización por un periodo corto de tiempo (primeros 30 días) para obtener ganancias moderadas a altas, para luego ser utilizadas como «bancos de verde» con altas cargas y con suplementación para mejorar la recría de corderos así como la mejora de la carga de todo el sistema productivo. Posteriormente, estos corderos pueden finalizar su engorde en pasturas especializadas para este objetivo en el otoño (ej. praderas permanentes con festucas y verdeos anuales invernales).

\section{RESUMEN}

En el Cuadro 23 se presenta la información resumida de las ganancias individuales (g/an/día), productividad por unidad de superficie (kgPV/ha) y carga animal (corderos/ha) para las diferentes base forrajeras utilizadas en estas experiencias en la Unidad Experimental» «Glencoe» de INIA Tacuarembó.

El Cuadro 23 muestra cómo los niveles de ganancia diaria y productividad por unidad de superficie están, en general, por encima de los logrados sobre campo natural en un contexto de manejo de cargas animales sustancialmente mayores con respecto a esta base forrajera tradicional mencionada.

Teniendo en cuenta las mejores opciones tecnológicas evaluadas para la producción y terminación de corderos pesados sobre pasturas dominadas por leguminosas, en condiciones de secano se obtuvieron ganancias promedio en el rango de 80 a 130 g/an/día y productividades por hectárea de 100 a $120 \mathrm{~kg}$ de peso vivo en períodos de 100 a 120 días. La suplementación en cargas más sostenibles, permitió la mejora de la productividad individual o por hectárea. Para el objetivo de mejora de la recría es posible explorar otras opciones forrajeras con o sin suplementación, con son los casos de los cultivos anuales estivales evaluados. 
Cuadro 23. Niveles de productividad animal logrados en sistemas de recría/engorde de corderos pesados durante el período estival sobre distintas opciones forrajeras en la región de Basalto.

\begin{tabular}{|c|c|c|c|c|c|}
\hline Base Forrajera & $\begin{array}{l}\text { Carga } \\
\text { (an/ha) }\end{array}$ & $\begin{array}{c}\text { Período } \\
\text { (meses y días) }\end{array}$ & $\begin{array}{c}\text { GMD } \\
(\text { g/an/d) }\end{array}$ & $\begin{array}{c}\text { Producción } \\
\text { (kgPV/ha) }\end{array}$ & Observaciones \\
\hline \multicolumn{6}{|l|}{ LOTUS DRACO } \\
\hline $\begin{array}{l}\text { (Mejoramiento de } \\
\text { Campo con Lotus } \\
\text { corniculatus cv. } \\
\text { INIA Draco) }\end{array}$ & $9-18$ & $\begin{array}{l}\text { Dic-May } \\
\text { (133 días) }\end{array}$ & $84-129$ & $117-190$ & $\begin{array}{l}100 \% \text { de los corderos termina- } \\
\text { dos }^{*} \text { a una carga de } 9 \text { corderos/ha }\end{array}$ \\
\hline $\begin{array}{l}\text { TREBOL ROJO + } \\
\text { ACHICORIA }\end{array}$ & & & & & \\
\hline $\begin{array}{l}\text { (Trifolium pratense } \\
\text { cv. LE } 116 \text { y } \\
\text { Cichorium intybus } \\
\text { cv. INIA Lacerta) }\end{array}$ & $10-32$ & $\begin{array}{c}\text { Ene-May } \\
(97-124 \text { días })\end{array}$ & $54-126$ & $122-190$ & $\begin{array}{l}\text { La mayor proporción de corderos } \\
\text { terminados* se logró con } 10 \\
\text { cord./ha y es posible lograrlo con } \\
16 \text { corderos/ha pero estos deben } \\
\text { estar suplementados }\end{array}$ \\
\hline \multicolumn{6}{|l|}{$\begin{array}{l}\text { TREBOL ROJO } \\
\text { BAJO RIEGO }\end{array}$} \\
\hline $\begin{array}{l}\text { (Trifolium pratense } \\
\text { cV. LE 116) }\end{array}$ & 25 & $\begin{array}{l}\text { Feb-Jun } \\
\text { (102 días) }\end{array}$ & $101-136$ & $258-347$ & $\begin{array}{l}100 \% \text { de los corderos terminados* } \\
\text { con o sin suplementación }\end{array}$ \\
\hline \multicolumn{6}{|l|}{$\begin{array}{l}\text { TREBOL BLANCO } \\
\text { +LOTUS } \\
\text { CORNICULATUS }\end{array}$} \\
\hline $\begin{array}{l}\text { (Pradera } \\
\text { convencional de } 4^{\text {to }} \\
\text { año con Trifolium } \\
\text { repens cv. Zapicán, } \\
\text { Lotus corniculatus } \\
\text { cv. San Gabriel; } \\
\text { Lolium multiflorum } \\
\text { espontáneo) }\end{array}$ & 6,3 & $\begin{array}{l}\text { Oct-Feb } \\
\text { (103 días) }\end{array}$ & $152-184$ & $98-120$ & $\begin{array}{l}100 \% \text { de los corderos terminados } \\
\text { con o sin suplementación }\end{array}$ \\
\hline MOHA & & & & & \\
\hline $\begin{array}{l}\text { (Setaria italica } \\
\text { cv. INTA Carapé) }\end{array}$ & $36-72$ & $\begin{array}{l}\text { Dic-Mar } \\
\text { (82 días) }\end{array}$ & $58-103$ & $304-342$ & $\begin{array}{l}\text { No se logró terminar* los corderos. } \\
\text { La suplementación después de } 40- \\
60 \text { días de comienzo del pastoreo } \\
\text { mejora sustancialmente la producti- } \\
\text { vidad animal. }\end{array}$ \\
\hline SUDANGRAS & & & & & \\
\hline $\begin{array}{l}\text { (Sorghum sudanense } \\
\text { cv. Comiray) }\end{array}$ & $37-71$ & $\begin{array}{l}\text { Dic-Mar } \\
\text { (82 días) }\end{array}$ & $(-30)-46$ & $140^{* *}$ & $\begin{array}{l}\text { No se logró terminar* los corderos. } \\
\text { Cargas > a 50/ha fueron excesivas } \\
\text { inclusive para una adecuada recría. } \\
\text { La suplementación después de } 40- \\
60 \text { días de comienzo del pastoreo } \\
\text { mejora sustancialmente la producti } \\
\text { vidad animal particularmente en las } \\
\text { cargas más sustentables (37 y } 54 \\
\text { corderos/ha) }\end{array}$ \\
\hline
\end{tabular}

Nota: an/ha = animales/ha; GMD = rango de ganancias medias diarias; Prod. = producción de carne en el período considerado; * = terminación según requisitos del Operativo de Corderos Pesados; ${ }^{*}=$ no se consideran los valores negativos por uso excesivo de carga animal. 


\section{BIBLIOGRAFÍA}

AKIKI, G.; FRISCH, W.; REZK, M. 1992. Efectos de la frecuencia de cambio de pastoreo y la estrategia de alimentación sobre el comportamiento de capones. Tesis Ingeniero Agrónomo, Facultad de Agronomía, Universidad de la República, Uruguay. $80 \mathrm{p}$.

ALgORTA, H.; GARCÍA PINTOS, A.; SANGUINETTI, A. 1989. Evaluación de la producción de carne y lana de ovinos que tienen acceso a una pastura de sudangrás, achicoria y trébol rojo. Tesis Ingeniero Agrónomo, Facultad de Agronomía, Universidad de la República, Uruguay. $162 \mathrm{p}$.

AROCENA, C.; DIGHIERO, A. 1999. Evaluación de la producción y calidad de carne de corderos sobre una mezcla forrajera de avena y raigrás, bajo efectos de la carga animal, suplementación y sistema de pastoreo para la región de Basalto. Tesis Ingeniero Agrónomo, Facultad de Agronomía, Universidad de la República, Uruguay. $150 \mathrm{p}$.

AYALA, W.; BARRIOS, E.; MAGALLANES, J.; PAIVA, M. 2013. Utilización de verdeos de verano en la alimentación de corderos. En: Seminario de Actualización Técnica Producción de Carne Ovina de Calidad. INIA Treinta y Tres. p 63-68. (Serie Actividades de Difusión; 719).

AYALA, W.; BERMÚDEZ, R. 2005. Alternativas de alimentación en la recría de corderos durante el verano. En: Jornada anual de producción animal - Resultados experimentales. INIA. pp. 33-37.

AZZARINI, M.; GAGGERO, C.; CARDELLINO, R. 2000. Efecto de la dotación sobre la producción de carne con corderos pesados tipo «SUL» en pasturas sembradas. Producción ovina, 13: 69-82.

AZZARINI, M.; GAGGERO, C.; CASTELLS, D.; CARDELLINO, R. 2001. Efecto de la castración, de la criptorquídea inducida y de la dotación, sobre el crecimiento y la producción de carne de corderos pesador tipo «SUL» en pasturas sembradas. Producción ovina, 14: 25-34.

BEATTIE, A.; THOMPSON, R. 1989. Controlled grazing management for sheep. Tasmanian Department of Agriculture. 50 p.
BELL, A.; SHANDS, C.; HEGARTY, R.; DUDDY, G. 2003. Feedlotting lambs. New Zealand: NZW Agriculture. 12 p.

BIRRELL, H. 1989. The influence of pasture and animal factors on the consumpltion of pasture by grazing sheep. Australian Journal of Agricultural Research., 40: 1261-1275.

BRITO, G.; PRINGLE, D. 2001. Conceptos generales de la ultrasonografía. En: Utilización de la ultrasonografía para la predicción de la composición y calidad de la canal. Montevideo: INIA. (Serie Actividades de Difusión; 261), p. 1-48.

BRITO, G.; SAN JULIÁN, R.; MONTOSSI, F.; CASTRO, L.; ROBAINA, R. 2002a. Caracterización de la terneza, pH, temperatura y color pos mortem en corderos pesados machos y hembras: Resultados preliminares. En: Montossi, F. (ed.) Investigación aplicada a la cadena agroindustrial cárnica. Avances obtenidos: Carne ovina de calidad (1998 - 2001). Montevideo: INIA. p. 131. 139. (Serie Técnica; 126).

BRITO, G.; SAN JULIÁN, R.; MONTOSSI, F.; DE BARBIERI, I.; DIGHIERO, A. RISSO, D.; CUADRO, R.; ZARZA, A. 2002b. Calidad de canal y carne de corderos pesados. En: Risso, D.; Montossi, F. (eds.) Mejoramientos de campo en la región de Cristalino: Fertilización y producción de carne de calidad y persistencia productiva, INIA Tacuarembó. Montevideo: INIA. p. 74-77. (Serie Técnica; 129).

CAMESASCA, M.; NOLLA, M; PREVE, F. 2002. Evaluación de la producción y calidad de carne y lana de corderos pesados sobre una pradera de segundo año de trébol blanco y lotus bajo los efectos de la carga animal, sexo, esquila, suplementación y sistema de pastoreo para la región de Basalto. Tesis Ingeniero Agrónomo. Montevideo, Uruguay. Facultad de Agronomía. 121p.

CARÁMBULA, M. 1977. Producción y manejo de pasturas sembradas. Montevideo: Hemisferio Sur. 464 p.

CARÁMBULA, M. 1991. Aspectos relevantes para la producción forrajera, INIA Treinta y Tres. Montevideo: INIA. 46 p. (Serie Técnica; 19). 
CARÁMBULA, M. 1996. Sistemas de pastoreo. En: Pasturas naturales mejoradas. Montevideo: Hemisferio Sur. p. 387-416

CARÁMBULA, M. 2007. Verdeos de verano. Montevideo: Hemisferio Sur. 226 p.

CASARETTO, A.; SCREMINI, P. 1997. Metodología de campo del Lombritest. En: Resistencia Antihelmíntica en Ovinos. Montevideo: SUL. p. 29-31.

CASTELLS, D.; PEREIRA, D. 1997. Metodología de laboratorio del Lombritest y conteo de huevos por gramo (HPG) Mac Master. En: Resistencia Antihelmíntica en Ovinos. Montevideo: SUL. p. 32-33.

CAZZULI, F.; CEDREZ, S.; ECHEVARRÍA, M. 2004. Engorde de corderos pesados sobre mejoramientos de campo con Trifolium repens cv, Zapicán y Lotus pedunculatus cv. Maku: efecto de la carga animal y el sistema de pastoreo. Tesis Ingeniero Agrónomo, Facultad de Agronomía, Universidad de la República, Uruguay. $157 \mathrm{p}$.

COOP. 1986. Matching feed supply and demand. En; Sheep Production, Volume 2: Feeding, Growth and Health. Mc Cutcheon, S.; Mc Donald, M.; Wickham, G. (Eds). Ray Richards Publisher in association with the New Zealand Institute of Agricultural Science. pp 137-162.

CORREA, D.; GONZÁLEZ, F.; PORCILE, V. 2000. Evaluación del efecto carga, frecuencia de pastoreo y suplementación energética sobra la producción y calidad de carne de cordero sobre una mezcla de triticale (Triticale secale) y raigrás (Lolium multiflorum) para la región de areniscas. Tesis Ingeniero Agrónomo, Facultad de Agronomía, Universidad de la República, Uruguay. 76 p.

DE BARBIERI, I.; RADO, F.; XALAMBRI, L. 2000. Efecto de la carga y de la suplementación sobre la producción y calidad de carne de corderos pesados pastoreando Avena byzantina en la región Este. Tesis Ingeniero Agrónomo. Montevideo, Uruguay. Facultad de Agronomía. 122 p.

DEVOTO, M.; GONZÁLEZ, G. 1999. Evaluación del comportamiento productivo de la moha de Hungría (Setaria italica (L.) P. Beauvois) en siembra directa. Tesis Ingeniero Agrónomo. Montevideo, Uruguay. Facultad de Agronomía. 72 p.
DIGHIERO, A.; MONTOSSI, F.; DE BARBIERI, I. 2013. Resultados y discusión de la información generada sobre pasturas y corderos a nivel de los predios comerciales. En: Montossi, F.; De Barbieri, I. (eds.). Tecnologías de engorde de corderos pesados sobre pasturas cultivadas en Uruguay. Montevideo: INIA. p. 27-158. (Serie Técnica; 206).

EASTON, W. 1994. Opportunity lotfeeding of lambs. Victoria, Australia, Swan Hill District Centre. Department of Agriculture. s.p.

FASSIO, A.; CAZZOLINO, D.; IBÁÑEZ, W.; FERNANDEZ, E. 2002. Sorgo: destino forrajero, INIA Treinta y Tres. Montevideo: INIA. 32 p. (Serie Técnica; 127).

FRANCO, R.; GUTIÉRREZ, D. 2009. Alternativas tecnológicas de producción de carne ovina de calidad durante el período estival en la región de Basalto: efecto de la carga animal, sexo y la suplementación con concentrados en corderos pastoreando una pastura de Lotus corniculatus cV. INIA Draco. Tesis Ingeniero Agrónomo. Montevideo, Uruguay. Facultad de Agronomía. 151 p.

GANZÁBAL, A. 1997a. Suplementación de ovinos en condiciones de pasturas mejoradas. En: Suplementación estratégica de la cría y recría ovina y vacuna, INIA Tacuarembó. Montevideo: INIA. p. III-1-4. (Serie Actividades de Difusión; 129).

GANZÁBAL, A. 1997b. Alimentación de ovinos con pasturas sembradas, INIA Las Brujas. Montevideo: INIA. 44 p. (Serie Técnica; 84).

GIORELLO, D.; JAURENA, M.; BOGGIANO, P.; PÉREZ GOMAR, E. 2013. Resultados experimentales de la zafra 2011-2012 publicados en el 2 do Seminario Internacional de Riego en Cultivos y Pasturas: respuesta al riego suplementario en pasturas y forrajes. En: Jornada de Divulgación: Riego en cultivos y pasturas sobre suelos de basalto, INIA Tacuarembó. Montevideo: INIA. p. 12-24. (Serie Actividades de Difusión; 706).

GORDON, L.; LASCANO, C. 1993. Foraging strategies of ruminant livestock on intensively managed grasslands: potential and constraints. En: 
INTERNATIONAL GRASSLAND CONGRESS $(170,1993)$ Proceedings. v. 1. p. 681-690.

GUARINO, L.; PITTALUGA, F. 1999. Efecto de la carga animal y la suplementación sobre la producción y calidad de carne y lana de corderos Corriedale sobre una mezcla de triticale y raigrás en la región de areniscas. Tesis Ingeniero Agronómo. Montevideo, Uruguay. Facultad de Agronomía. 128 p.

GUERRINA, A.; INVERNIZZI, A. 2002. Efecto de la carga animal en la recría de corderas sobre un mejoramiento de campo con Lotus pedunculatus cv. Maku. Tesis Ingeniero Agronómo. Montevideo, Uruguay. Facultad de Agronomía. 108 p.

HODGSON, J. 1990. Grazing management, science into practice. Longman Scientific \& Technical, Whittemore, C.; Simpson, K. (Ed). 203 pp.

HUGHES, T. 1983. Sward charachteristics influencing intake. En: Lamb growth. Technical Handbook. Familton, A. (Ed) Lincoln College: NZ. p. 65-78.

IGLESIAS, P.; RAMOS, N. 2003. Efecto de los taninos condensados y la carga sobre la producción y calidad de carne y lana de corderos pesados Corriedale en cuatro especies de leguminosas (Lotus corniculatus, Lotus pedunculatus, Lotus subbiflorus y Trifolium repens). Tesis Ingeniero Agronómo. Montevideo, Uruguay. Facultad de Agronomía. 50 p.

KIRTON A.; MORRIS, C. 1989. The effect of mature size, sex and breed on patterns of change during growth and development. En: Meat Production and Processing. New Zealand Society of Animal Production. Occasional publication, 11. Ed. Purchas, Butler-Hog and Davies.

KJENDHAL, J. 1984. Official Methods of Analysis, Washington: Association of Official Agricultural Chemists.LÓPEZ DA SILVA, A. 2001. Suplementación estival sobre pasturas [en línea]. Buenos Aires: Carta Agropecuaria sp. Consultado enero 2015. Disponible en http:// www.produccion-animal.com.ar/ informacion_tecnica/suplementacion/ 02suplementacion_estival.pdf
LUZARDO, S.; MONTOSSI, F.; DE BARBIERI, I.; DIGHIERO, A.; BRITO, G.; SAN JULIÁN, R. 2013. Asociaciones entre animales: calidad de canal y carne. En: Montossi, F.; De Barbieri, I. (eds.). Tecnologías de engorde de corderos pesados sobre pasturas cultivadas en Uruguay. Montevideo: INIA. p. 203-214 (Serie Técnica; 206).

MAGALLANES, J.; PAIVA, M. 2007. Efecto de la sombra y vellón en la performance de corderos en el verano. Tesis Ingeniero Agrónomo. Montevideo, Uruguay. Facultad de Agronomía. 81 p.

MIERES, J. 1997. Relaciones planta animal suplemento. En: Suplementación estratégica de la cría y recría ovina y vacuna, INIA Tacuarembó. Montevideo: INIA. 1-4. (Serie Actividades de Difusión; 129).

MONTOSSI, F. 1995. Comparative studies on the implications of condensed tannins in the evaluation of Holcus lanatus and Lolium spp.: swards for sheep performance. Ph.D Thesis, Massey (NZ), Massey University. 288 p.

MONTOSSI, F.; DE BARBIERI, I.; DIGHIERO, A.; SAN JULIÁN, R. 2013. Resultados productivos y económicos del proyecto de validación y de la investigación para el engorde de corderos sobre pasturas mejoradas en Uruguay; análisis, discusión y recomendaciones prácticas. En: Montossi, F.; De Barbieri, I. (eds.). Tecnologías de engorde de corderos pesados sobre pasturas cultivadas en Uruguay. Montevideo: INIA. p. 215-241. (Serie Técnica; 206).

MONTOSSI, F.; RISSO, D.; DE BARBIERI, I.; SAN JULIÁN, R.; CUADRO, R.; ZARZA, A.; DIGHIERO, A.; MEDEROS, A. 2002. Producción y calidad de canal y carne ovina: corderos pesados precoces. En: Risso, D.; Montossi, F. (eds). Mejoramientos de campo en la región de Cristalino: fertilización, producción de carne de calidad y persistencia productiva, INIA Tacuarembó. Montevideo: INIA. p. 78-87. (Serie Técnica; 129).

MONTOSSI, F.; RISSO, D.; PIGURINA, G. 1996. Consideraciones sobre utilización de 
pasturas. En: Risso, D.; Berretta, E.; Morón, A. (eds.). Producción y manejo de pasturas, INIA Tacuarembó. Montevideo: INIA. p. 93-105.

MONTOSSI, F.; PIGURINA, G.; SANTAMARINA, I.; BERRETTA, E. 2000. Selectividad animal y valor nutritivo de la dieta de ovinos y vacunos en sistemas ganaderos: teoría y práctica, INIA Tacuarembó. Montevideo: INIA. 84 p.

MOTT, G. 1960. Grazing pressure and the measurement of pasture production. En: INTERNATIONAL GRASSLAND CONGRESS (80., 1960). Proceedings. p. 606-611.

ORCASBERRO, R. 1997. Suplementación y performance de ovinos y vacunos alimentados con forraje. En: Carámbula, M.; Vaz Martins, D.; Indarte, E. (eds.). Pasturas y producción animal en áreas de ganadería extensiva. Montevideo: INIA. p. 225-238. (Serie Técnica; 13).

PEREIRA, J.; AZZARINI, M. 2003. Corderos «Super-pesados»: trabajo de validación de tecnología. Lana Noticias, 135: 4-9.

PÉREZ GOMAR, E.; MENÉNDEZ, P. BLANCO, E.; SILVEIRA, M. 2008. Riego en suelos de Basalto. En: Alternativas tecnológicas para la producción estival en la región de Basalto, INIA Tacuarembó. Unidad Experimental Glencoe. Montevideo: INIA. p. 21-23.

PIAGGIO, L. 2013. Suplementación de la recría y engorde de ovinos sobre campo natural. En: Seminario de Actualización Técnica: Producción de carne ovina de calidad, INIA Treinta y Tres. Montevideo: INIA. p 41-45. (Serie Actividades de Difusión; 719).

PIGURINA, G. 1997. Suplementación dentro de una estrategia de manejo en áreas de ganadería extensiva. En: Carámbula, M.; Vaz Martins, D.; Indarte, E. (eds.). Pasturas y producción animal en áreas de ganadería extensiva. Montevideo: INIA. p. 195-200. (Serie Técnica; 13).

RATTRAY, P.; THOMPSON, K.; HAWKER, H.; SUMNER, R. 1987. Pasture for sheep production. Nicol, A (ed). Livestock feeding on pasture. Hamilton: New Zealand Society of Animal Production. (Occasional publication; 10). p 89-103.
RUSSEL, A. 1995. Ultrasonography and body composition in sheep. En: Goddard, P. Veterinary ultrasonography. Macaulay Land Use Research Institute, Craigiebuckler, Aberdeen, UK. CAB International. p. 315-323.

RUSSEL, J. F.; DONEY, J. M.; GUNN, R. G. 1969. Subjective assessment of body fat in live sheep. The Journal of Agricultural Science, 72: 451-454.

SAN JULIÁN, R.; LUZARDO, S.; BRITO, G.; MONTOSSI, F. 2007. Efecto de diversas dietas en las características de la canal y de la calidad de la carne en corderos Corriedale de Uruguay. En: Montossi, F.; Sañudo, C. (eds.). Cooperación Hispano-Uruguaya: diferenciación y valorización de la carne ovina y bovina del Uruguay en Europa: Influencia de sistemas de bienestar animal, atributos sensoriales, aceptabilidad, percepción de consumidores y salud humana, INIA Tacuarembó. Montevideo: INIA. p. 91-96. (Serie Técnica; 168).

SAN JULIÁN, R.; MONTOSSI, F.; BERRETTA, E.; LEVRATTO, J.; ZAMIT, W.; RÍOS, M. 1998. Alternativas de alimentación y manejo invernal de la recría ovina en la región de Basalto. En: Berretta, E. (ed.). Seminario de actualización en tecnologías para Basalto, INIA Tacuarembó. Montevideo: INIA. p. 209227. (Serie Técnica; 102).

SILVEIRA, C. 2009. Efecto de diferentes proporciones de pastura y grano en la dieta de corderas cruzas, sobre la calidad de la carne, particularmente referida al valor nutritivo de la misma. Tesis Ingeniero Agrónomo. Montevideo, Uruguay. Facultad de Agronomía. 245 p.

SOEPARN, O.; DAVIES, H. 1982. Studies on the growth and carcass composition in Daldale wether lambs. 1. The effect of dietary energy concentration and pasture species. Australian Journal of Agricultural Research, 38:403-415.

STUTH, J. 1991. Foraging behaviour. En: Grazing management: an ecological perspective. Heitschmidt, R, Stuth, J. (Ed). Portland, Oregon: Timber Press. p. 65-83.

TERRA, J.; SCAGLIA, G.; GARCÍA PRÉCHAC, F. 2000. Moha: Caractertísticas del cultivo 
y comportamiento en rotaciones forrajeras con siembra directa, INIA Treinta y Tres. Montevideo: INIA. 62 p. (Serie Técnica; 111).

URRESTARAZÚ, A. 2004. Productividad estival de corderos pesados en la región basáltica: efecto de la carga animal, sistema de pastoreo y género, sobre una mezcla forrajera de trébol rojo (Trifolium pratense) y achicoria (Cichorium intybus). Tesis Ingeniero Agrónomo, Facultad de Agronomía, Universidad de la República, Uruguay. $231 p$.
VAN SOEST, P. 1982. Nutritional Ecology of the Ruminant. New York: Cornell University.

VAZ MARTINS, D.; IBÁÑEZ, V. 2003. Moha: ¿cuándo se debe cortar para heno?. Revista Plan Agropecuario,108. pp 5053.

WILLIAMSON, J.; BLAIR, H.; GARRICK, D.; POMROY, W. AND DOUCH, P. 1994. The relationship between internal parasite burden, faecal egg count and mucosal mast cells in fleece weight selected and control sheep. Proceedings of the New Zealand Society of Animal Production, 54: 9-13. 


\section{CAPÍTULO IV: CONSIDERACIONESY REFLEXIONES FINALES}

\section{INTRODUCCIÓN}

En un contexto de buenas perspectivas para la comercialización de carne ovina en el mercado nacional e internacional, especialmente considerando las demandas crecientes de la consolidación de corrientes de comercialización con China y Medio Oriente así como la apertura de nuevos mercados para Uruguay (EE.UU, México), debe destacarse la importancia de la carne ovina como un componente clave de la mejora de la competitividad de las cadenas cárnica ovina y textil-lanera nacional. Ello se refleja claramente con la importancia creciente y complementaria a la lana que tiene la producción de carne ovina dentro del predio en el ingreso del productor, en un contexto de intensificación de la producción, particularmente con la incorporación de la producción de corderos pesados, la mejora de la eficiencia reproductiva y la inclusión de nuevos biotipo más especializados en la producción de carne ovina (Montossi et al., 2013a; Montossi et al., 2014).

Es importante destacar no solo la importancia productiva, económica y comercial de la producción de carne, sino todo lo que el rubro ovino significa para el país en términos sociales. Este rubro promueve la producción y sustentabilidad de predios pequeños y medianos y favorece el empleo de mano de obra a lo largo de toda las cadenas cárnica ovina y textil-lanera. También es el soporte del mantenimiento de familias en el medio rural en suelos marginales con escasas opciones de diversificación productiva, ubicadas en las regiones con menor índice de desarrollo humano del Uruguay. La mayor parte de esta población ovina - un $60 \%$ - se encuentra en los departamentos de Artigas, Salto, Paysandú, Tacuarembó y Durazno (DIEA, 2013), donde, de los 14.732 productores que tienen más de 50 cabezas ovinas $-37 \%$ del total- unos 5.500 productores, están en los departamentos antes mencionados. Cuando la evaluación se realiza sobre la base de los 1981 productores que tienen más de 1000 cabezas, estos departamentos representan alrededor del $70 \%$ del stock del sector ovino nacional. Esta producción se desarrolla esencialmente sobre campo natural, con menos de un ovino por hectárea, siendo preferentemente utilizadas las pasturas mejoradas para el engorde de corderos pesados.

El verano es la estación del año con la mayor variabilidad interanual en términos de precipitaciones, lo cual impacta directamente en la producción y el valor nutritivo del forraje de la base forrajera que tienen los productores ganaderos y en particular aquellos que desarrollan su producción sobre suelos marginales como es el caso de la producción ovina en la región del Basalto. Esta variabilidad natural, a su vez se ve distorsionada por los efectos del cambio climático, el cual vuelve a los sistemas pastoriles más vulnerables que nunca, con una frecuencia más alta de aparición de períodos de sequías, especialmente durante el verano.

Específicamente para la producción de carne ovina en sistemas pastoriles, el verano se vuelve un «cuello de botella» que puede determinar el éxito o el fracaso del negocio ganadero ovino. En otras partes del mundo como Australia, Nueva Zelanda o nuestra región sudamericana, el rubro ovino tiene problemas parecidos a los que enfrentamos en este país: la producción de carne ovina está fuertemente estacionalizada y existe una demanda insatisfecha debido a la falta de continuidad en la oferta de producto. En la revisión bibliográfica internacional que se realizó en esta publicación, quedó demostrado que hay múltiples tecnologías disponibles para aumentar la productividad y eficiencia de la recría ovina y de la producción de corderos pesados en el período estival. Sin embargo, para lograr este aumento de la productividad y eficiencia, es necesaria la apli- 
cación del uso intensivo de pasturas mejoradas de alta productividad, con niveles de suplementación creciente, uso de cruzamientos y la incorporación de riego suplementario. En nuestras condiciones, debido a restricciones asociadas a cuestiones agroecológicas, logísticas, capital de inversión, disponibilidad y capacitación de los recursos humanos, socioculturales y de disponibilidad de tecnología y aspectos comerciales, las propuestas tecnológicas provenientes de otros países tiene una serie de limitantes para ser aplicadas en una forma sistémica a nivel nacional, y particularmente en las regiones donde se concentra la producción ovina nacional (ej. regiones de Basalto y Cristalino del Este). Sin duda, la generación y transferencia de tecnología adecuada a la realidad productiva, económica, comercial y sociocultural de estas regiones se transforma en una necesidad real para lograr un cambio positivo y crecimiento sostenible en nuestras condiciones.

\section{CONSIDERACIONES GENERALES}

\subsection{Consideraciones productivas}

En el contexto particular de los sistemas de producción ganaderos de la región del Basalto y de la propuesta tecnológica de intensificación desarrollada en la presente publicación, que tiene como objetivo principal favorecer la productividad ovina (recría y/o engorde de corderos) durante el período estival, se destaca:

a. Existen oportunidades en el uso cultivos anuales estivales como la moha y sorgo forrajero para mejorar la productividad de corderos, con una alta capacidad de carga, pero limitantes en cuanto al potencial a lograr en términos de la ganancia de peso vivo individual. Estas ganancias pueden ser mejoradas con una suplementación estratégica, principalmente proteica. Para el cumplimiento de los requerimientos (peso, terminación y edad) del
Operativo de Corderos Pesados del Uruguay, es necesario un período adicional post-utilización del verdeo anual estival de mejora de la alimentación y manejo (ej. utilización de pasturas perennes con festucas y verdeos anuales invernales con o sin uso de suplementación según objetivo de producción) durante el período otoño-invierno. Estas bases forrajeras de cultivos anuales estivales también pueden jugar un rol clave como «bancos de verde» para mantener altas cargas animales en un espacio reducido de área en el establecimiento, lo que puede complementar otros objetivos globales de mejora de la productividad del propio proceso de recría ovina y del sistema productivo como un todo.

b. El uso de campo natural reservado complementado con el uso de una suplementación restringida con concentrados energético-proteicos favorece la mejora de la productividad (individual y por unidad de superficie) con relación al empleo tradicional del campo natural como única dieta de los corderos post destete. Ésta es una herramienta que acelera el proceso de recría, pero debe ser acompañada con una estrategia complementaria de alimentación y manejo durante el otoñoinvierno para completar el proceso de engorde y alcanzar los requerimientos específicos ya mencionados.

c. La alternativa de utilización de «bancos verdes especializados para favorecer el crecimiento de corderos» durante el verano en base al uso de leguminosas puras o en mezcla, ya sea el caso del Lotus corniculatus cv. INIA Draco o la mezcla de Trifolium pratense cv. LE 116 y Cichorium intybus cv. INIA Lacerta permiten lograr productividades interesantes individuales y por unidad de superficie.

d. La información generada demuestra el efecto determinante de la elección de una carga animal óptima para cumplir con los umbrales mínimos de pesos vivos $\geq 35 \mathrm{~kg}$ y una condición cor- 
poral e» 3,5 unidades en corderos pesados.

e. A ello se le debe incorporar la selección del correcto sistema de pastoreo controlado que favorezca el rebrote, valor nutricional, capacidad de carga y persistencia adecuada de las pasturas de verano empleadas.

f. La suplementación estratégica de corderos sobre estas bases forrajeras estivales, con niveles restringidos de oferta de suplementos, es una opción válida para mejorar la performance individual y por unidad de superficie, asegurar la productividad frente a situaciones de déficit forrajero que normalmente se presenta en el verano y mejorar la proporción de corderos terminados de acuerdo a los requisitos del Operativo de Corderos Pesados del Uruguay.

Por otro lado, se puede decir que, en periodos cortos de tiempo, la recría e invernada de corderos sobre las pasturas mejoradas en base a leguminosas con adecuado crecimiento estival, la suplementación estratégica colaboró en:

- mejorar el crecimiento de los corderos.

- aumentar la capacidad de carga del sistema de recría y engorde.

- favorecer la terminación de los animales.

- aumentar el peso de las canales y el calibre/peso de cortes valiosos.

- mejorar la estabilidad del sistema, particularmente cuando se presentan períodos cortos de producción de pasturas y restricciones en la valor nutricional del forraje (ej. sequías).

g. El peso al destete ylo al inicio del proceso de recría y engorde es un elemento clave a la hora incorporar el uso de sistemas intensivos mejorados de recría y engorde de corderos durante el período estival. Bajos pesos vivos al destete y/o al inicio del proceso de recría o engorde (inferiores a 23 - $25 \mathrm{~kg}$ ) y/o destetes tardíos (ej. después de la segunda quincena de enero) dificultan el logro del engorde estival de corderos pesados en un período de 100 a 120 días de invernada. El favorecer una alta producción de leche de las madres y el uso de una alimentación preferencial de corderos al pie de la madres (ej. creep feeding y creep grazing; Banchero et al., 2006) son algunas de las opciones para logra una mejora del peso al destete que apoye todo el proceso productivo y el logro de este objetivo.

h. La información incipiente de la incorporación en el Basalto de un área estratégica que incluya el uso del riego suplementario sobre pasturas puras de Trifolium pratense aparece como una alternativa tecnológica válida para favorecer el crecimiento y terminación de los corderos pesados en el período estival sobre suelos de alto potencial productivo. Estos resultados productivos auspiciosos requieren del desarrollo de nuevos experimentos para complementar la información generada y ajustar esta tecnología para las condiciones del Basalto.

i. La aplicación de un Plan Sanitario adecuado es esencial para la aceleración del crecimiento de los corderos, tanto durante la lactancia como en el post destete, con especial referencia al control de parásitos gastrointestinales (PI), las clostridiosis y el ectima contagioso. Nunca se debe subestimar el impacto negativo en lo productivo y económico que puede tener el manejo inadecuado del punto de vista sanitario, particularmente cuando se considerar el bajo costo relativo de estas medidas frente al costo total del negocio. Estos trabajos experimentales tuvieron en cuenta la aplicación del plan mencionado y en particular con un conocimiento adecuado de la eficacia de las drogas antihelmínticas utilizadas vía la aplicación del test de evaluación de resistencia «lombritest» a los PI. 
j. El uso de la tecnología de los cruzamientos acompañada de un adecuado nivel de alimentación, mejora el crecimiento de los corderos así como el peso y rendimiento de las canales y proporción de cortes valiosos obtenidos. Ello es clave cuando el proceso de recría y engorde debe ser eficiente y dentro de una ventana reducida de tiempo para llegar al mercado en el momento adecuado. Para un uso eficiente de los recursos y poder expresar el potencial que ofrece esta tecnología, es necesario que los niveles de alimentación y manejo en el sistema de recría y/o engorde no sean limitantes.

k. Los corderos deben disponer de agua de buena calidad para beber. Los factores como espacio inadecuado, altos niveles de sal, contaminación del agua con algas, comida, polvo o heces pueden resultar en una reducción del consumo de agua y una consecuente reducción del consumo de alimento, afectando negativamente la performance de los corderos. Los requerimientos diarios individuales promedio de agua para los corderos en sistemas de engorde superan los 4 litros. Este valor promedio puede variar dependiendo de la época del año, la cantidad de sombra disponible y la ración ofrecida, como así también de las temperaturas prevalentes, peso corporal de los corderos, contenido de humedad de la ración y nivel de sal (tanto en la ración como en el agua). Resultados propios de este equipo de trabajo (Silveira, 2009) registraron consumos de agua diario promedio en el rango de 3,35-5,90 litros por animal. Cuando los animales permanecen en climas calientes por tiempo prolongado se han registrado consumos de hasta 9 litros/día/cordero. Muchos factores afectan el consumo de agua: temperatura del ambiente, lluvias, nieve y rocío, actividad, edad, fase de producción, cantidad de lana, ritmo respiratorio del animal, así como frecuencia del suministro de agua, consumo de alimentos, nivel nutricional, composición de la ración y pastura. En general, el consumo de agua es el doble que el del alimento (en base seca), pero cualquiera de los factores indicados puede alterar esta proporción. El consumo de agua puede llegar a ser 12 veces más alto en verano que en invierno (NRC, 1985).

I. Debe también proveerse de sombra y protección contra los imprevistos del clima a los corderos durante el verano. En base a los experimentos de este equipo de trabajo y los de Ayala et al. (2013), no se observaron diferencias significativas en la producción animal por efecto de la sombra durante el período estival en sistemas de recría/ engorde de corderos. Sin embargo, los estudios de conducta animal muestran que los corderos siempre hicieron uso intensivo de la sombra, en particular en los momentos de mayor temperatura y radiación durante el día. Los animales que no tenían acceso a la misma, se agitan y jadean demostrando síntomas de estrés y posiblemente estarían afectados negativamente en su bienestar animal. Es por ello que se recomienda el uso de sombra en una visión holística de la producción animal. Futuros trabajos de investigación confirmatorios se requieren en esta área.

m. La inclusión de la opción de la utilización del encierre a corral en el engorde de corderos pesados es una opción tecnológica factible de implementar en el Uruguay, aunque es altamente dependiente del precio del cordero. Esta alternativa tiene un elevado costo de producción asociado a la importante proporción de los concentrados incluidos en la alimentación de este sistema intensivo. Las evaluaciones económicas recientes de la aplicación de esta tecnología demuestran restricciones para justificar su aplicación en los sistemas productivos a nivel comercial. 
n. En cuanto a la evaluación de especies y variedades forrajeras como las Brassicas sp y Plantago lanceolata (llantén) durante el periodo estival sobre suelos medios a profundos en el Basalto en condiciones de secano, nuestro equipo de trabajo ha realizado algunas experiencias, pero hasta el momento los resultados no han sido auspiciosos y se requiere de mayor investigación para concluir sobre la posibilidad de implementar o no el uso de estas opciones forrajera para la mejora de la recría y/o engorde estival de corderos en la región. Por otro lado, en la región del Cristalino los trabajos realizados en INIA Treinta y Tres por Barrios y Ayala (2013) con llantén y brassicas fueron muy positivos demostrando un gran potencial productivo para la producción de carne ovina con corderos en la mencionada región.

\subsection{Consideraciones económicas}

Entre los principales factores económicos que determinan la viabilidad del negocio de engorde de corderos pesados durante el período estival, está el precio que se obtiene por el producto. En referencia a ello y más allá de los potenciales incentivos presentes por entrada temprana en el año por parte de la industria frigorífica, un estudio realizado por Buffa y Mondelli (2014) sobre la estacionalidad del precio promedio del cordero pesado en los últimos 5 años (20082013) demuestra que es conveniente planificar su venta preferentemente entre los meses de julio a octubre (Cuadro 1).

A modo de ejemplo, la diferencia de vender un cordero en marzo versus octubre, favorece al productor en un $9 \%$ en comparación a una venta de octubre.

Sin embargo, también en los cálculos realizados por Buffa y Mondelli (2014) se de- muestra que el momento de venta de los corderos impacta sobre la cantidad total de cabezas en el predio, específicamente la cantidad de ovejas que pueden ingresar al sistema. En definitiva, la venta temprana en el año de los corderos pesados tiene un efecto negativo en cuanto a precio (Cuadro 1), pero por otro lado habilita y es compensado en parte por tener un efecto positivo al permitir mejorar la capacidad de carga animal (ej. ovejas) del sistema y por lo tanto posibilita generar una mayor cantidad de corderos para vender posteriormente. Esto resulta en que el margen bruto de un sistema que vende los corderos en mayo (precios bajos) en comparación con uno que venda los corderos en octubre (precios altos), son muy similares.

Adicionalmente, en base a la información generada en la presente publicación, es claro que las tecnologías manejadas requieren de una inversión en insumos y mayor demanda de mano de obra capacitada. Estas inversiones pueden estar acompañadas por el riesgo y la incertidumbre que significan las restricciones asociadas a la variabilidad climática que normalmente se presenta durante el verano y en particular en la región de Basalto. Para favorecer la entrega temprana de corderos por parte de los productores de ovinos a la industria, los incentivos de precios a lo largo del año y entre años, deben ser lo suficientemente atractivos para que los productores incorporen sistemáticamente la mejora de la recría estival y el engorde de corderos y ello seguramente permitirá reducir la estacionalidad de la faena de corderos en el Uruguay.

\subsection{Algunas recomendaciones prácticas}

En términos generales, para tener un proceso eficiente del punto de vista productivo y económico en estos procesos de recría y/ o engorde estival de corderos, este equipo de investigadores recomienda realizar:

Cuadro 1. Precios mensuales promedio 2008-2013 (adaptado de Buffa y Mondelli, 2014).

\begin{tabular}{|cccccccccccc|}
\hline $\mathbf{E}$ & $\mathbf{F}$ & $\mathbf{M}$ & $\mathbf{A}$ & $\mathbf{M}$ & $\mathbf{J}$ & $\mathbf{J}$ & $\mathbf{A}$ & $\mathbf{S}$ & $\mathbf{0}$ & $\mathbf{N}$ & $\mathbf{D}$ \\
\hline$-13 \%$ & $-8 \%$ & $-3 \%$ & $1 \%$ & $1 \%$ & $4 \%$ & $6 \%$ & $7 \%$ & $8 \%$ & $6 \%$ & $-1 \%$ & $-8 \%$ \\
\hline
\end{tabular}


a. Un seguimiento de un grupo representativo (15 a $20 \%$ de los animales) con controles cada 20 a 30 días de la evolución de peso y condición corporal, lo cual permite realizar una evaluación objetiva del cumplimiento de los objetivos propuestos de ganancia de peso y de terminación de los animales, así como agilizar el proceso de toma de decisiones de orden correctivo. Este elemento es imprescindible para realizar un engorde eficiente $y$ permite hacer un seguimiento cercano de los animales, asegurando el monitoreo y control de otros aspectos de manejo y/o sanitarios (diagnóstico de parasitosis internas o externas, problemas de pietín, etc.) así como también los relacionados a la comercialización, donde el peso es una variable determinante

b. La formación de lotes de corderos según rangos de peso vivo, lo cual asegura el ajuste de las necesidades nutricionales diferenciales de los mismos (en términos de energía y proteína) y la adecuación a la disponibilidad y valor nutritivo del forraje disponible (determinados en forma objetiva), permitiendo así agilizar el proceso de engorde a través de una priorización del uso de los recursos, particularmente cuando se presentan condiciones limitantes (ej. uso de altas cargas, oferta reducida de forraje, etc.).

c. Un tamaño adecuado de los lotes de engorde, para un manejo correcto y en base a experiencias generadas por este equipo de trabajo a nivel comercial, el tamaño del lote no debería ser mayor a 500 corderos. Esto es aún más importante si se realiza suplementación.

d. Una presupuestación forrajera previa al comienzo del engorde, considerando los objetivos de producción (ganancia diaria y peso de canal a obtener) y la opción forrajera a utilizar (así como el potencial uso de suplementos), lo cual definirá en una primera instancia la capacidad de carga del sistema de engorde, uno de los mayores determinantes del beneficio económico del negocio, junto al precio de compra y venta de animales. Esta publicación genera información tecnológica para el Uruguay y en particular para las condiciones agroecológicas del Basalto sobre la producción, valor nutritivo y capacidad de carga de diferentes alternativas forrajeras, y la producción animal esperada.

e. Una correcta elección de los animales en su origen. Por ello, los corderos se deben seleccionar (propios o comprados) lo más homogéneos posibles entre sí en términos de peso y condición corporal, pero también en cuanto a un proceso de cría y recría similar, así como una correcta sanidad previa. De no ser es así, la eficiencia del engorde es afectada por animales con problemas de ganancia y/o desparejos en sus pesos, lo cual dificulta la operativa general del proceso productivo y de comercialización y rentabilidad del negocio.

f. Sobre las pasturas dominadas por leguminosas, se recomienda generar una acumulación de forraje de buena calidad durante la primavera previo al comienzo de la recría y/o en engorde de 1800-2000 kgMS/ha (8 $10 \mathrm{~cm}$ de altura), para realizar un correcto manejo de las pasturas y de los animales.

g. En períodos de recría/engorde cortos (100 a 120 días) y eficientes (ganancias superiores a 130 gramos/animal/ día) sobre diferentes opciones forrajeras manejadas, los trabajos experimentales de INIA demuestran la conveniencia productiva de utilizar sistemas controlados de pastoreo, con 7 días de pastoreo y 21 días de descanso, frente a otras opciones más intensivas (como por ejemplo pastoreo diario) o más extensivas como el pastoreo continuo. Esta es una estrategia «segura», particularmente cuando se presentan condiciones climáticas adversas (ej. sequías). 
h. Como decisión táctica, se debe saber cuánto forraje se dispone durante el proceso de engorde. El uso de la regla graduada por parte de los productores y/o sus asesores es deseable para lograr los objetivos de ganancia de peso y de manejo adecuados para cada pastura y en cada estación. En este sentido, esta técnica permite, de una manera sencilla, barata y con una demanda reducida de tiempo, disponer de información inmediata sobre la cantidad de forraje que se dispone en cada potrero y/o pastura, así como ajustar las expectativas de ganancia de peso que se pueden obtener. La medición de la altura del forraje debe ser acompañada de estimaciones visuales de la proporción de verde en el forraje total teniendo en cuenta la estación del año, dada la rapidez y mediana-alta exactitud que tiene esta herramienta. Se la considera como una herramienta de gran potencial de adopción por parte de los productores, colaboradores rurales y asesores profesionales, independientemente del grado de intensificación que tenga el predio. En este sentido, Montossi et al. (2013b) presentan asociaciones entre la altura medida por regla graduada y la disponibilidad de forraje para las especies forrajeras utilizadas en la presente publicación.

i. Un correcto manejo de los corderos inmediatamente al destete. Recién destetados, separados de sus madres, los corderos son una categoría sensible y no adaptada al manejo del Hombre. Por ello, se deben tomar precauciones en cuanto a la adaptación de los corderos al manejo intensivo sobre pasturas mejoradas con eléctricos y eventualmente con la suplementación. En este sentido, es recomendable mantener a estos en los bretes por 24 a 28 horas con agua ad libitum para beber, así como proveerlos de alimentos (fardos y/o pequeñas concentraciones de raciones) y la presencia de líneas de eléctricos para que los animales experimenten por primera vez esta forma de manejo y de presencia humana. Todo ello contribuye a una mejor adaptación de los animales al nuevo sistema de manejo y evitar el cansancio y frustración posteriores a nivel de los productores y sus colaboradores.

\section{CONCLUSIONES E IMPLICANCIAS FUTURAS}

Los futuros trabajos del INIA están y estarán centrados en profundizar estudios asociados a la suplementación estival de corderos en sistemas con autoconsumo o infrecuentes. Asimismo, también se ajustarán los niveles de proteína necesarios para mejorar la productividad de corderos y bajar los costos de la suplementación para hacer más atractiva esta práctica, en un marco de incremento en los costos de producción, restricciones en la disponibilidad de mano de obra, sobre todo calificada, así como la incorporación de nuevos biotipos, la aplicación del riego en pasturas/cultivos enfrentando un aumento de la variabilidad y cambio climático, etc.

También se está trabajando en la evaluación de nuevas alternativas forrajeras que están siendo liberadas por los programa de mejora genética de gramíneas (ej. perennes estivales) y leguminosas del INIA para las regiones ganaderas del Uruguay.

Nuestros objetivos no solo están centrados en el aumento de la producción durante estos meses del verano, sino también en optimizar el uso de los recursos y su sustentabilidad (suelo, agua) de los predios, contemplando aspectos de bienestar animal.

Los resultados presentados en esta publicación evidencian la disponibilidad de tecnologías forrajeras y de suplementación estratégica que permiten mejorar los procesos de recría y/o engorde en las condiciones agroecológicas del Basalto durante el verano. La disponibilidad de áreas reducidas y estratégicas con estas opciones forrajeras como las evaluadas por este equipo de trabajo, siendo estas partes de una rotación 
anual y/o interanual de pasturas y forrajes, pueden ser utilizadas para acelerar estos procesos productivos mencionados con su consiguiente impacto positivo a nivel de todo el sistema productivo.

Estos trabajos experimentales contribuyen a la generación de coeficientes técnicos que permitan analizar con mayor objetividad el retorno económico de la incorporación de estas tecnologías, tanto en el proceso de recría y/o engorde de los corderos durante el período estival, como en la evaluación de su impacto a nivel de todo el sistema productivo y la simulación de las implicancias productivas, económicas y financieras de la variación de precios en los insumos y en los productos (carne y lana).

Por otra parte, el desarrollo del negocio Operativo Cordero Pesado está cimentado a través de su permanencia por casi dos décadas, lo que contribuye a facilitar los aspectos de logística, comercialización y financiación, con las consecuentes ventajas de una planificación y confianza generada en el largo plazo.

Si bien es una alternativa productiva y económicamente muy válida para todos los productores en el territorio nacional frente a otras alternativas de negocios, el Operativo Cordero Pesado se ajusta muy bien a los pequeños y medianos productores, ya que serían potenciales «clientes ideales» para implementar esta opción productiva y comercial en las regiones ganaderas más extensivas. Esto a su vez, trae aparejadas ventajas socioeconómicas para los productores, sus familias y entornos sociales en el territorio así como los beneficios generados a nivel de toda la cadena involucrada.

\section{BIBLIOGRAFÍA}

AYALA, W.; BARRIOS, E.; MAGALLANES, J.; PAIVA, M. 2013. Utilización de verdeos de verano en la alimentación de corderos. En: Seminario de actualización técnica: producción de carne ovina de calidad, INIA Treinta y Tres. Montevideo: INIA. p. 6368. (Serie de Actividades de Difusión; 719).
BANCHERO, G.; MONTOSSI, F.; GANZÁBAL, A. 2006. Alimentación estratégica de corderos: La experiencia del INIA en la aplicación de las técnicas de alimentación preferencial de corderos en el Uruguay, INIA La Estanzuela. Montevideo: INIA. 30 p. (Serie Técnica; 156).

BARRIOS, E.; AYALA, W. 2013. Utilización de Plantago lanceolata en la alimentación de corderos en el período estival. En: Seminario de actualización técnica: producción de carne ovina de calidad, INIA Treinta y Tres. Montevideo: INIA. p. 55-61. (Serie Actividades de Difusión; 719).

BUFFA, I.; MONDELLI, J. 2014. Estrategias productivas y su impacto económico en sistemas de producción de carne ovina de intensificación variable. En: Saravia, H.; Ayala, W.; Barrios, E. (eds.). Seminario de actualización técnica: producción de carne ovina de calidad. Montevideo: INIA. p. 161-173. (Serie Técnica; 211).

MONTOSSI, F.; DE BARBIERI, I.; DIGHIERO, A. 2013. El uso de la altura del forraje: una herramienta disponible para el manejo eficiente de sistemas pastoriles orientados a la producción ovina. En: Montossi, F.; De Barbieri I. (eds.). Tecnologías de engorde de corderos pasados sobre pasturas cultivadas en Uruguay. Montevideo: INIA. p. 159-182. (Serie Técnica; 206).

MONTOSSI, F.; DE BARBIERI, I.; DIGHIERO, A.; SAN JULIÁN, R. 2013. Resultados productivos y económicos del proyecto de validación y de la investigación para el engorde de corderos sobre pasturas mejoradas en Uruguay: análisis, discusión y recomendaciones prácticas. En: Montossi, F.; De Barbieri I. (eds.). Tecnologías de engorde de corderos pasados sobre pasturas cultivadas en Uruguay. Montevideo: INIA. p. 215-241. (Serie Técnica; 206).

MONTOSSI, F.; SOARES DE LIMA, J.; BRITO, G.; BERRETTA, E. 2014. Impacto en lo productivo y económico de las diferentes orientaciones productivas y tecnologías propuestas para la región del Basalto. En: Berretta, E.; Montossi, F.; Brito, G. (eds.). Alternativas tecnológicas para los 
sistemas ganaderos del Basalto. Montevideo: INIA. p. 557-568. (Serie Técnica; 217).

N.R.C. 1985. Nutrient requirements of sheep. Washington: National Academy Press. $99 \mathrm{p}$.

SILVEIRA, C. 2009. Efecto de diferentes proporciones de pastura y grano en la dieta de corderas cruzas, sobre la calidad de la carne, particularmente referida al valor nutritivo de la misma. Tesis Ingeniero Agrónomo. Montevideo: Facultad de Agronomía. 245 p.

URUGUAY. MGAP. DIEA. 2013. Anuario estadístico agropecuario 2013. Montevideo: DIEA. 270 p. 
Impreso en Editorial Hemisferio Sur S.R.L.

Buenos Aires 335

Montevideo - Uruguay

\section{Depósito Legal 336-655/15}

